\title{
Spectroscopic and Theoretical Study on Siloxy-Based Molybdenum and Tungsten Alkylidyne Catalysts for Alkyne Metathesis
}

\author{
Alexander Haack, Julius Hillenbrand, Maurice van Gastel, Alois Fürstner, ${ }^{*}$ Frank Neese* \\ Max-Planck-Institut für Kohlenforschung, 45470 Mülheim/Ruhr, Germany \\ *Email: neese@kofo.mpg.de,fuerstner@kofo.mpg.de
}

\section{Supporting Information}

\section{Contents}

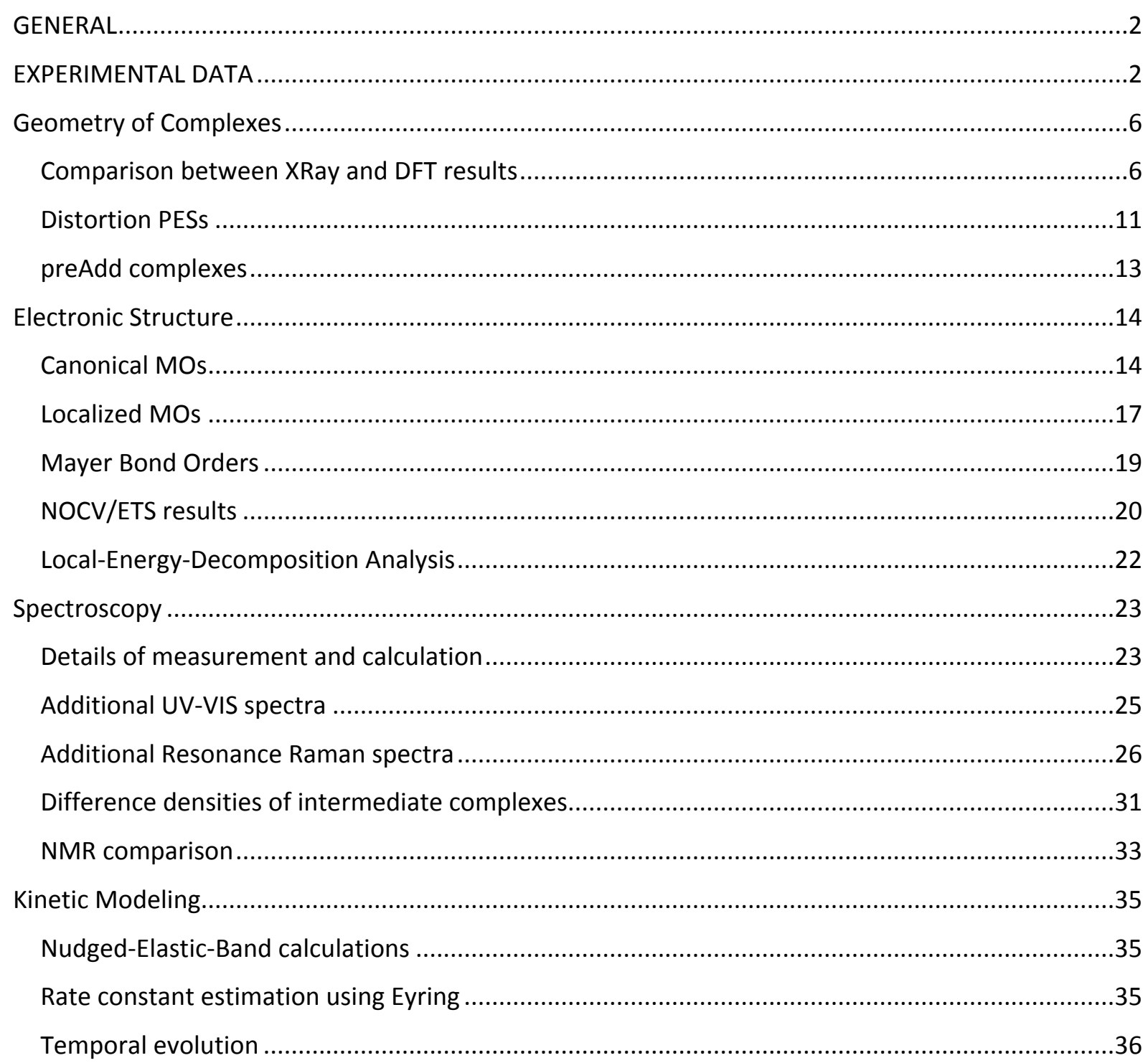




\section{GENERAL}

Unless stated otherwise, all reactions were carried out under Ar in flame-dried glassware. The solvents and commercially available compounds (Aldrich) used were purified by distillation over the drying agents indicated and were transferred under $\mathrm{Ar}: \mathrm{Et}_{2} \mathrm{O}\left(\mathrm{CaH}_{2}\right)$, THF $(\mathrm{Mg} /$ anthracene), toluene $((\mathrm{Na} / \mathrm{K})$,

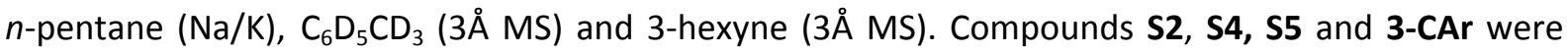
prepared as described in the literature. ${ }^{1,2}$ The molecular sieves used in this investigation were dried for $24 \mathrm{~h}$ at $150^{\circ} \mathrm{C}$ (sand bath) under vacuum prior to use and were stored and transferred under argon atmosphere.

IR: Spectrum One (Perkin-Elmer) spectrometer, wavenumbers $(\tilde{v})$ in $\mathrm{cm}^{-1}$.

MS (EI): Finnigan MAT 8200 (70 eV), ESI-MS: ESQ3000 (Bruker), accurate mass determinations: Bruker APEX III FT-MS (7 T magnet) or Mat 95 (Finnigan). Elemental analysis: H. Kolbe, Mülheim/Ruhr.

NMR spectra were acquired on Bruker Avancelll 300, 400, $500 \mathrm{MHz}$ or an AvanceNeo $600 \mathrm{MHz}$ NMR spectrometer in the solvents indicated; chemical shifts $(\delta)$ are given in ppm relative to TMS, coupling constants $(J)$ in $\mathrm{Hz}$. The solvent signals were used as references and the chemical shifts converted to the TMS scale $\left(\mathrm{CDCl}_{3}: \delta_{\mathrm{C}} \equiv 77.0 \mathrm{ppm}\right.$; residual $\mathrm{CHCl}_{3}$ in $\mathrm{CDCl}_{3}: \delta_{\mathrm{H}} \equiv 7.26 \mathrm{ppm} ; \mathrm{CD}_{2} \mathrm{Cl}_{2}: \delta_{\mathrm{C}} \equiv 53.8 \mathrm{ppm}$; residual ${ }^{1} \mathrm{H}: \delta_{\mathrm{H}} \equiv 5.32 \mathrm{ppm} ; \mathrm{C}_{6} \mathrm{D}_{5} \mathrm{CD}_{3}: \delta_{\mathrm{C}} \equiv 20.7 \mathrm{ppm}$; residual $\left.\mathrm{D}_{5} \mathrm{C}_{6} \mathrm{CD}_{2} \mathrm{H}: \delta_{\mathrm{H}}=2.09 \mathrm{ppm}\right)$. Chemical shifts were referenced indirectly to the ${ }^{1} \mathrm{H}$ chemical shift of the solvent. ${ }^{3}$

\section{EXPERIMENTAL DATA}

\section{Complex S1}

A $100 \mathrm{~mL}$ Schlenk flask was equipped with a magnetic stir bar and was flame dried under vacuum. The<smiles></smiles>
flask was filled with argon and $\mathrm{Mo}(\equiv \mathrm{CPh}) \mathrm{Br}_{3}(\mathrm{dme})(\mathrm{S2})(1.20 \mathrm{~g}, 2.20 \mathrm{mmol})$ was dissolved in THF (25 mL). Then a solution of $\mathrm{NaOtBu}(633 \mathrm{mg}, 6.59 \mathrm{mmol})$ in THF $(10 \mathrm{~mL})$ was added dropwise at $25^{\circ} \mathrm{C}$ to the stirred solution. Stirring was continued for $14 \mathrm{~h}$ at ambient temperature before the solvent was removed in vacuo to obtain a dark brown solid. A second, flame dried $50 \mathrm{~mL}$ Schlenk flask was equipped with a magnetic stir bar and a Celite $(2 \mathrm{~cm})$ packed argon frit. The dark brown solid was suspended in $n$-pentane $(4 \times 5 \mathrm{~mL})$ and was filtered through the Celite ${ }^{\circ}$ pad. The resulting filtrate was concentrated and the residue dried under vacuum (10-3 mbar) to give complex S1 as a brown solid $(717 \mathrm{mg}, 80 \%)$ free of any residual THF. ${ }^{1} \mathrm{H}$ NMR $\left(400 \mathrm{MHz}, \mathrm{C}_{6} \mathrm{D}_{6}\right): \delta=7.52-7.49(\mathrm{~m}, 2 \mathrm{H}), 7.13-7.07(\mathrm{~m}, 2 \mathrm{H}), 6.88(\mathrm{tt}, J=7.2,1.3 \mathrm{~Hz}, 1 \mathrm{H}), 1.49$ (s, 27H). ${ }^{13} \mathrm{C}$ NMR $\left(101 \mathrm{MHz}, \mathrm{C}_{6} \mathrm{D}_{6}\right): \delta=276.6,146.7,129.7,128.4,127.0,80.3,32.8 .{ }^{95} \mathrm{Mo}$ NMR (26 
$\left.\mathrm{MHz}, 60^{\circ} \mathrm{C}, \mathrm{C}_{6} \mathrm{D}_{5} \mathrm{CD}_{3}\right): \delta=62.0$. The analytical and spectroscopic data are in agreement with those reported in the literature. ${ }^{4}$

\section{Complex S3}

A $250 \mathrm{~mL}$ Schlenk flask was equipped with a magnetic stir bar and flame dried under vacuum. The flask

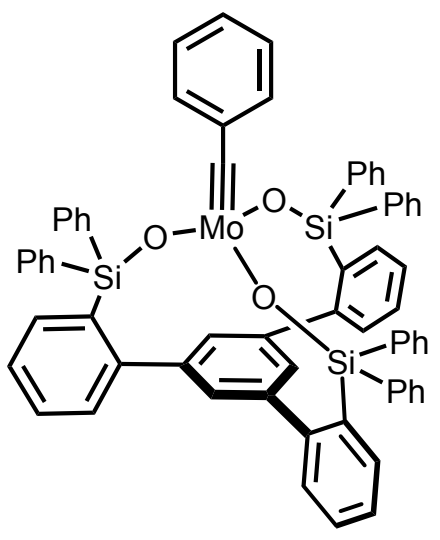
was filled with argon and charged with ligand \$4 (964 $\mathrm{mg}, 1.07 \mathrm{mmol}$ ), which was azeotropically dried with benzene $(3 \times 5 \mathrm{~mL})$ to remove residual water. Toluene $(81 \mathrm{~mL})$ was added and the mixture vigorously stirred for $10 \mathrm{~min}$ to obtain a clear solution. Then a solution of complex S1 (454 mg, $1.12 \mathrm{mmol})$ in toluene $(16 \mathrm{~mL})$ was added dropwise and stirring was continued for $3 \mathrm{~h}$ at ambient temperature. The solvent was removed in vacuo and the yellow/orange solid was washed with $n$ pentane $(3 \times 5 \mathrm{~mL})$ and $\mathrm{Et}_{2} \mathrm{O}(3 \times 5 \mathrm{~mL})$ to give a yellow/orange powder containing crude mixture of $\mathbf{S 3} /[\mathbf{S 3}]_{2}(1.14 \mathrm{~g}, 98 \%)$. A $10 \mathrm{~mL}$ Schlenk flask was equipped with a magnetic stir bar and flame dried under vacuum. The flask was filled with argon and charged with the crude mixture of $\mathbf{S 3} /[\mathbf{S 3}]_{2}(70.0 \mathrm{mg}, 64.6 \mu \mathrm{mol})$ and $\mathrm{C}_{6} \mathrm{D}_{5} \mathrm{CD}_{3}(1 \mathrm{~mL})$ to give a yellow suspension. The mixture was vigorously stirred at $60^{\circ} \mathrm{C}$ for $1 \mathrm{~h}$ to give an orange solution containing only monomeric complex S3. ${ }^{1} \mathrm{H}$ NMR $\left(600 \mathrm{MHz}, \mathrm{C}_{6} \mathrm{D}_{5} \mathrm{CD}_{3}\right): \delta=7.81-7.77(\mathrm{~m}, 12 \mathrm{H}), 7.75-7.73(\mathrm{~m}, 3 \mathrm{H}), 7.25(\mathrm{~s}, 3 \mathrm{H}), 7.12-7.06$ $(\mathrm{m}, 12 \mathrm{H}), 7.06-7.01(\mathrm{~m}, 12 \mathrm{H}), 6.89-6.85(\mathrm{~m}, 3 \mathrm{H}), 6.58(\mathrm{t}, J=7.7 \mathrm{~Hz}, 2 \mathrm{H}), 6.49(\mathrm{tt}, J=6.9,1.1 \mathrm{~Hz}, 1 \mathrm{H})$, $6.24-6.19(\mathrm{~m}, 2 \mathrm{H}) .{ }^{13} \mathrm{C} N M R\left(151 \mathrm{MHz}, \mathrm{C}_{6} \mathrm{D}_{5} \mathrm{CD}_{3}\right): \delta=310.7,149.5,146.3,144.1,138.0,137.4,135.3$, 135.0, 130.5, 130.1, 129.8, 129.3, 128.6, 128.2, 127.3, 127.2, 126.2, 20.4. ${ }^{29}$ Si NMR (79 MHz, $\left.\mathrm{C}_{6} \mathrm{D}_{5} \mathrm{CD}_{3}\right)$ : $\delta=-9.6 .{ }^{95} \mathrm{Mo} \mathrm{NMR}\left(26 \mathrm{MHz}, 60^{\circ} \mathrm{C}, \mathrm{C}_{6} \mathrm{D}_{5} \mathrm{CD}_{3}\right): \delta=377.2$. IR (film): v 3045, 1583, 1484, 1427, 1409, 1261, 1112, 1063, 1029, 1001, 871, 830, 759, 738, 696, 622, 566, 548, 528, 506, $464 \mathrm{~cm}^{-1}$. HRMS-ESI (m/z): calculated for $\mathrm{C}_{67} \mathrm{H}_{50} \mathrm{MoO}_{3} \mathrm{Si}_{3}{ }^{+}[\mathrm{M}]^{+}, 1084.21163$; found, 1084.212010. Elemental analysis (\%) calculated for $\mathrm{C}_{67} \mathrm{H}_{50} \mathrm{MoO}_{3} \mathrm{Si}_{3}$ : C 74.28, H 4.65, Mo 8.86, Si 7.78; found: C 74.31, H 4.67, Mo 8.80, Si 7.71.

\section{Complex 2-MTd}




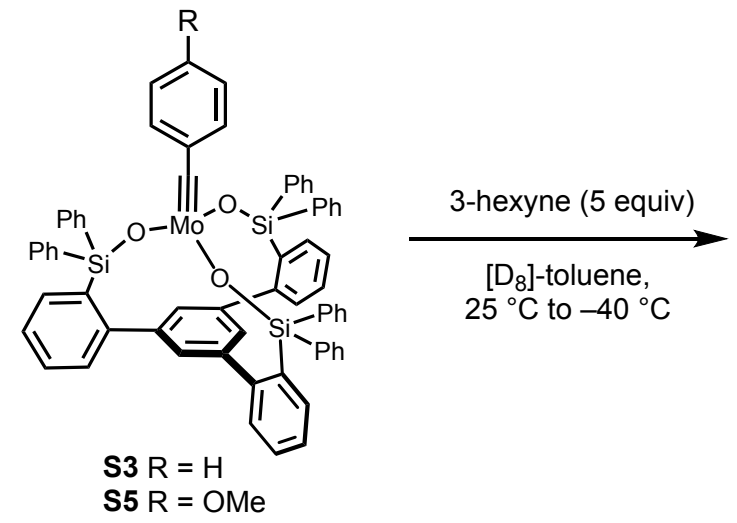

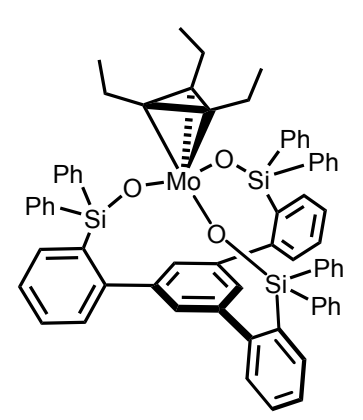

with S3 90:10 (2-MTd:S3) with S5 93:7 (2-MTd:S5)

A $10 \mathrm{~mL}$ Schlenk flask was equipped with a magnetic stir bar and was flame dried under vacuum. The flask was filled with argon, charged with $[\mathbf{S 5}]_{2}(13.5 \mathrm{mg}, 0.012 \mathrm{mmol})$ and suspended in $\mathrm{C}_{6} \mathrm{D}_{5} \mathrm{CD}_{3}(0.6$ $\mathrm{mL}$ ) to give a yellow suspension. A flame dried J. Young NMR tube was filled with argon, charged with this suspension and heated to $60^{\circ} \mathrm{C}$ until full conversion to monomeric complex 108 was observed. After cooling to $25^{\circ} \mathrm{C}$, 3-hexyne $(6.9 \mu \mathrm{L}, 61 \mu \mathrm{mol})$ was added to the yellow solution and an instant color change to black was observed. The full characterization of $\mathbf{1 4 7}$ was conducted by NMR spectroscopy at $25^{\circ} \mathrm{C} .{ }^{1} \mathrm{H}$ NMR $\left(600 \mathrm{MHz}, \mathrm{C}_{6} \mathrm{D}_{5} \mathrm{CD}_{3}\right): \delta=7.81-7.76(\mathrm{~m}, 12 \mathrm{H}), 7.68-7.64(\mathrm{~m}, 3 \mathrm{H}), 7.27(\mathrm{~s}, 3 \mathrm{H}), 7.18$ $-7.13(\mathrm{~m}, 6 \mathrm{H}), 7.10-7.06(\mathrm{~m}, 12 \mathrm{H}), 6.93-6.89(\mathrm{~m}, 3 \mathrm{H}), 7.13-6.98(\mathrm{~m}, 6 \mathrm{H}), 1.75(\mathrm{~m}, 6 \mathrm{H}), 0.48(\mathrm{t}, J=$ $7.4 \mathrm{~Hz}, 9 \mathrm{H}) .{ }^{13} \mathrm{C}$ NMR $\left(151 \mathrm{MHz}, \mathrm{C}_{6} \mathrm{D}_{5} \mathrm{CD}_{3}\right): \delta=150.3,144.0,139.1,137.2,136.7,135.2,129.6,129.3$, 129.2, 128.3, 127.4, 125.2, 83.9, 18.5, 15.4. ${ }^{29} \mathrm{Si} N \mathrm{NMR}\left(119 \mathrm{MHz}, \mathrm{C}_{6} \mathrm{D}_{5} \mathrm{CD}_{3}\right): \delta=-8.48$. The spectroscopic data are in agreement with those reported in the literature. ${ }^{2,5}$

A $10 \mathrm{~mL}$ Schlenk flask was equipped with a magnetic stir bar and was flame dried under vacuum. The flask was filled with argon, charged with $[\mathbf{S} 3]_{2}(11.3 \mathrm{mg}, 0.010 \mathrm{mmol})$ and suspended in $\mathrm{C}_{6} \mathrm{D}_{5} \mathrm{CD}_{3}(0.5$ $\mathrm{mL}$ ) to give a yellow suspension. A flame dried J. Young NMR tube was filled with argon, charged with this suspension and heated to $60^{\circ} \mathrm{C}$ until full conversion to monomeric complex $\mathbf{S 3}$ was observed. After cooling to $25^{\circ} \mathrm{C}$, 3-hexyne $(5.9 \mu \mathrm{L}, 52 \mu \mathrm{mol})$ was added to the yellow solution and an instant color change to black was observed. A variable-temperature NMR study was conducted from $25^{\circ} \mathrm{C}$ to $-70^{\circ} \mathrm{C}$ (Figure S1).

A)
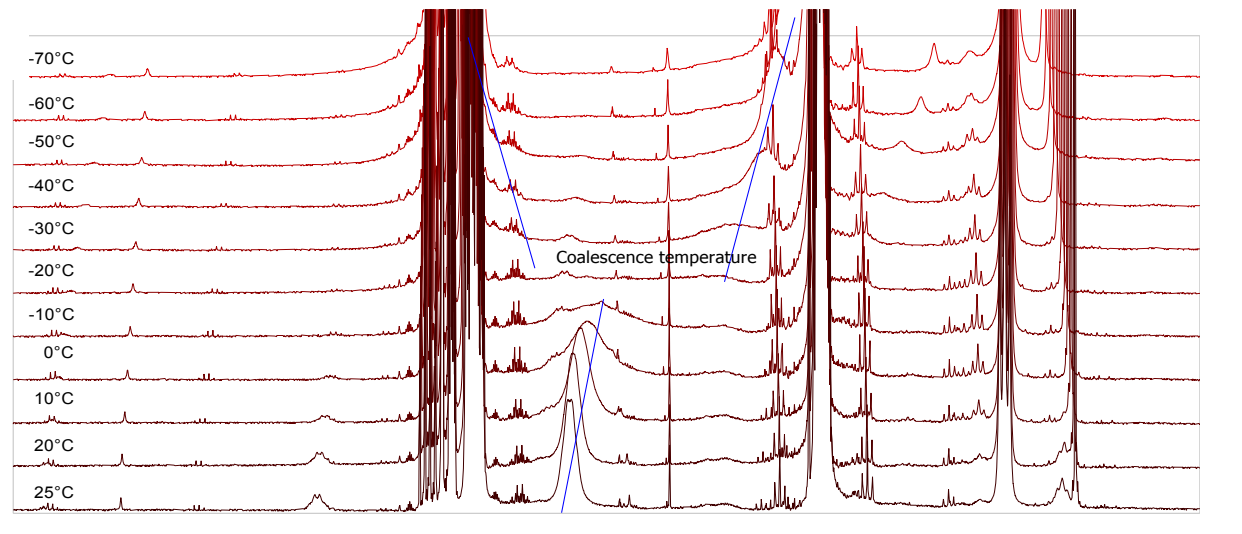

two broad peak coalescence one broad peak

B)

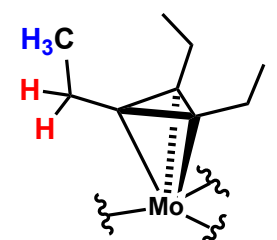




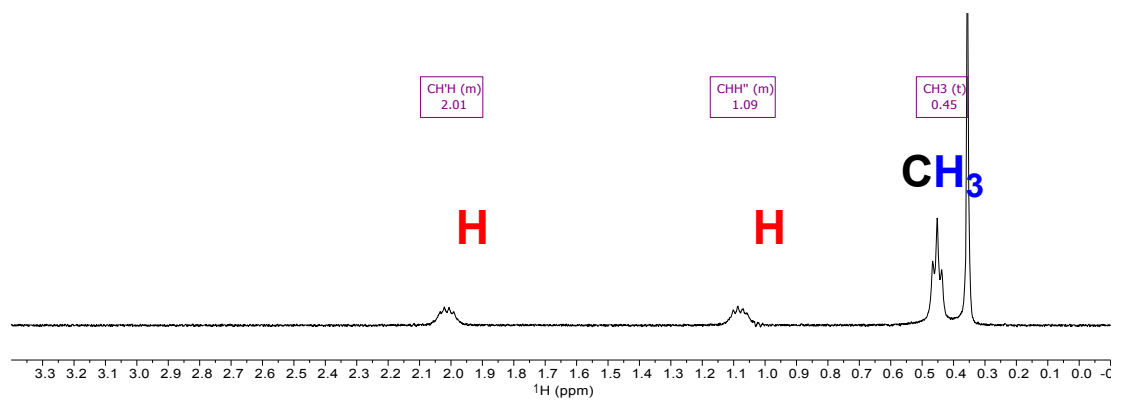

Figure S1. A.) Low-temperature ${ }^{1} \mathrm{H}$ NMR study of 2-MTd from $25^{\circ} \mathrm{C}$ to $-70{ }^{\circ} \mathrm{C}$ in $\left[\mathrm{D}_{8}\right]$-toluene; B.) $1 \mathrm{D}$ selective NOESY NMR of 2-MTd obtained upon excitation of the $\mathrm{CH}_{3}$ group at $-70^{\circ} \mathrm{C}$; methylene protons in red; methyl group in blue.

\section{NMR Investigation of Reaction of Catalysts 3-CAr with 3-Hexyne}

A $10 \mathrm{~mL}$ Schlenk flask was equipped with a magnetic stir bar and was flame dried under vacuum. The flask was filled with argon, charged with $3-C A r(11.6 \mathrm{mg}, 0.016 \mathrm{mmol})$ and dissolved in $\mathrm{C}_{6} \mathrm{D}_{5} \mathrm{CD}_{3}(0.5$ $\mathrm{mL}$ ) to give an orange solution. A flame dried J. Young NMR tube was filled with argon and the solution was transferred to the NMR tube. A ${ }^{1} \mathrm{H}$ NMR spectrum of this solution was acquired (Figure $\mathbf{S 2} \mathrm{A}$ ) and then 3-hexyne $(8.9 \mu \mathrm{L}, 79 \mu \mathrm{mol})$ was added to it. The ${ }^{1} \mathrm{H}$ NMR spectrum at $25{ }^{\circ} \mathrm{C}$ revealed that the major species is dissociated complex 3-CAr and small quantities of a new, dynamic species were detected (Figure S2 B and insert).
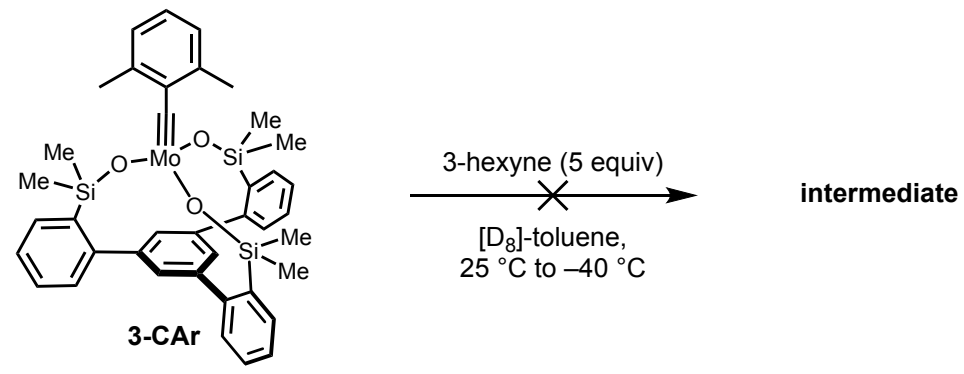

Although cooling to $-40{ }^{\circ} \mathrm{C}$ improved the quality of the broad signals $(3.0-3.7 \mathrm{ppm})$ in the ${ }^{1} \mathrm{H}$ NMR spectrum, we were not able to detect any ${ }^{1} \mathrm{H},{ }^{13} \mathrm{C} \mathrm{HMBC}$ NMR signals to determine the composition of the dynamic species (Figure $\mathbf{S 2} \mathbf{C}$ and insert). 


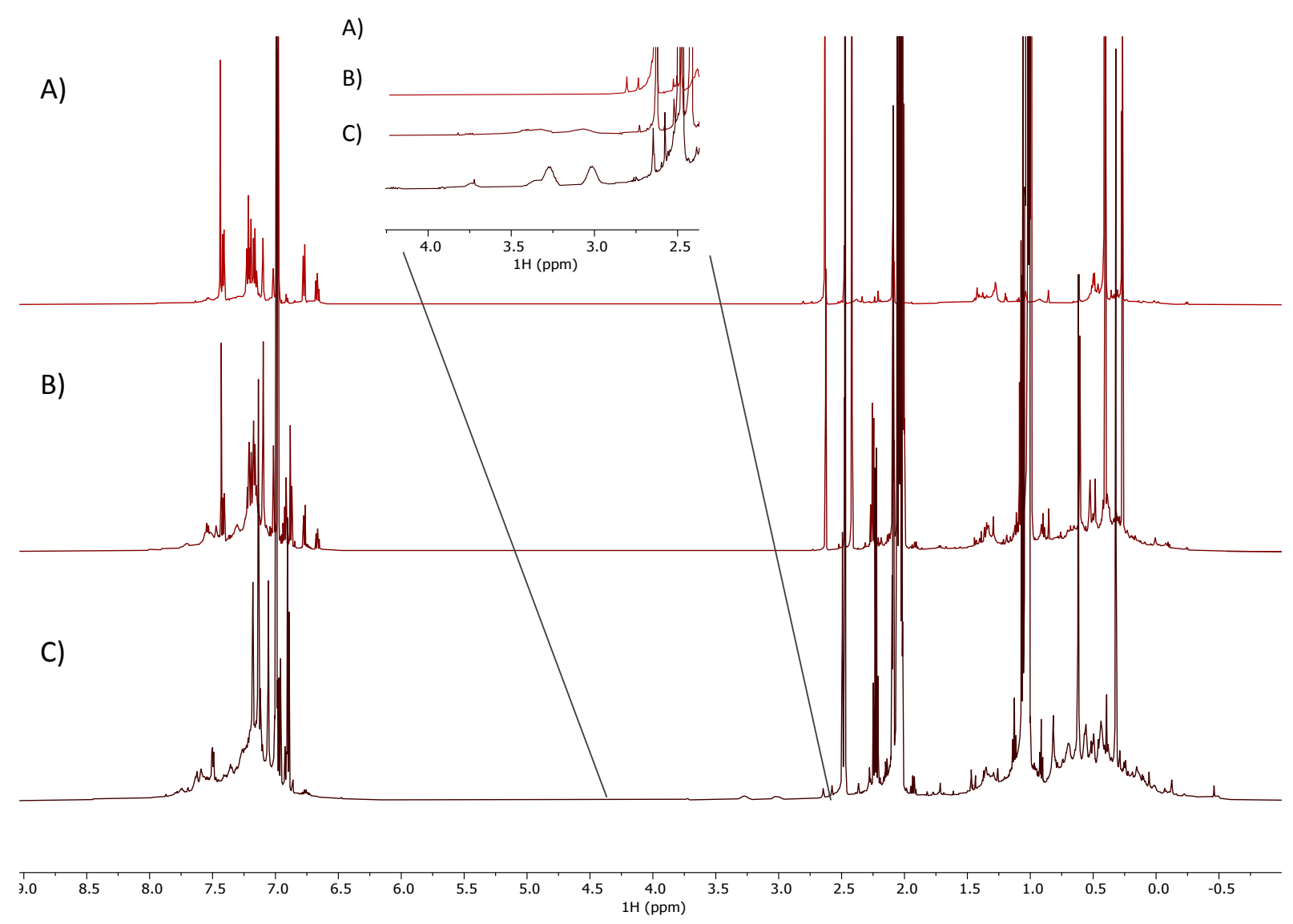

Figure S2. A) ${ }^{1} \mathrm{H}$ NMR of complex 3-CAr in $\mathrm{C}_{6} \mathrm{D}_{5} \mathrm{CD}_{3}$ at $25^{\circ} \mathrm{C}$. B) ${ }^{1} \mathrm{H}$ NMR of complex 3-CAr with 5 equiv of 3-hexyne in $\mathrm{C}_{6} \mathrm{D}_{5} \mathrm{CD}_{3}$ at $25^{\circ} \mathrm{C}$. C) ${ }^{1} \mathrm{H}$ NMR of complex 3-CAr with 5 equiv of 3-hexyne in $\mathrm{C}_{6} \mathrm{D}_{5} \mathrm{CD}_{3}$ at $-40{ }^{\circ} \mathrm{C}$, insert shows small quantities of a dynamic species.

\section{Geometry of Complexes}

Comparison between XRay and DFT results

Table S1: Geometry Comparison between X-ray [LEKFOY] and DFT optimized structure of 1-CAr

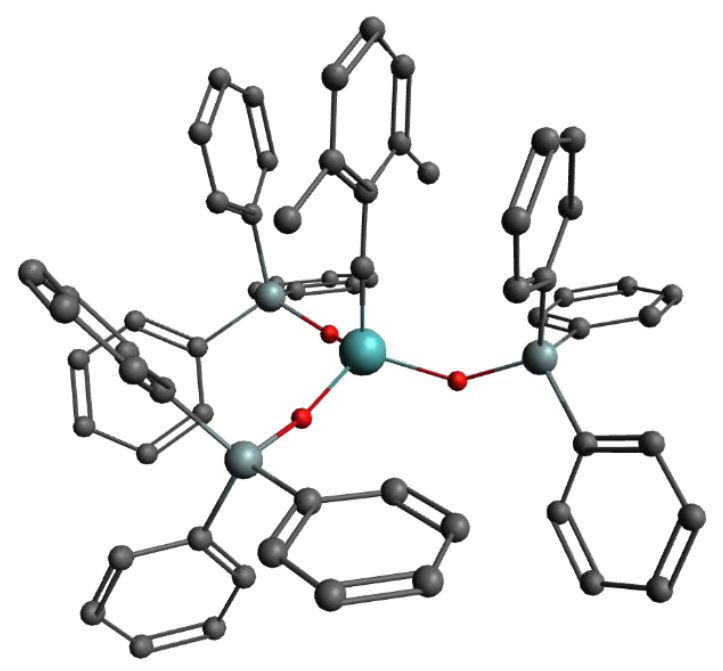




\begin{tabular}{lcc}
\hline & X-ray & DFT \\
\hline B(Mo=C) & $1.748(2)$ & 1.753 \\
A(Mo-C-C) & $171.4(1)$ & 172.8 \\
B(Mo-O) & $1.885(1)$ & 1.892 \\
D(O-Mo-O-O) & $132.40(6)$ & 127.4 \\
A(C-Mo-O) & $103.3(1), 103.4(1), 108.5(1)$ & 105 \\
A(Mo-O-Si) & $146.4(1), 154.1(1), 169.4(1)$ & $138,140,160$ \\
B(O-Si) & $1.65(1), 1.65(1), 1.63(1)$ & $1.67,1.67,1.65$ \\
D(C-Mo-O-Si) & $1.2(1), 4.4(2), 98.3(4)$ & $48,6,14$ \\
\hline
\end{tabular}




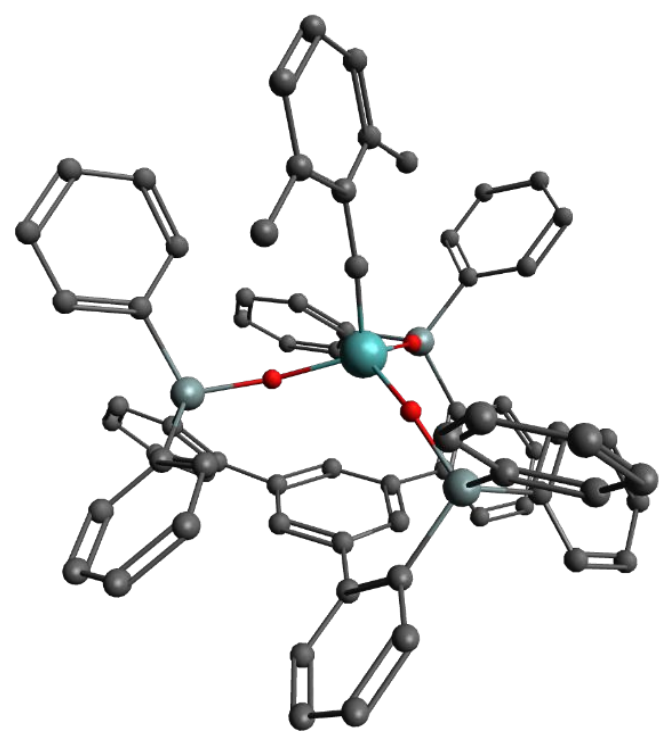

\begin{tabular}{lcc}
\hline & X-ray & DFT \\
\hline B(Mo=C) & $1.742(2)$ & 1.753 \\
A(Mo-C-C) & $177.1(1)$ & 174.5 \\
B(Mo-O) & $1.8811(13), 1.8797(13), 1.8984(14)$ & $1.89,1.87,1.89$ \\
D(O-Mo-O-O) & $137.20(9)$ & 133.5 \\
A(C-Mo-O) & $103.42(8), 103.23(8), 102(61(8)$ & 104 \\
A(Mo-O-Si) & $170.55(9), 164.40(8), 156.20(9)$ & $154,163,156$ \\
B(O-Si) & $1.6320(14), 1.6338(15), 1.6351(15)$ & 1.648 \\
D(C-Mo-O-Si) & $105.0(6), 124.0(4), 147.2(3)$ & $160,49,109$ \\
\hline
\end{tabular}


Table S3: Geometry Comparison between X-ray [IPUXAV] and DFT optimized structure of 1-MCBD. $C_{\alpha}$ refers to the carbons directly bonded to the molybdenum, the subscripts ax and eq on the oxygen atoms refer to the trigonal-bipyramidal ligand coordination.

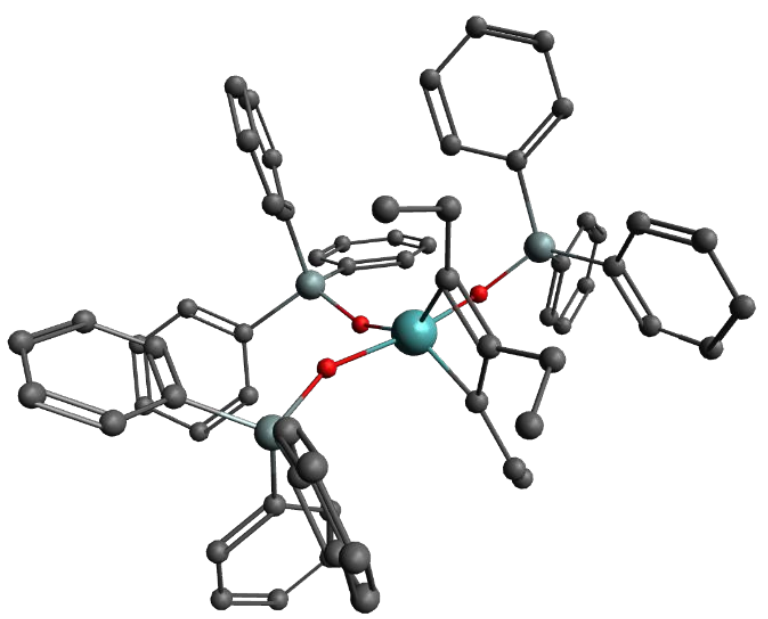

\begin{tabular}{|c|c|c|}
\hline & X-ray & DFT \\
\hline $\mathrm{B}\left(\mathrm{Mo}-\mathrm{C}_{\alpha}\right)$ & $1.882(2), 1.896(2)$ & 1.90 \\
\hline $\mathrm{B}\left(\mathrm{Mo}^{-\mathrm{C}_{\beta}}\right)$ & $2.117(2)$ & 2.133 \\
\hline $\mathrm{A}\left(\mathrm{C}_{\alpha}-\mathrm{Mo}-\mathrm{C}_{\alpha}\right)$ & $83.95(10)$ & 83.3 \\
\hline$A\left(C_{\alpha}-C_{\beta}-C_{\alpha}\right)$ & 120.73(19) & 121.0 \\
\hline $\mathrm{A}\left(\mathrm{O}_{\mathrm{eq}}-\mathrm{Mo}-\mathrm{C}_{\alpha}\right)$ & $143.38(8), 132.65(8)$ & $141.3,135.3$ \\
\hline$A\left(O_{e q}-M o-C_{\beta}\right)$ & $175.30(8)$ & 176.5 \\
\hline B(Mo-O) & ax: $2.0043(13), 2.0000(13)$ eq: $1.9030(15)$ & ax: 2.00 , eq: 1.919 \\
\hline $\mathrm{A}\left(\mathrm{O}_{\mathrm{ax}}-\mathrm{Mo}-\mathrm{O}_{\mathrm{eq}}\right)$ & $84.58(6), 82.46(6)$ & $84.2,82.5$ \\
\hline $\mathrm{D}\left(\mathrm{O}_{\mathrm{ax}}-\mathrm{Mo}-\mathrm{O}_{\mathrm{eq}}-\mathrm{O}_{\mathrm{ax}}\right)$ & $173.21(6)$ & 177.3 \\
\hline A(Mo-O-Si) & ax: 145.14(9), 147.86(9), eq: 142.61(9) & ax: 145,154 , eq: 145 \\
\hline$B(O-S i)$ & ax: $1.6051(14), 1.6070(14)$, eq: $1.6268(15)$ & ax: 1.630 , eq: 1.654 \\
\hline
\end{tabular}


Table S4: Geometry Comparison between X-ray [QOSTIE] and DFT optimized structure of 2-MTd

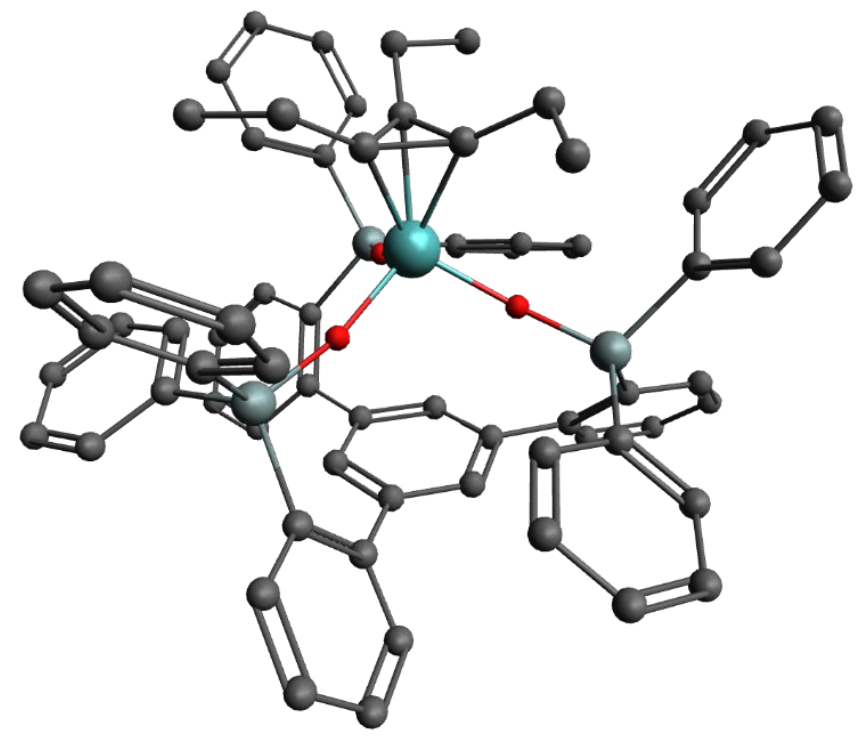

\begin{tabular}{lcc}
\hline & X-ray & DFT \\
\hline B(Mo-C) & $2.058(5), 2.0645(5), 2.065(5)$ & 2.066 \\
D(C-Mo-C-C) & $64.8(3)$ & 64.7 \\
B(Mo-O) & $1.891(3), 1.897(3), 1.907(3)$ & 1.912 \\
A(C-Mo-O) & $92.42(15), 92.92(17), 93.52(16)$ & 93.0 \\
A(O-Mo-O) & $100.73(12), 100.95(13), 101.90(13)$ & 101.1 \\
D(O-Mo-O-O) & $103.8(1)$ & 104.0 \\
A(Mo-O-Si) & $169.21(19), 170.20(18), 170.38(18)$ & 168.6 \\
B(O-Si) & $1.619(3), 1.620(3), 1.629(3)$ & 1.636 \\
D(C-Mo-O-Si) & $11(1), 15(1), 22(1)$ & 40.9 \\
\hline
\end{tabular}


Table S5: Geometry Comparison between X-ray [CAFDIA] and DFT optimized structure of 4-MCBD'. $C_{\alpha}$ refers to the carbons directly bonded to the molybdenum, the subscripts ax and eq on the oxygen atoms refer to the trigonal-bipyramidal ligand coordination (although the geometry is rather a square monopyramidal one).

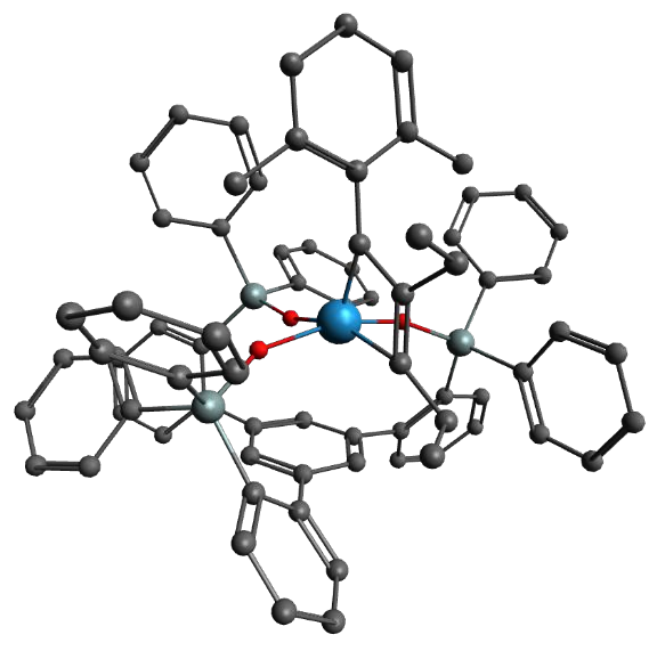

\begin{tabular}{|c|c|c|}
\hline & X-ray & DFT \\
\hline$B\left(W-C_{\alpha}\right)$ & $\alpha: 1.8730(17), \alpha^{\prime}: 1.9648(15)$ & $\alpha: 1.894, \alpha^{\prime}: 1.990$ \\
\hline$B\left(W-C_{\beta}\right)$ & $2.1517(17)$ & 2.172 \\
\hline$A\left(C_{\alpha}-W-C_{\alpha}\right)$ & $82.97(17)$ & 82.2 \\
\hline$A\left(C_{\alpha}-C_{\beta}-C_{\alpha^{\prime}}\right)$ & $121.5(1)$ & 122.0 \\
\hline$A\left(O_{e q}-W-C_{\alpha}\right)$ & $\alpha: 123.68(6), \alpha^{\prime}: 153.20(6)$ & $\alpha: 120.9, \alpha^{\prime}: 156.7$ \\
\hline$A\left(O_{e q}-W-C_{\beta}\right)$ & $166.23(6)$ & 163.2 \\
\hline$A(W-0)$ & ax: $1.9516(12), 1.9883(12)$, eq: $1.9025(11)$ & ax: 1.98 , eq: 1.935 \\
\hline$A\left(O_{a x}-W-O_{e q}\right)$ & $85.08(5), 82.08(5)$ & $84.8,82.4$ \\
\hline$D\left(O_{a x}-W-O_{e q}-O_{a x}\right)$ & $166.44(5)$ & 162.4 \\
\hline$A(W-O-S i)$ & ax: 149.75(8), 153.86(8), eq: $155.25(8)$ & ax: 154 , eq: 162.4 \\
\hline B(O-Si) & ax: $1.6066(13)$, eq: $1.6191(12), 1.6270(12)$ & ax: 1.63 , eq: 1.648 \\
\hline
\end{tabular}




\section{Distortion PESs}

To study the sterical stress imposed on the alkylidyne complexes by the different silanolate geometries, we turned to a small model system, i.e., $\mathrm{Mo}\left(\mathrm{OSiH}_{3}\right)_{3}(\mathrm{CMe})$. Varying the Mo-O-C angle/C-Mo-O-Si dihedral of all three groups simultaneously and recording the value of the respective other angle after reoptimization yields a potential energy surface (PES) showing two valleys (Figure S3). They correspond to the optimal combination of these two parameters. With the global minimum being at a Mo-O-Si angle of about $133^{\circ}$ and a zero dihedral (concave geometry), 1-CEt (blue data) lies close to the optimum. The basal arene forces the tripodal ligands to occupy large Mo-O-Si angles and consequently, they follow one of the valleys away from the global minimum. Interestingly, 2-CEt (orange data) shows a larger variance of the three groups, while 3-CEt (green data) is more homogeneous. The former mentioned "flat" ligand environment can thus be understood as being the optimal dihedrals for the given Mo-O-Si angle, enforced by the basal arene. The convex environment of 2-CEt is probably due to the sterically more demanding phenyl-groups. However, the calculated electronic energies show the sterical stress is very similar for both tripodal systems and the more heterogeneous angles and dihedrals in 2-CEt are not adding too much energy. This is probably because the dihedral is not well defined for such large angles.

We again used a model system, $\mathrm{Mo}\left(\mathrm{OSiH}_{3}\right)_{3}\left(\mathrm{C}_{3} \mathrm{H}_{3}\right)$, to study the sterical stress in the metallatetrahedrane configurations. Again, we recorded the PES of simultaneously changing all three Mo-O-Si angles or C-Mo-O-Si dihedrals (see Figure S4). The global minimum is, again, at a small angle $\left(143^{\circ}\right)$ and zero dihedral. While 1-MTd and 3-MTd occupy geometries close to the valley of larger dihedrals, 2-MTd lies in the other valley, keeping the small dihedral and linearizing the angle. Despite these differences, the sterical stress is rather similar between all three complexes.

Interestingly, while the sterical stress decreases for the two tripodal complexes (approximately by the same amount), it increases for the monodentate system (compare Figure S3 and Figure S4Figure S3).

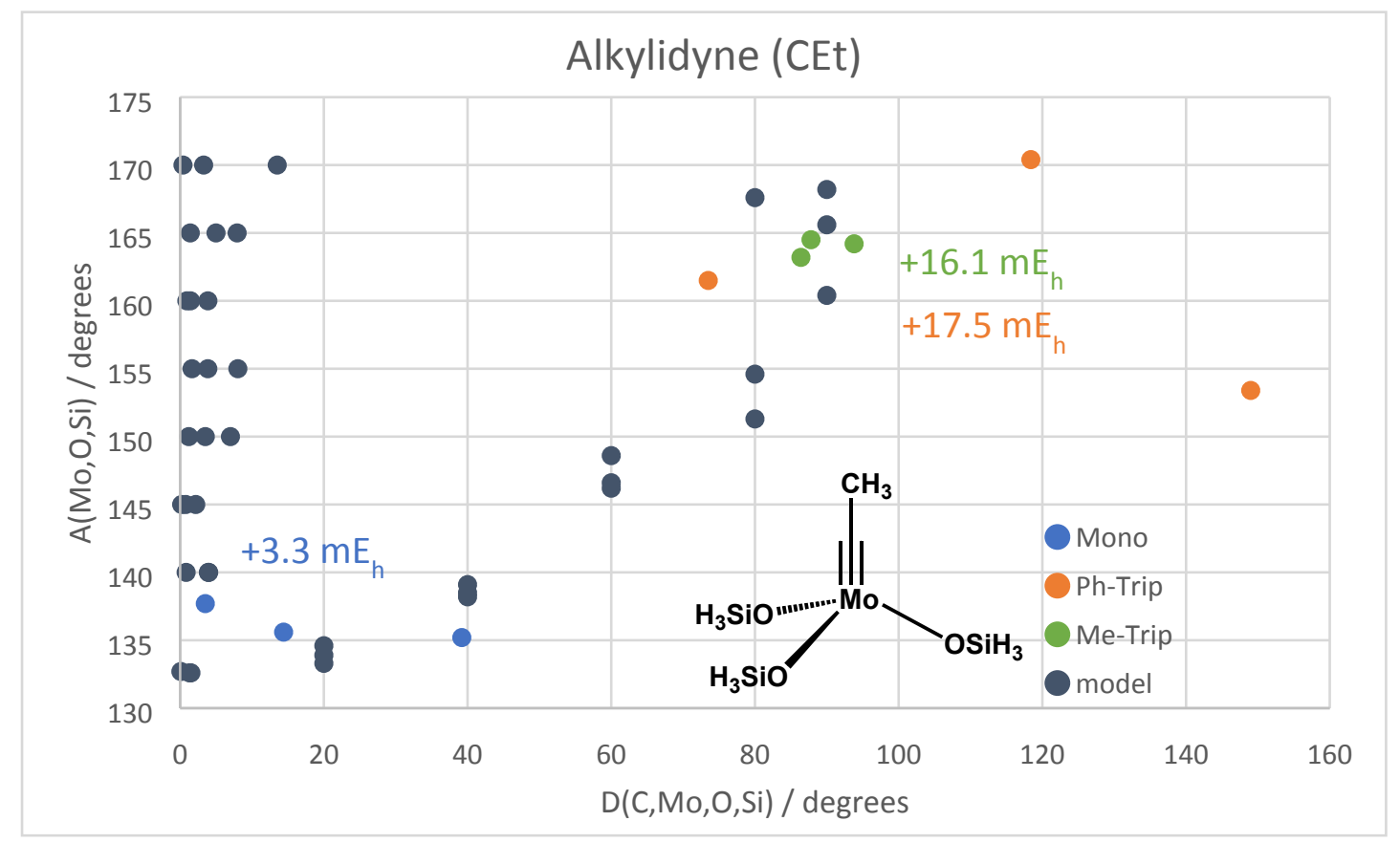

Figure S3: Alkylidyne model PES. The values for the three ligand bonds of each system are depicted as well. The electronic energies for the three systems are calculated by enforcing the model alkylidyne to occupy the same angle/dihedral values as in the actual complexes. 


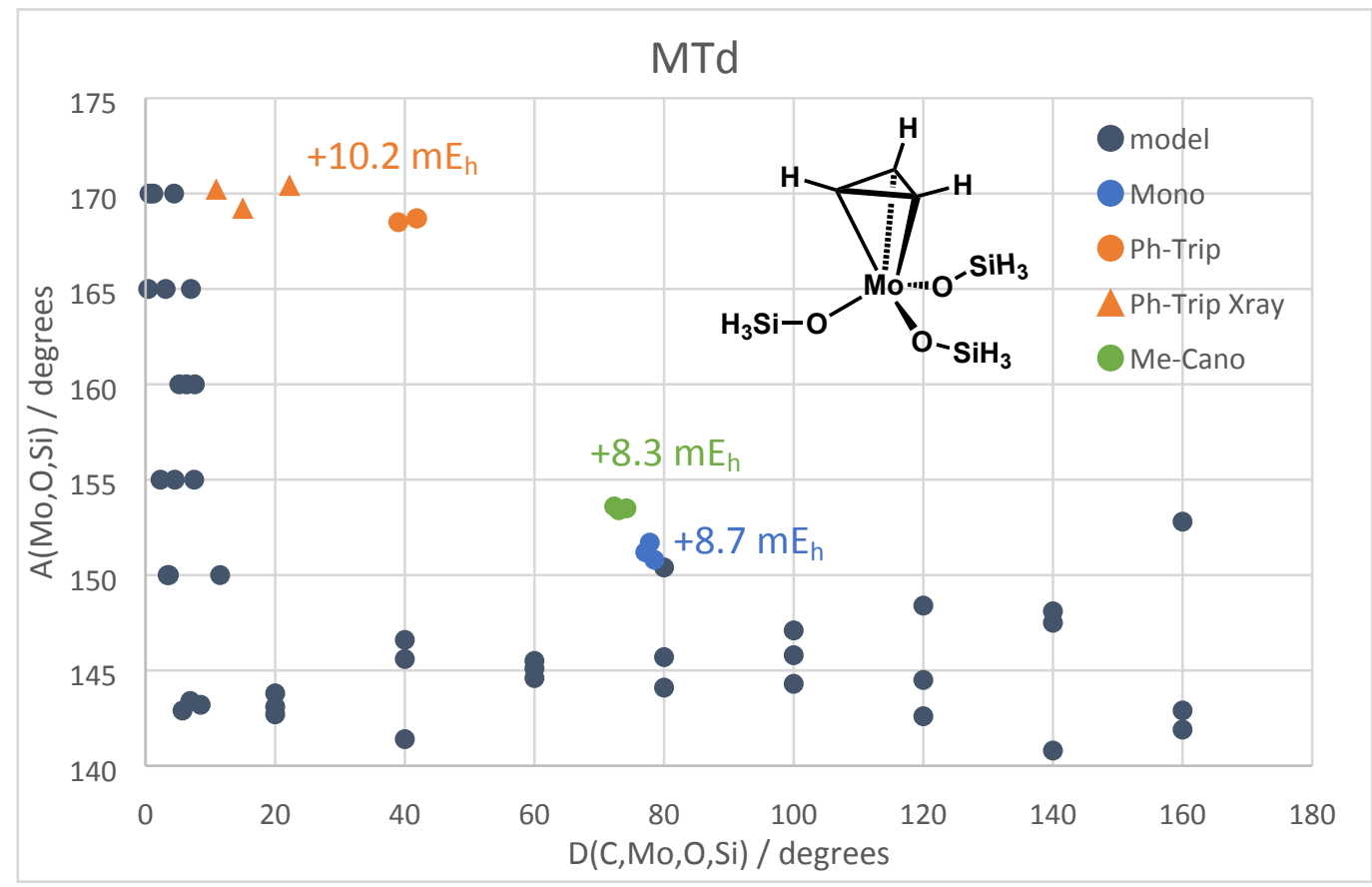

Figure S4: Metallatetrahedran model PES. The values for the three ligand bonds of each system are depicted as well. The electronic energies for the three systems are calculated by enforcing the model MTd to occupy the same angle/dihedral values as in the actual complexes. 
preAdd complexes

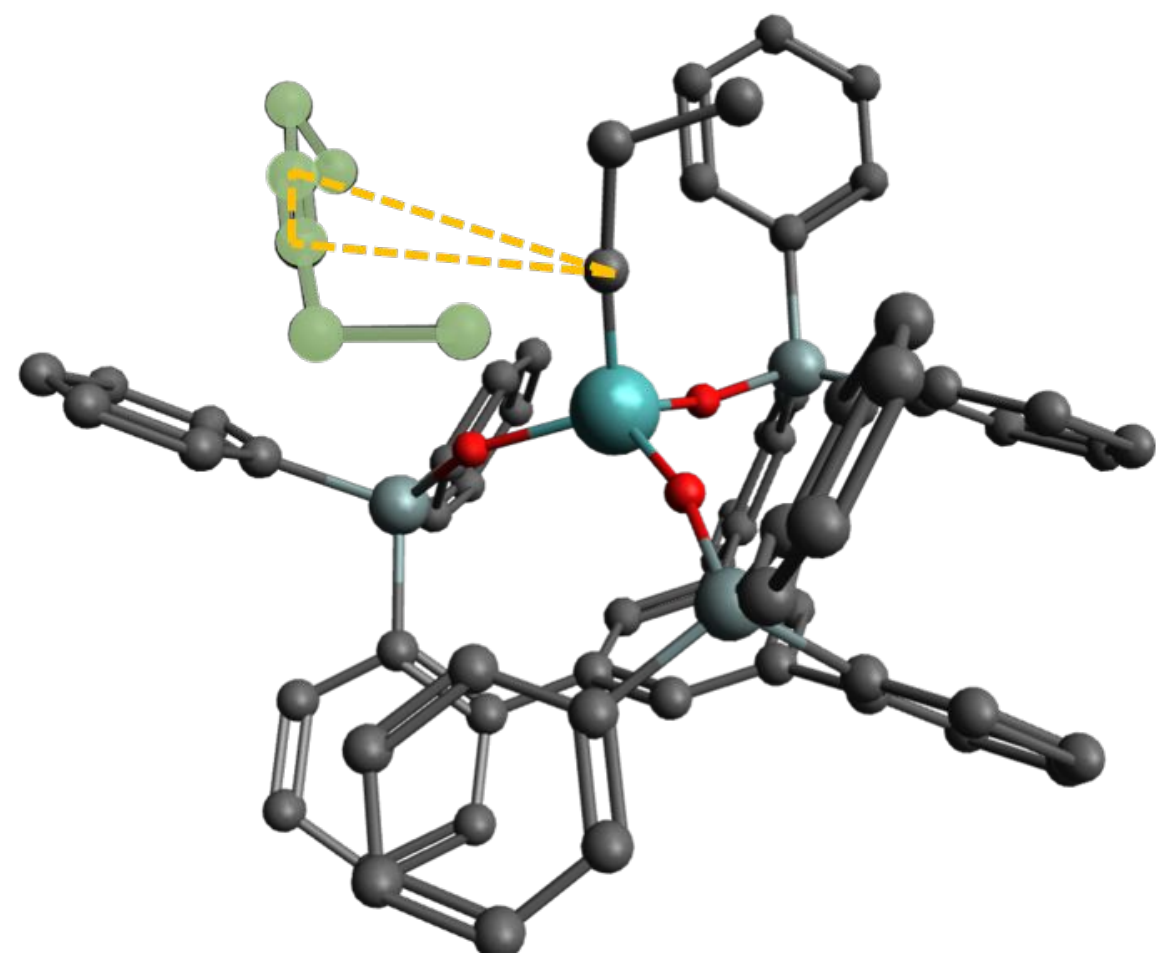

Figure S5: preAdd complex of the 2-CEt + 3-hexyne reaction system. The alkyne is only loosely bound and the alkylidyne complex is only marginally distorted.

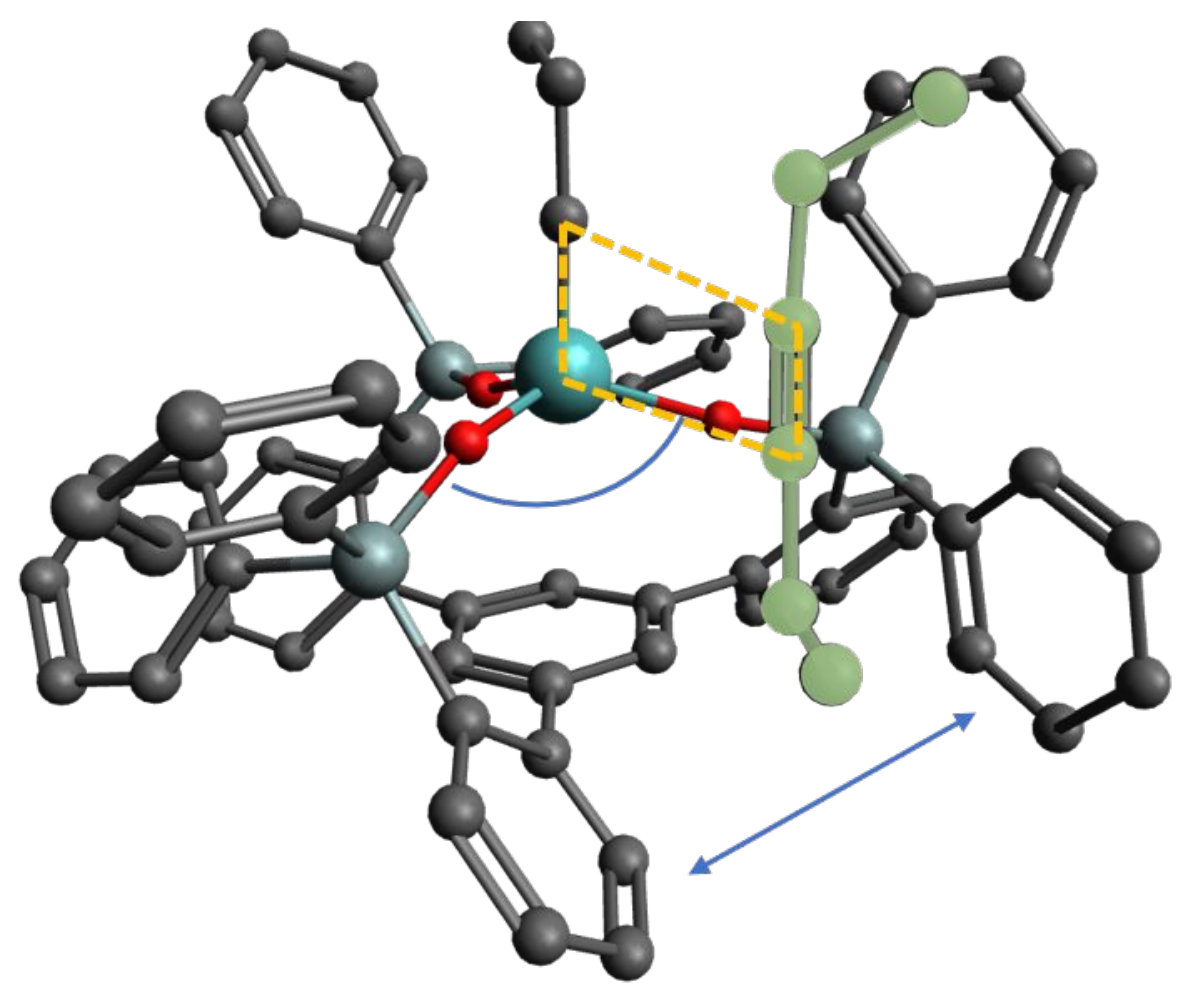

Figure S6: preAdd2 complex of the 2-CEt + 3-hexyne reaction system. The alkyne is placed between two silanolate phenyl groups, which's dispersion interaction had to be cleaved. The alignment of the alkyne and alkylidyne triple bond is close to parallel. 


\section{Electronic Structure}

Canonical MOs

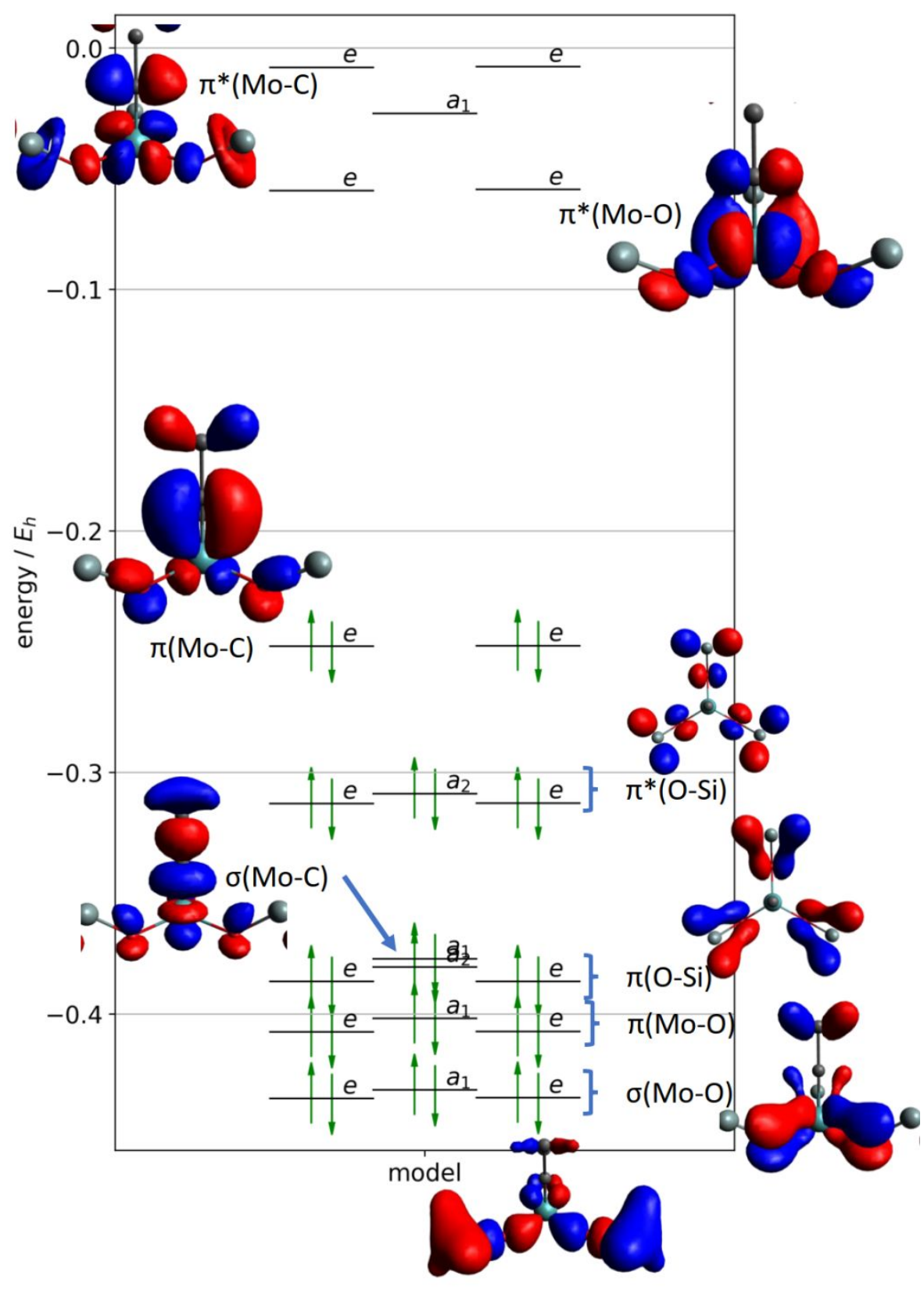

Figure S7: canonical MO diagram of the model alkylidyne complex $\mathrm{Mo}\left(\mathrm{OSiH}_{3}\right)_{3}(\mathrm{CMe})\left(\mathrm{C}_{3 \mathrm{v}}\right.$ symmetry). 


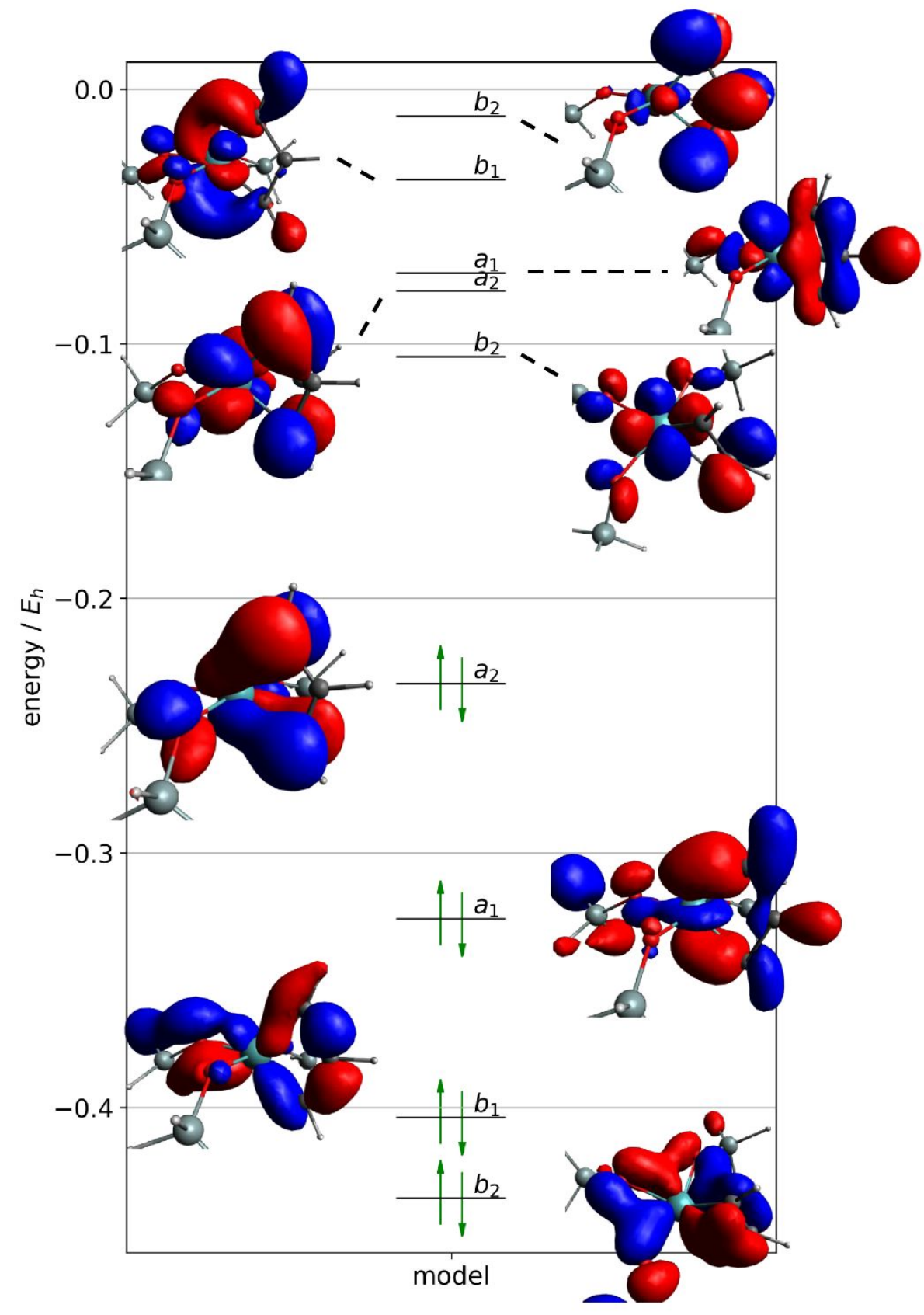

Figure S8: Canonical MO diagram of the model metallacyclobutadiene, $\mathrm{Mo}\left(\mathrm{OSiH}_{3}\right)_{3}\left(\mathrm{C}_{3} \mathrm{H}_{3}\right)\left(\mathrm{C}_{2 v}\right.$ symmetry). 


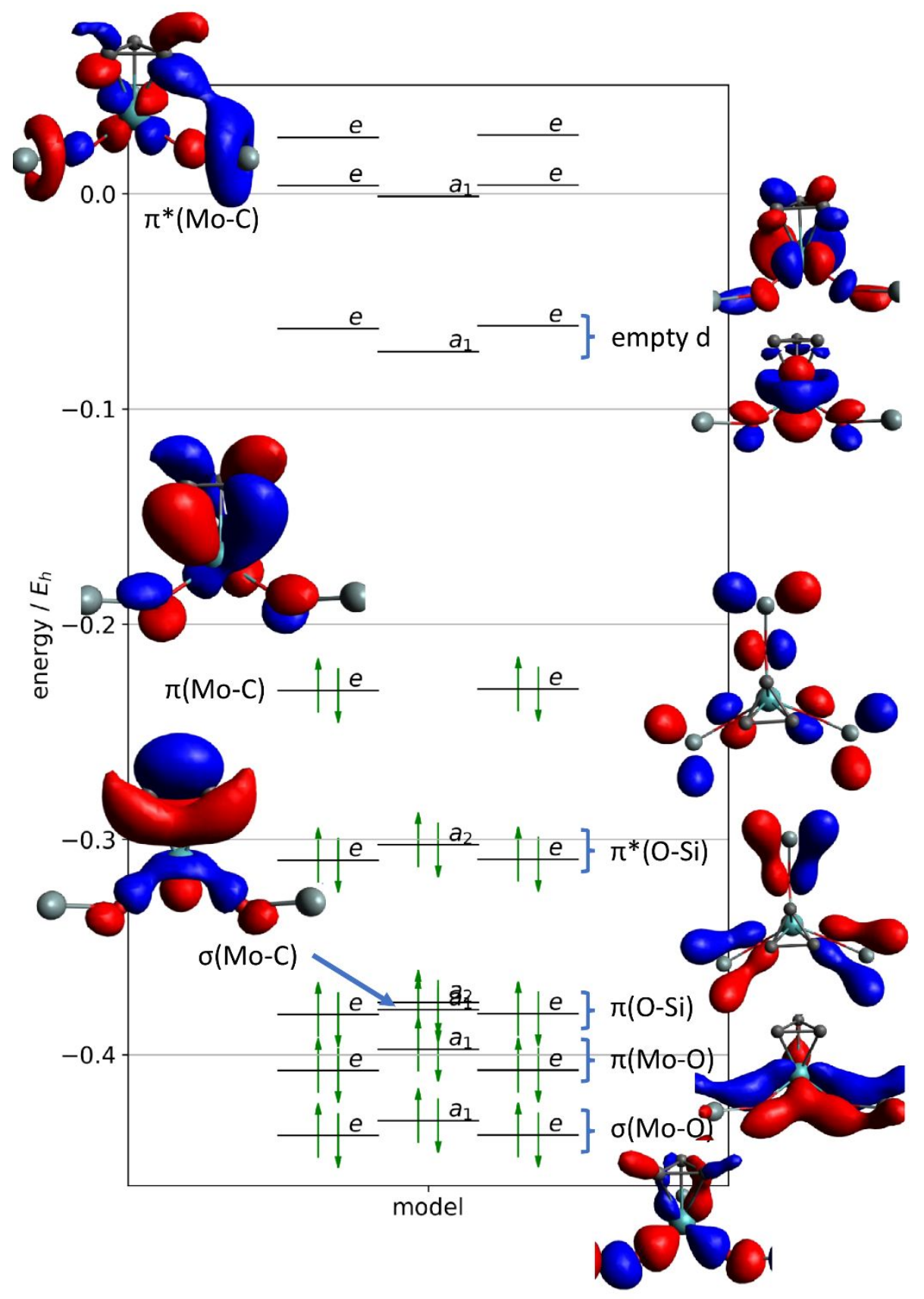

Figure S9: Canonical MO diagram of the metallatetrahedrane structure for the model complex $\mathrm{Mo}\left(\mathrm{OSiH}_{3}\right)_{3}\left(\mathrm{C}_{3} \mathrm{H}_{3}\right)\left(\mathrm{C}_{3 \mathrm{v}}\right.$ symmetry). 


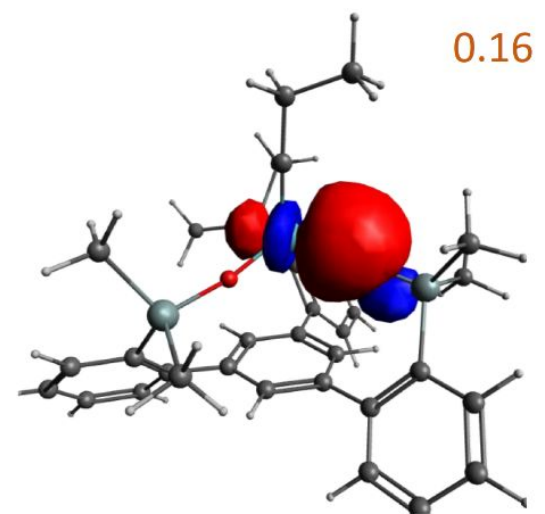

Mo-O o

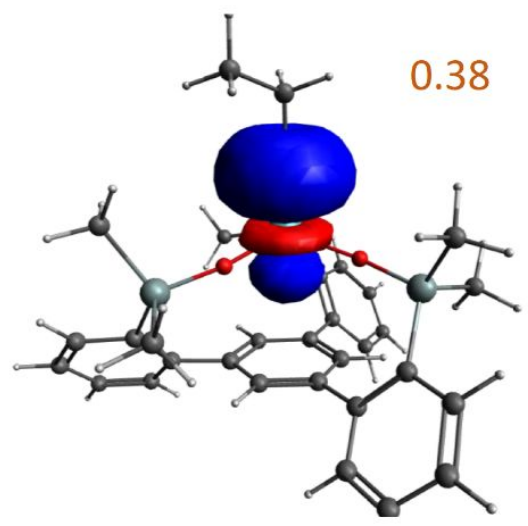

Mo-C $\sigma$

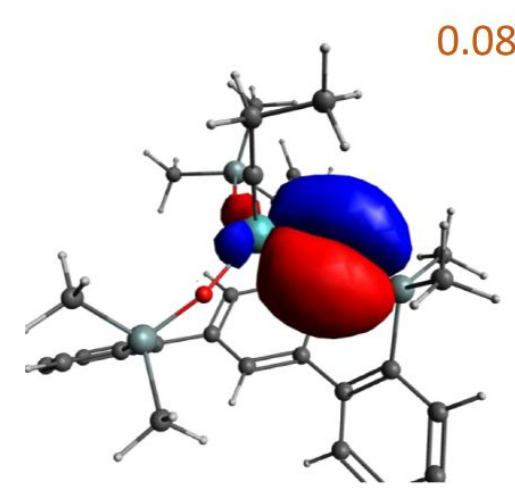

$\mathrm{Mo}-\mathrm{O} \pi$

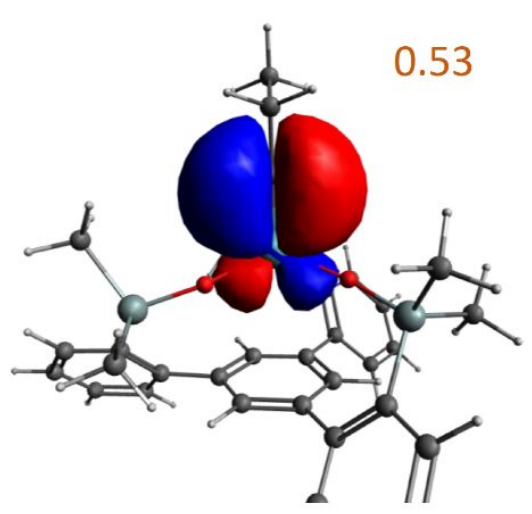

Mo-C $\pi$

Figure S10: Localized Molecular Orbitals (Pipek-Mezey algorithm) of the 3-CEt complex, acting as example. The Mulliken Population at the molybdenum of the individual LMOs is also depicted. This is a measure of the amount of electron donation due to the respective orbital ( 0.5 corresponds to an equal share of the electrons, hence a non-polar covalent bond). 


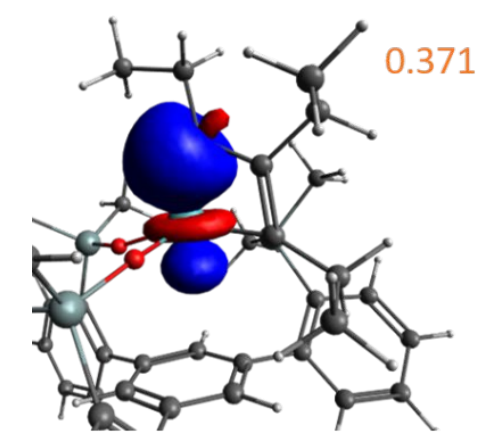

Mo- $\mathrm{C}_{\alpha} \sigma$

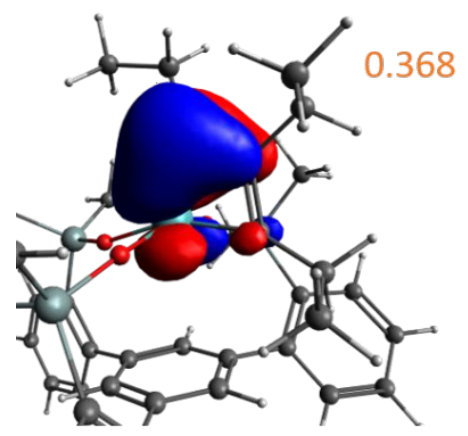

$\mathrm{Mo}-\mathrm{C}_{\alpha}-\mathrm{C}_{\beta} \pi$

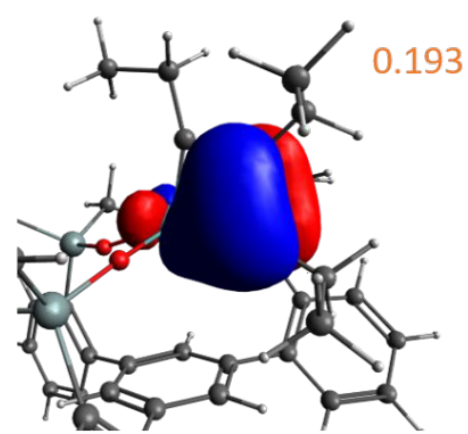

Mo- $\mathrm{C}_{\alpha^{\prime}}-\mathrm{C}_{\beta} \pi$

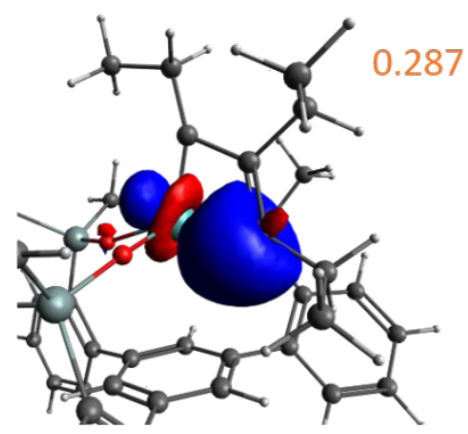

Mo- $\mathrm{C}_{\alpha^{\prime}} \sigma$

Figure S11: Localized Molecular Orbitals (Pipek-Mezey algorithm) of the 3-MCBD complex, acting as example. The Mulliken Population at the molybdenum of the individual LMOs is also depicted. This is a measure of the amount of electron donation due to the respective orbital ( 0.5 corresponds to an equal share of the electrons, hence a non-polar covalent bond).

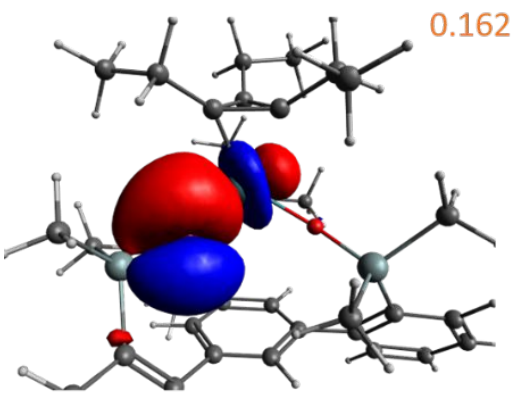

Mo-O o

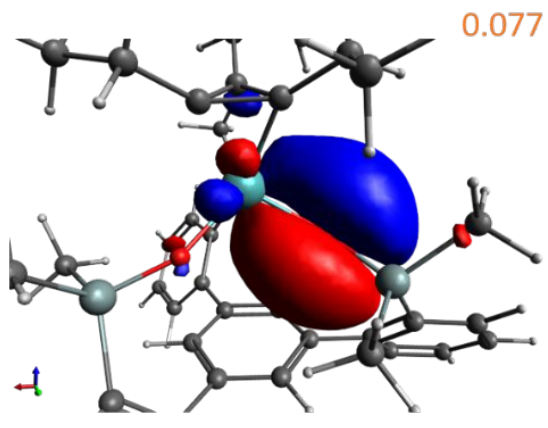

$\mathrm{Mo}-\mathrm{O} \pi$

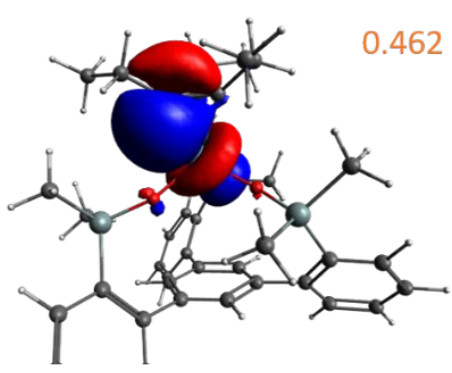

Mo-C $\sigma$

Figure S12: Localized Molecular Orbitals (Pipek-Mezey algorithm) of the 3-MTd complex, acting as example. The Mulliken Population at the molybdenum of the individual LMOs is also depicted. This is a measure of the amount of electron donation due to the respective orbital ( 0.5 corresponds to an equal share of the electrons, hence a non-polar covalent bond). 


\section{Mayer Bond Orders}

Table S6: Averaged Mayer bond orders and Loewdin partial charges for different propylidyne complexes.

\begin{tabular}{lcccc}
\hline & 1-CEt & 2-CEt & 3-CEt & 4-CEt \\
\hline BO(M-C) & 2.531 & 2.589 & 2.565 & 2.764 \\
BO(M-O) & 0.957 & 0.838 & 0.892 & 0.949 \\
BO(O-Si) & 0.945 & 0.952 & 1.018 & 0.984 \\
q(M) & 0.6751 & 0.6882 & 0.7334 & 0.7929 \\
\hline
\end{tabular}

Table S7: Mayer Bond orders and Loewdin partial charges for different metallacyclobutadiene complexes.

\begin{tabular}{lcccc}
\hline & 1-MCBD & 2-MCBD & 3-MCBD & 4-MCBD \\
\hline BO(M-C & $1.3198,1.4490$ & $1.1220,1.4976$ & $1.1128,1.5434$ & $1.2272,1.5693$ \\
BO( $\left.\mathbf{C}_{\alpha}-C_{\beta}\right)$ & $1.1981,1.1635$ & $1.1890,1.0663$ & $1.3319,1.0367$ & $1.2293,0.9418$ \\
BO(M-C $\left.C_{\beta}\right)$ & 0.2467 & 0.3024 & 0.2841 & 0.6944 \\
BO(M-O & $0.8454,0.8297$ & $0.7613,0.7771$ & $0.8317,0.8440$ & $0.7005,0.7477$ \\
BO(M-O $\left.\mathbf{O}_{\mathbf{t}}\right)$ & 0.7452 & 0.7053 & 0.7856 & 0.8147 \\
$\mathbf{q}(\mathbf{M})$ & 0.734203 & 0.752787 & 0.778664 & 0.887939 \\
\hline
\end{tabular}

Table S8: Averaged Mayer bond orders and Loewdin partial charges for different metallatetrahedran complexes

\begin{tabular}{lcccc}
\hline & 1-MTd & 2-MTd & 3-MTd & 4-MTd \\
\hline BO(M-C) & 0.828 & 0.844 & 0.857 & 0.955 \\
BO(M-O) & 0.802 & 0.733 & 0.820 & 0.882 \\
BO(C-C) & 0.756 & 0.734 & 0.750 & 0.770 \\
BO(O-Si) & 0.998 & 0.912 & 1.012 & 0.932 \\
q(M) & 0.744 & 0.748 & 0.781 & 0.926 \\
\hline
\end{tabular}




\section{NOCV/ETS results}

Table S9: Contributions to $E_{\text {orb }}$ from each NOCV pair. Values in $\mathrm{kcal} / \mathrm{mol}$. Only contribution larger than $2 \mathrm{kcal} / \mathrm{mol}$ are listed.

\begin{tabular}{ccccc}
\hline \multicolumn{2}{c}{ MCBD } & \multicolumn{2}{c}{ MTd } \\
\hline NOCV pairs & Mo & W & Mo & W \\
\hline $\mathbf{1}$ & -219.245 & -290.983 & -549.793 & -639.048 \\
$\mathbf{2}$ & -56.235 & -46.167 & -164.877 & -173.109 \\
$\mathbf{3}$ & -102.741 & -145.373 & -110.362 & -151.145 \\
$\mathbf{4}$ & -33.133 & -31.603 & -22.082 & -44.893 \\
$\mathbf{5}$ & -26.277 & -41.632 & -24.005 & -32.572 \\
$\mathbf{6}$ & -6.300 & -6.743 & -7.576 & -14.569 \\
$\mathbf{7}$ & -4.038 & -4.495 & -3.975 & -4.827 \\
$\mathbf{8}$ & -2.199 & -2.823 & & \\
\hline
\end{tabular}

As seen in Table S9, some NOCV pairs are much more stabilizing in case of tungsten. For the more interesting case of the tungstenacyclobutadiene (4-MCBD), NOCV pairs 1, 3 and 5 are shown here, they all correspond to $\mathrm{M}-\mathrm{C} \sigma$-bonds. $\mathrm{M}-\mathrm{C} \pi$-bonds are more similar between the two metals.
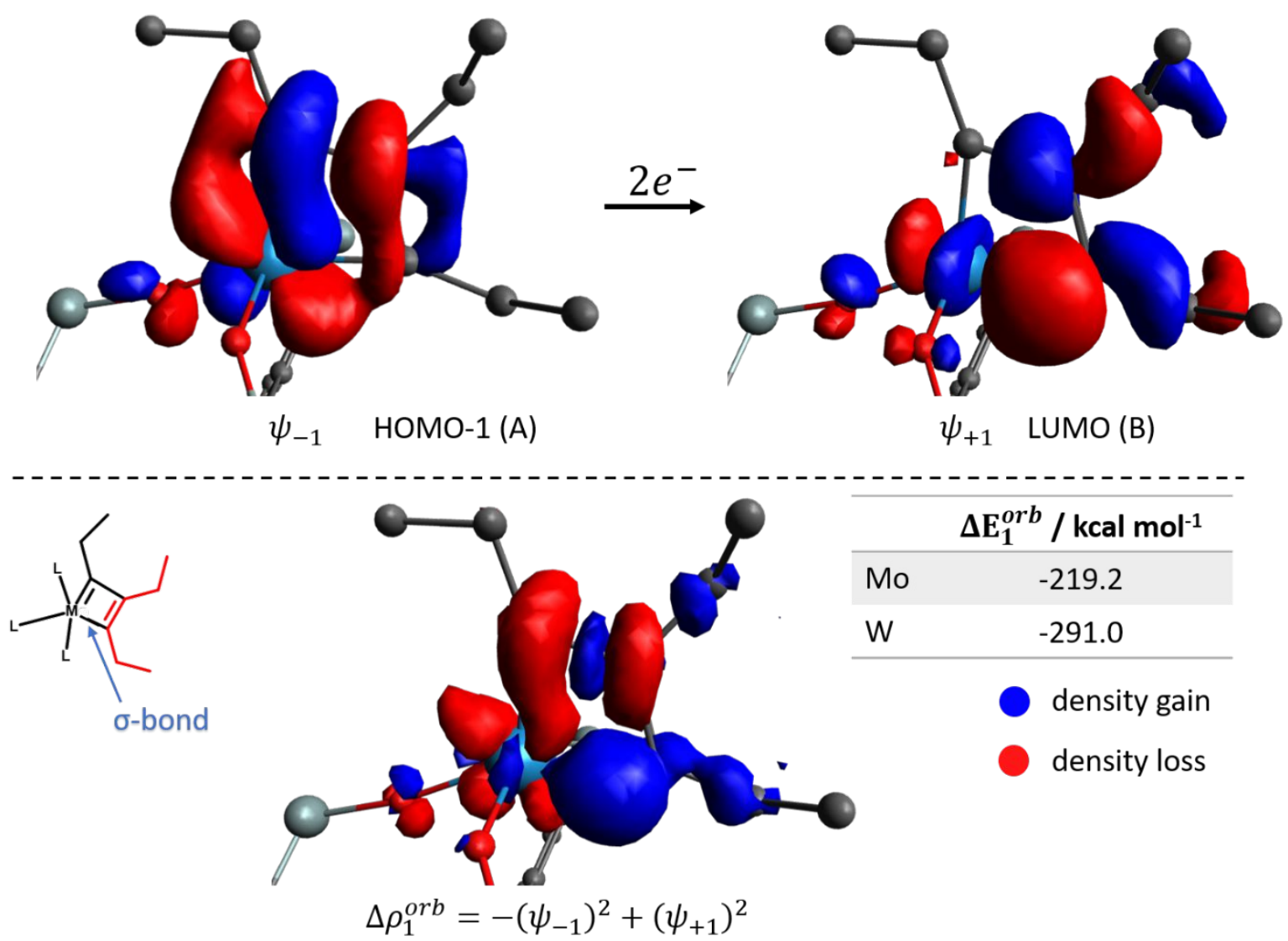

Figure S13: NOCV pair $\psi_{ \pm 1}$ and the resulting difference density $\Delta \rho_{1}^{\text {orb }}$ for the metallacyclobutadienes. Fragment $A=$ Alkylidyne, Framgent $B=$ Alkyne. 

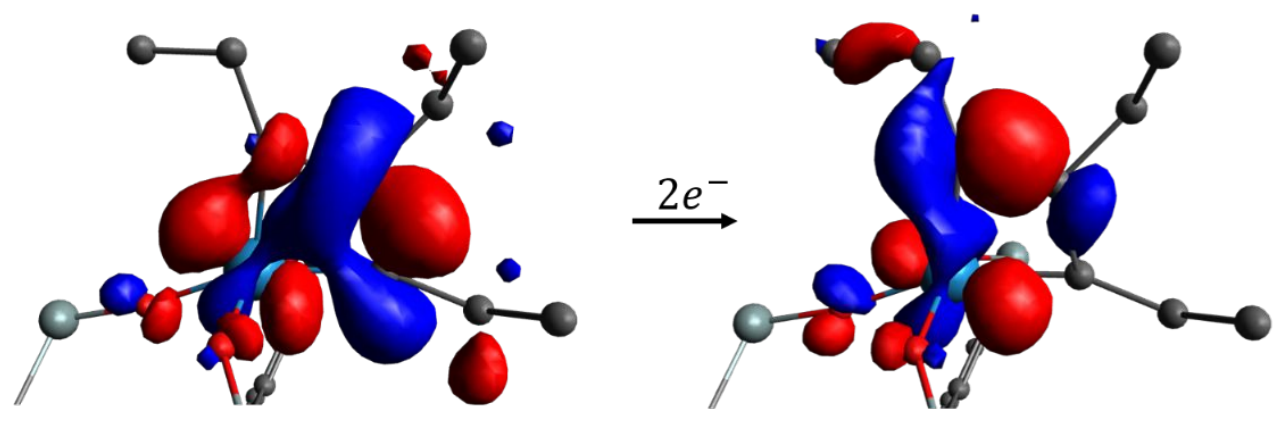

$\psi_{-3} \quad \mathrm{HOMO}-1(\mathrm{~B})$

$\psi_{+3} \quad \operatorname{LUMO}(\mathrm{A})$
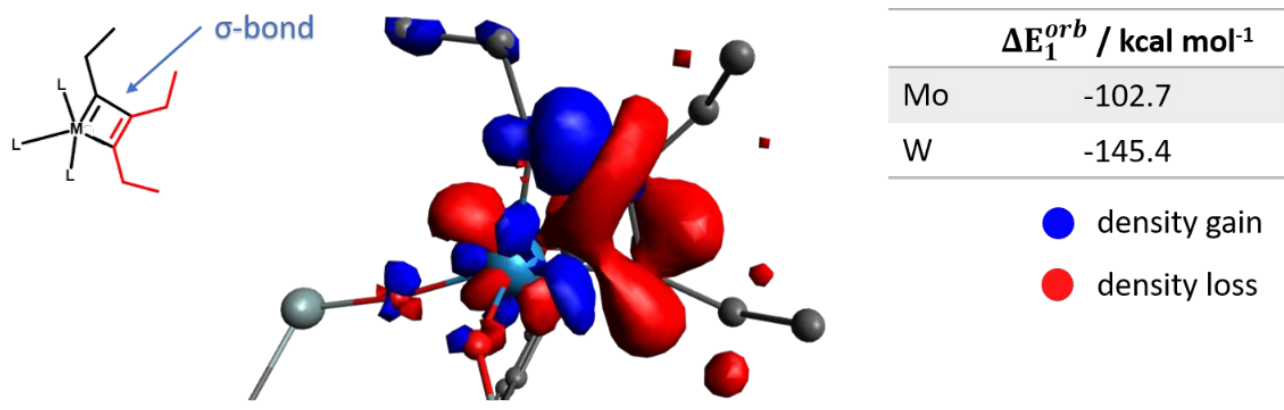

$$
\Delta \rho_{3}^{o r b}=-\left(\psi_{-3}\right)^{2}+\left(\psi_{+3}\right)^{2}
$$

Figure S14: NOCV pair $\psi_{ \pm 3}$ and the resulting difference density $\Delta \rho_{3}^{\text {orb }}$ for the metallacyclobutadienes. Fragment $A=$ Alkylidyne, Framgent $B=$ Alkyne.
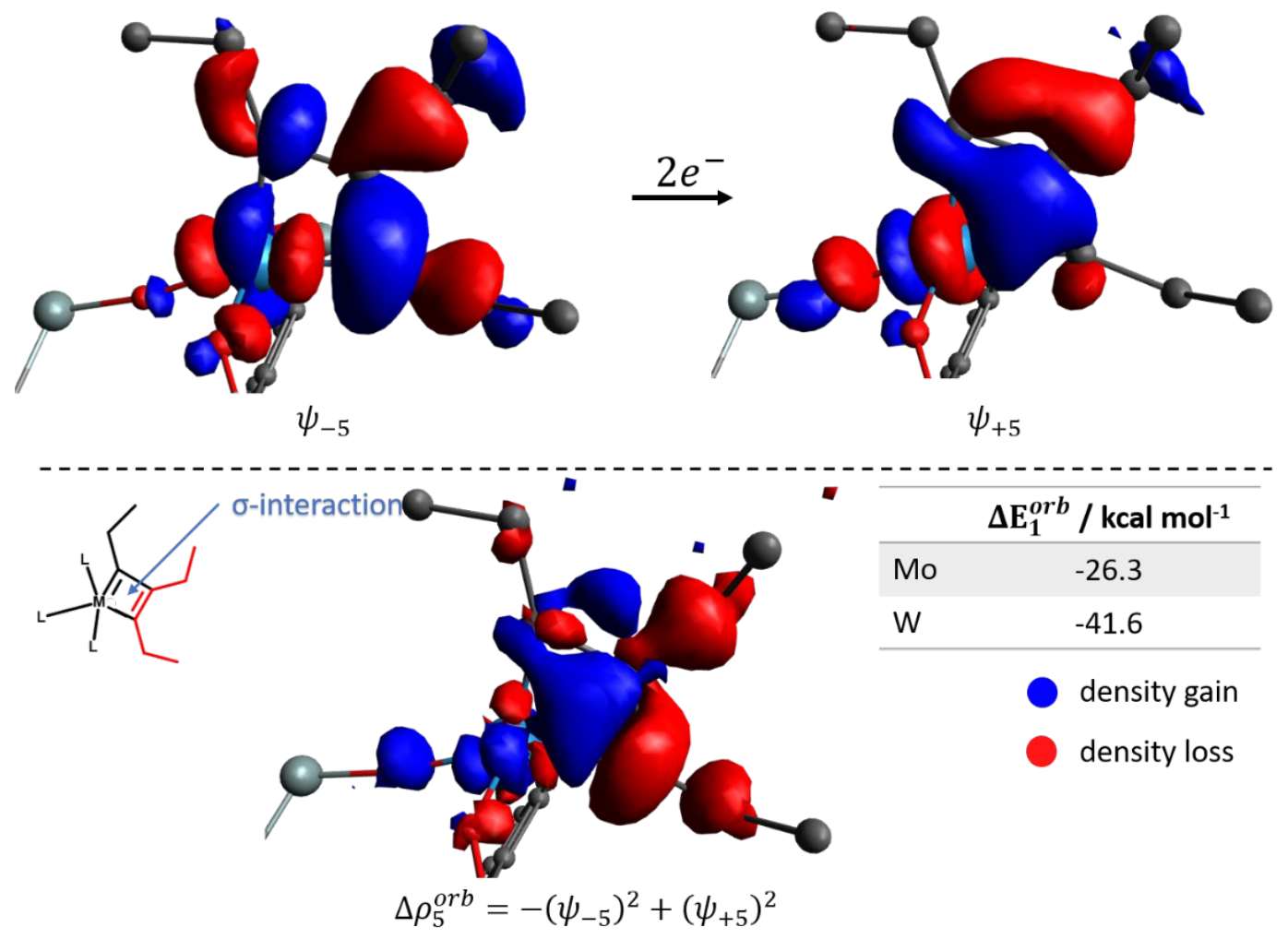

Figure S15: NOCV pair $\psi_{ \pm 5}$ and the resulting difference density $\Delta \rho_{5}^{\text {orb }}$ for the metallacyclobutadienes. Fragment $A=$ Alkylidyne, Framgent $B=$ Alkyne. 


\section{Local-Energy-Decomposition Analysis}

To determine the dispersion energy caused by the $\mathrm{C}-\mathrm{H}-\pi$ interaction between the ethyl- and phenylgroups in complex 2-MTd, we made use of the LED scheme implemented in ORCA. The data was calculated on the DLPNO-CCSD(T)/def2-TZVP level of theory using TightPNO settings. Since the interaction is intramolecular and not intermolecular, the fragments had to assigned under breaking of bonds. Figure S16 shows the assignment of the fragments. By assigning three fragments, we minimize any error due to bond-breaking and other internal dispersion effects. We only needed to consider the dispersion interaction between fragments 2 and 3, which is shown in Table S10.

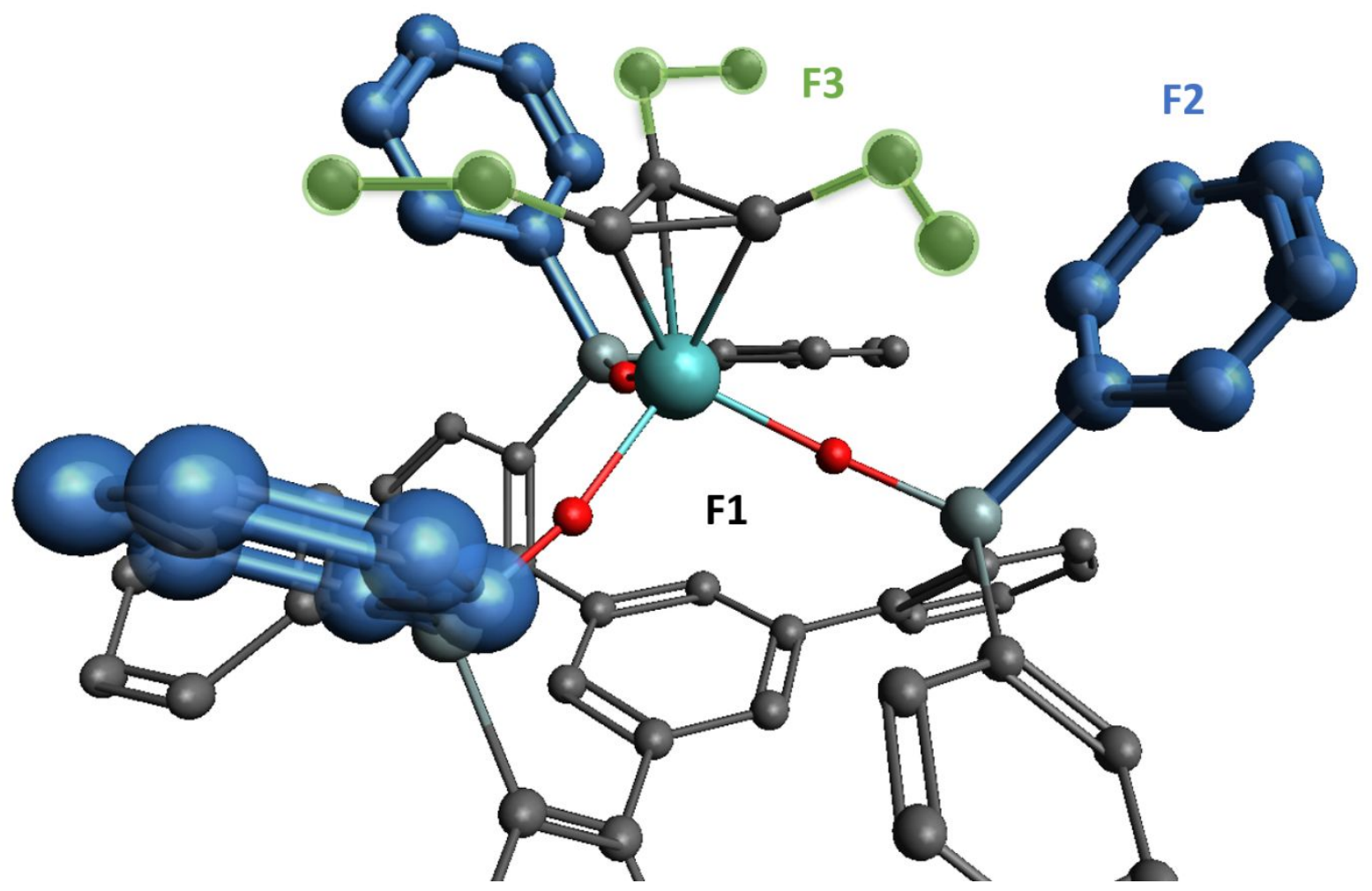

Figure S16: Fragmentation for intramolecular LED analysis in complex 2-MTd.

Table S10: Dispersion interactions obtained by LED analysis on the DLPNO-CCSD(T)/def2-TZVP level of theory between fragments 2 and 3. All energied in $\mathrm{kJ} / \mathrm{mol}$.

\begin{tabular}{lc}
\hline & F2 $\leftrightarrow$ F3 \\
\hline Dispersion (strong pairs) & -35.63 \\
Dispersion (weak pairs) & -4.90 \\
Dispersion (total) & -40.53 \\
\hline
\end{tabular}




\section{Spectroscopy}

\section{Details of measurement and calculation}

UV-VIS measurements were performed on a Cary-6000i UV-VIS-NIR spectrometer. Resonance Raman measurements were performed on a home-built system that is based on a Trivista 555 triple monochromator. For the Gaussian deconvolution of the measured UV-VIS spectra, the amplitude $A$ and position of each Gaussian as well as one common width $\sigma$ were fitted in a least square sense to match a chosen part of the measured spectrum. Each of these Gaussians was then converted to a stick with oscillator strength $f_{\text {osc }}$, corresponding to the individual transitions, by:

$$
f_{\text {osc }}=1.44 \times 10^{-19} \times c \times \sqrt{2 \pi \sigma^{2}} \times A
$$

Here $c$ is the speed of light in $\mathrm{cm} / \mathrm{s}$, the amplitude of the Gaussians $A$ is given in $\mathrm{L} / \mathrm{mol} / \mathrm{cm}$ and the width $\sigma$ is given in $\mathrm{cm}^{-1}$.

In the TD-DFT calculations, only singlet states were considered. Additionally, the sticks obtained from the calculations were converted to Gaussian functions having the same width $\sigma$ as experimentally determined. The sum of these Gaussians then represents the calculated envelope spectrum.

DPSS Lasers of Cobolt-Hübner have been used as monochromatic light sources. The samples were measured as free-hanging frozen droplets on a small loop at the edge of a glass pipette. Cooling to $100 \mathrm{~K}$ is provided by a Cryostream 600 unit that uses a cold nitrogen gas stream isolated by a laminarflow warm nitrogen stream around it to prevent condensation of moisture and also providing semianaerobic conditions. The scattered light was collected by a protected-silver off-axis parabolic mirror of Thorlabs and collimated onto the entrance slit of the monochromator by a quartz lense. Data have been post-processed by removing cosmic spikes, which result from cosmic particles reaching the CCD detector. They were identified by measuring up to 30 spectra without averaging them. Since the cosmic spikes are singular events, they only appear in one of these spectra. After all spikes were removed, the spectra were averaged. For every solution measured, a measurement of the pure solvent was conducted using the same settings. Both solution and solvent spectra were baseline corrected using the IALS method:

\section{Used IALS code (written for Python 3)}

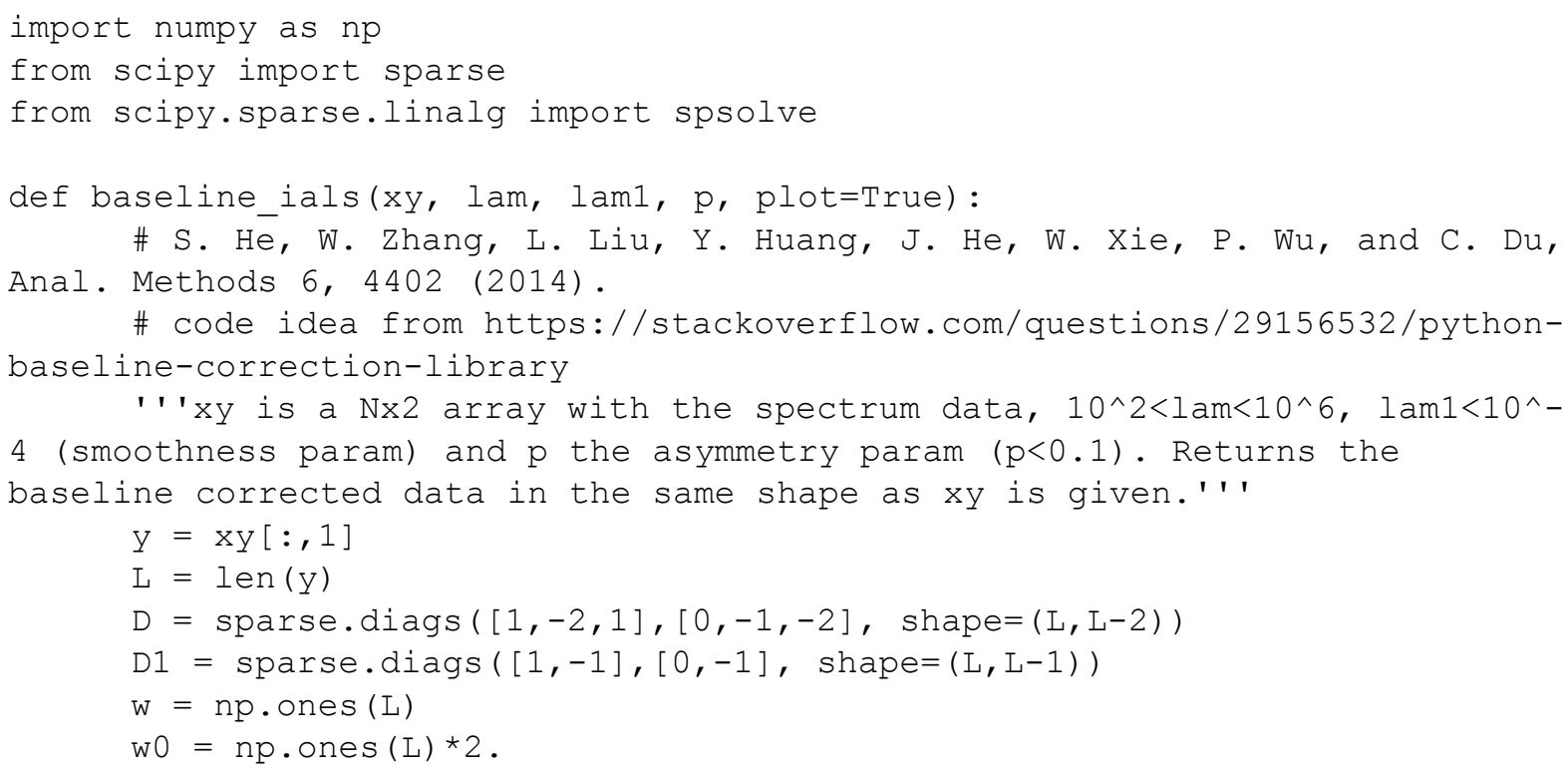




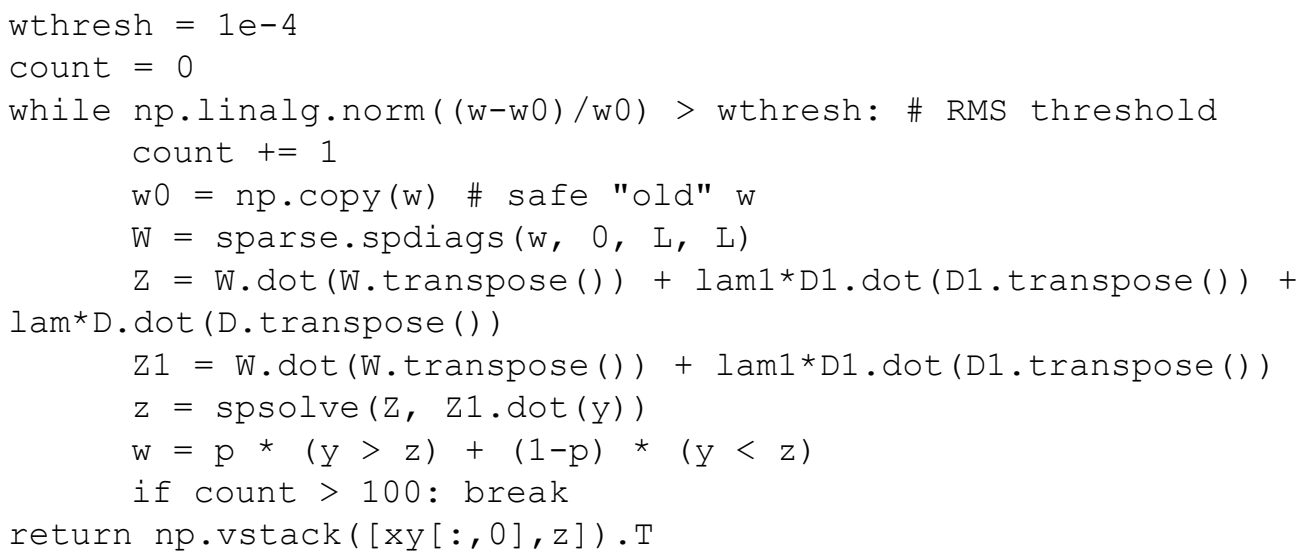

Then, the solution and solvent spectra were calibrated by assigning the most intense solvent peaks to their known position (from previously recorded reference spectra) and fitting these data by a secondorder polynomial. After normalizing both spectra, they were subtracted and common artifacts (caused by non-optimal overlap of solvent peaks) were removed.

To simulate Resonance-Raman spectra, the displacements between the potential minima of the ground and excited states - expressed in normal coordinates - are needed. The ground state minimum is known from the geometry optimization shown above. To estimate the equilibrium of the excited states, first, the vertical excitation energy and the gradient of the excited states PES are obtained using the above mentioned TDDFT calculations on the B3LYP-D3(BJ)/def2-TZVP level of theory. Second, the Hessian of the excited state is needed. To save computation time, we approximate it by the ground state Hessian, already obtained at the TPSS-D3(BJ)/def2-TZVP level of theory. Knowing the gradient and Hessian, an extrapolation can be performed which yields an estimate of the position of the excited state minimum. The obtained displacements (in dimensionless normal coordinates) were then used in the ORCA_ASA program to simulate the Resonance-Raman intensities of each vibrational mode upon a chosen excitation. The excitation energies were manually shifted according to the difference between the respective sticks in the UV-VIS-NIR measurements. This way, the excitation energy within the Resonance-Raman calculations has the same difference to the TDDFT transition energy as the laser excitation has to the UV-VIS-NIR transition in the experiment. 


\section{Additional UV-VIS spectra}

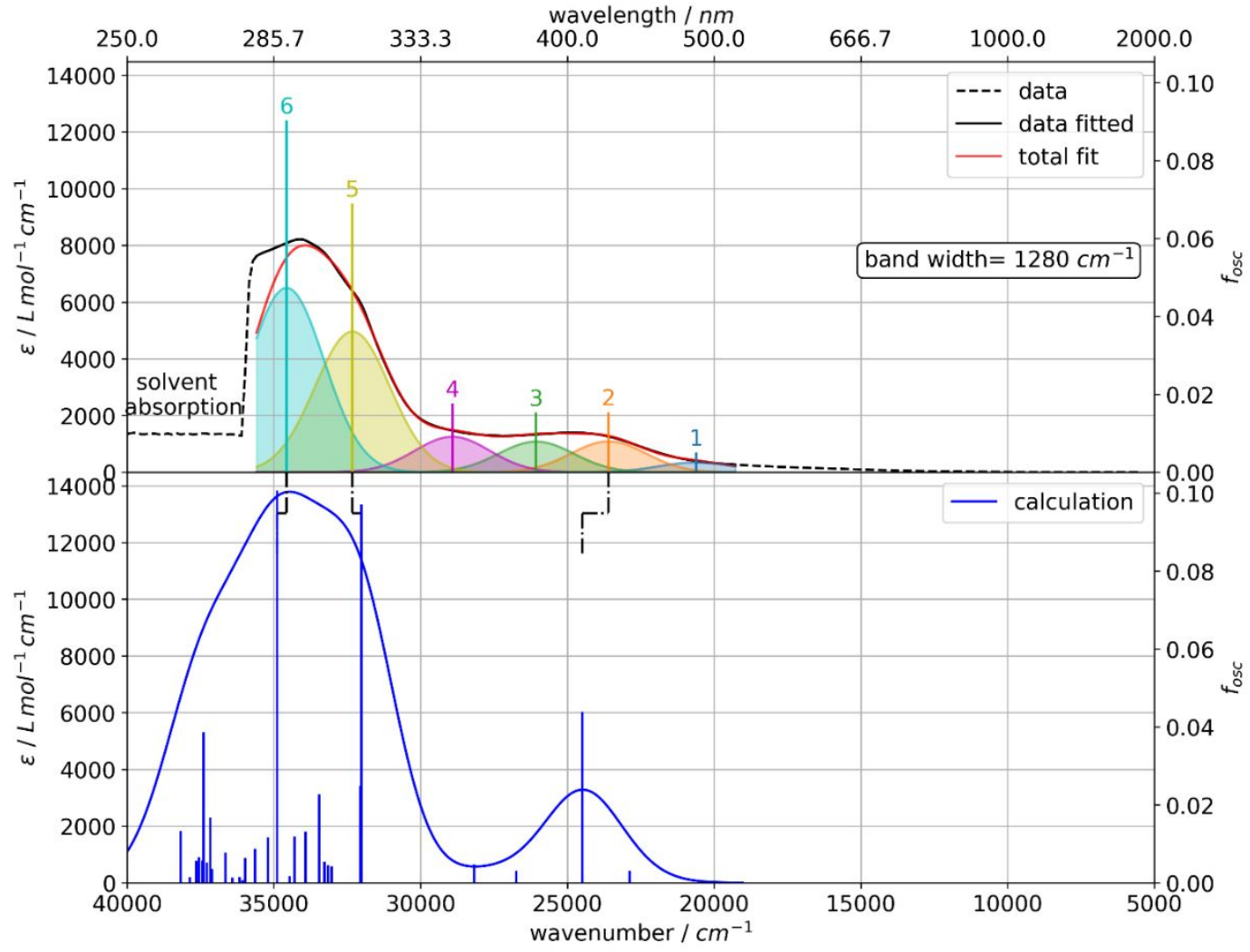

Figure S17: Measured and calculated UV-VIS-NIR spectra of 1-CAr. The measurement was conducted with $1 \mathrm{mM}$ solution in toluene at room temperature. For the TDDFT calculation, the first 30 singlet states were considered.

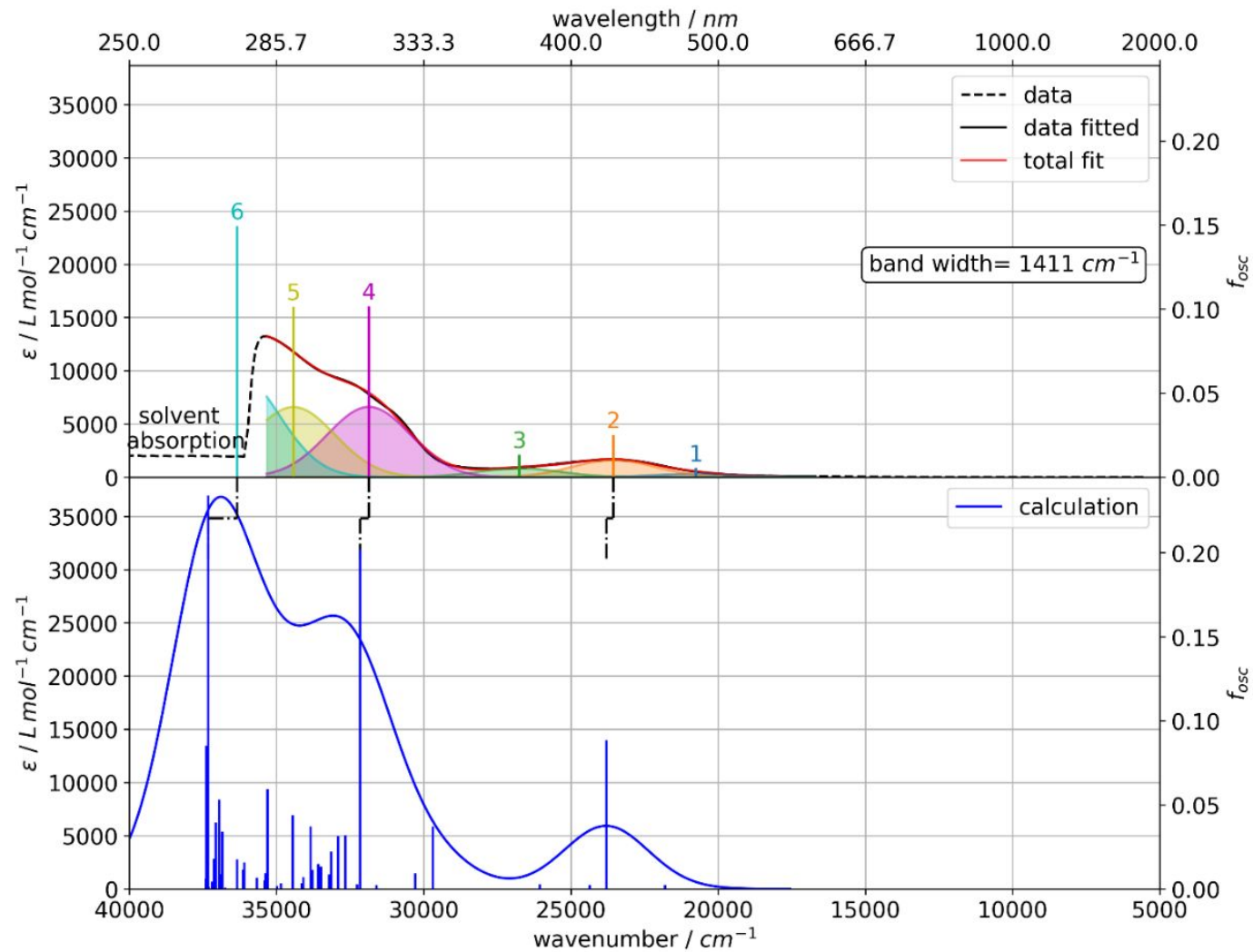

Figure S18: Measured and calculated UV-VIS-NIR spectra of 2-CAr. The measurement was conducted with $1 \mathrm{mM}$ solution in toluene at room temperature. For the TDDFT calculation, the first 40 singlet states were considered. 


\section{Additional Resonance Raman spectra}
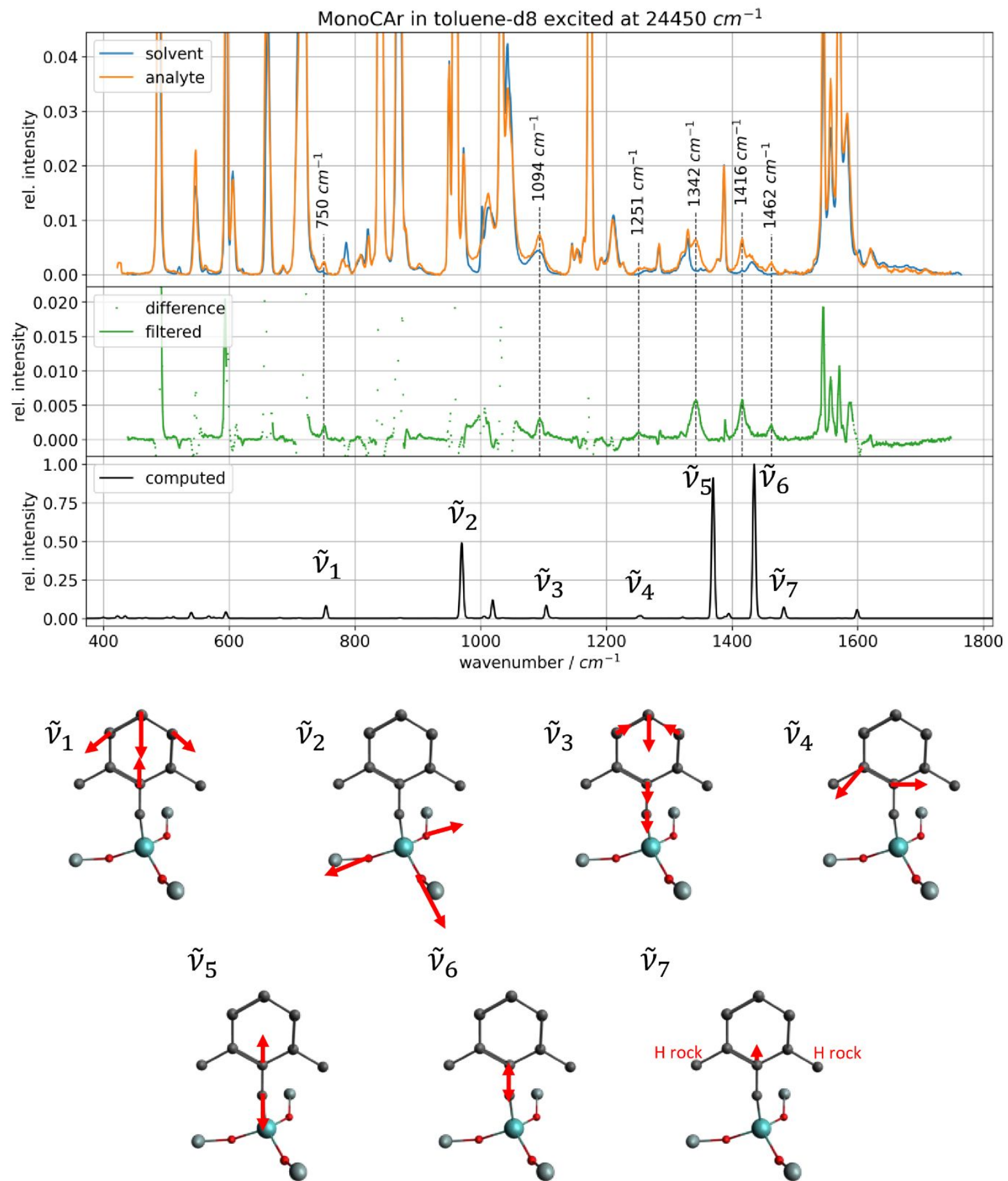

$\tilde{v}_{6}$

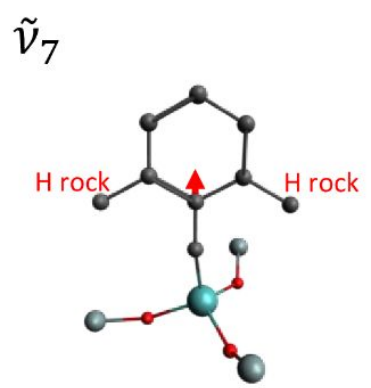

Figure S19: Resonance-Raman spectra of the 1-CAr complex (3 mM in toluene- $\left.d_{8}\right)$ at $100 \mathrm{~K}$. An excitation laser with a photon energy of $24450 \mathrm{~cm}^{-1}$ was used at a power of $45 \mathrm{~mW}$ 

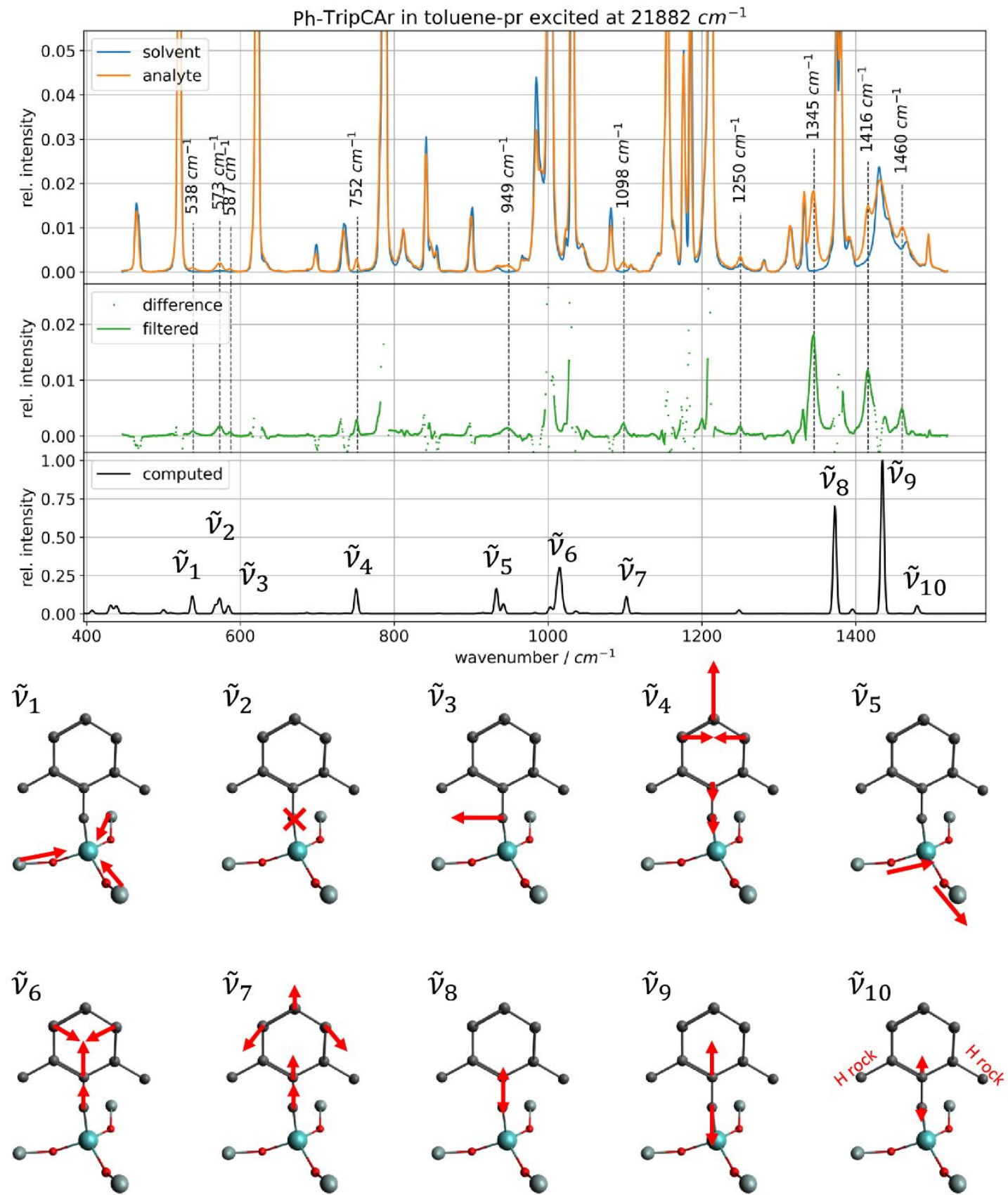

Figure S20: Resonance-Raman spectra of the 2-CAr complex (3 $\mathrm{mM}$ in toluene) at $100 \mathrm{~K}$. An excitation laser with a photon energy of $21882 \mathrm{~cm}^{-1}$ was used at a power of $50 \mathrm{~mW}$ 

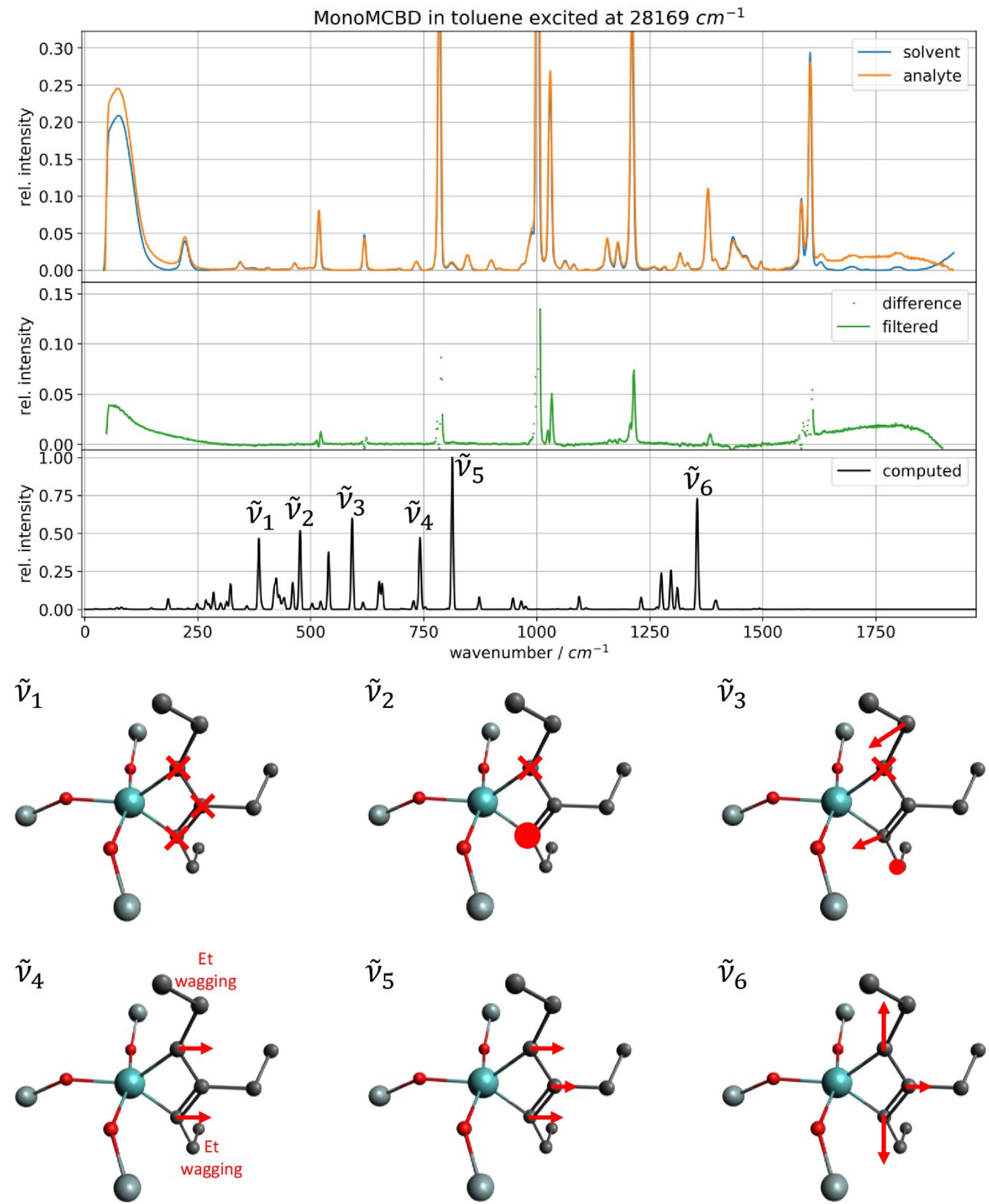

Figure S21: Resonance-Raman spectra of intermediate 1-MCBD (0.3 mM in toluene) at $100 \mathrm{~K}$. An excitation laser with a photon energy of $28169 \mathrm{~cm}^{-1}$ was used at a power of $20 \mathrm{~mW}$. Higher concentrations gave strong fluorescence, especially when irradiating the solid crystals of 1-MCBD directly. 
4-MCBD in 5eqHexyne excited at $24691 \mathrm{~cm}^{-1}$

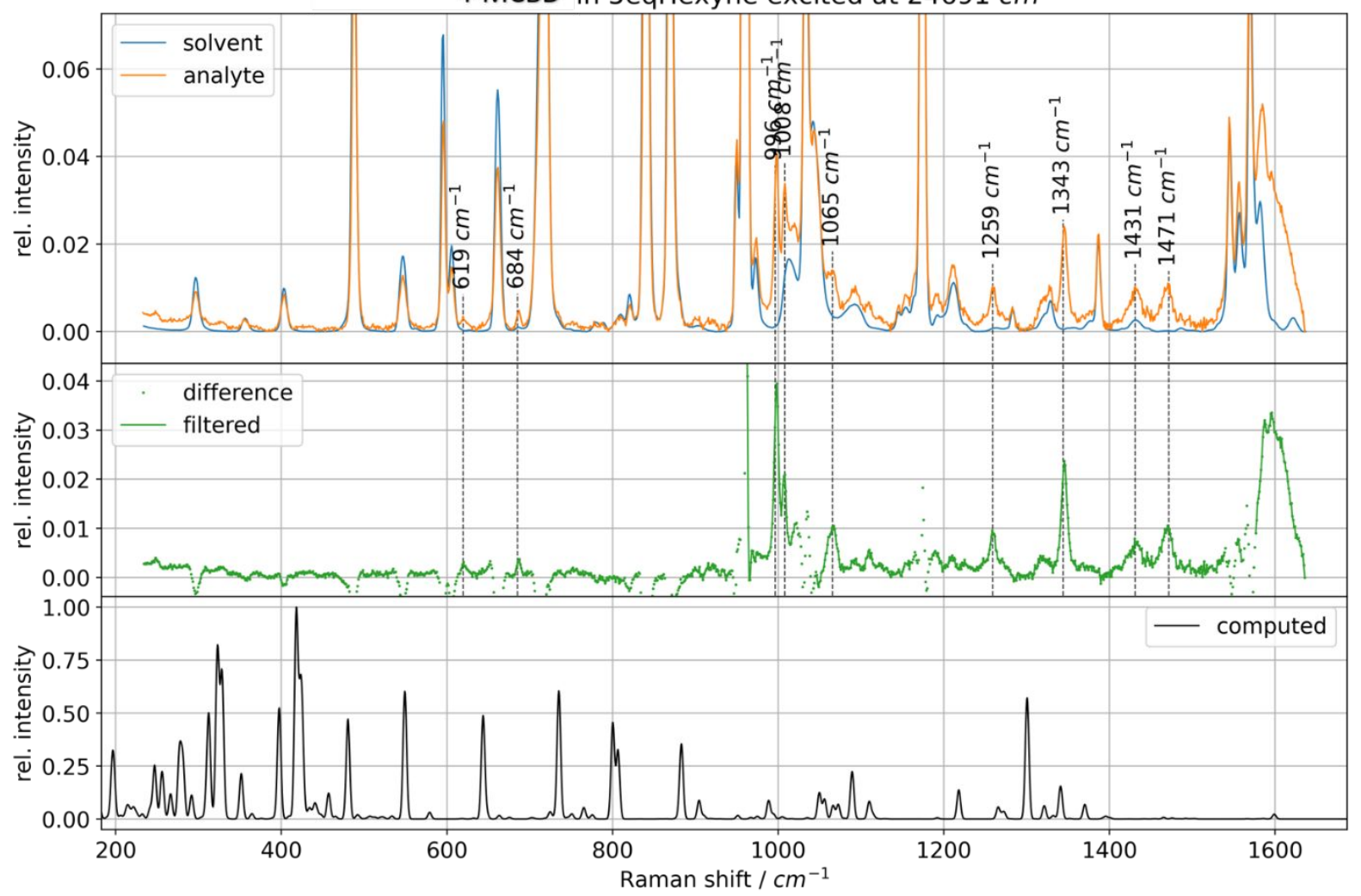

Figure S22: Resonance-Raman spectra of intermediate 4-MCBD (48 mM in toluene) at $100 \mathrm{~K}$. An excitation laser with a photon energy of $24691 \mathrm{~cm}^{-1}$ was used at a power of $10 \mathrm{~mW}$. 

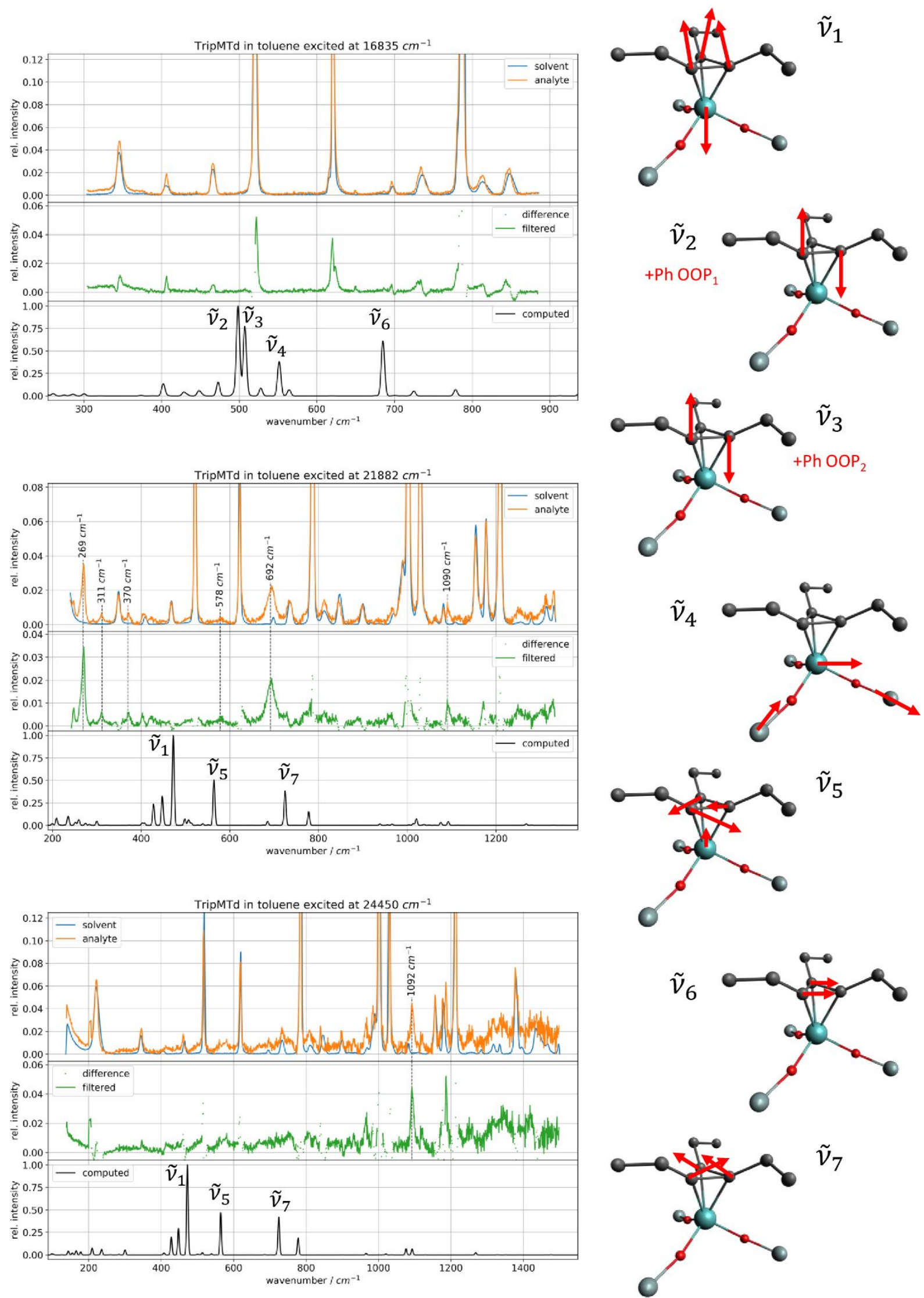

Figure S23: Resonance-Raman spectra of intermediate 2-MTd (20 mM in toluene) at $100 \mathrm{~K}$. Excitation lasers with photon energies of $16835 \mathrm{~cm}^{-1}, 21882 \mathrm{~cm}^{-1}$ and $24450 \mathrm{~cm}^{-1}$ were used, each at a power of $20 \mathrm{~mW} . \tilde{v}_{1}, \tilde{v}_{5}$ and $\tilde{v}_{7}$ describe different twisting motions of the $C_{3}$-unit while moving up or down, relative to the molybdenum atom. OOP=out-of-plane 
Difference densities of intermediate complexes

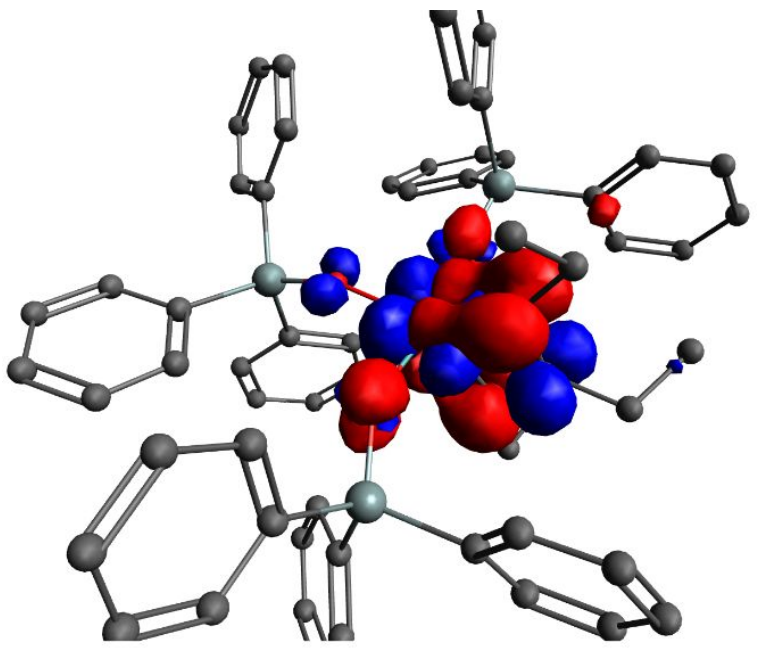

transition 1

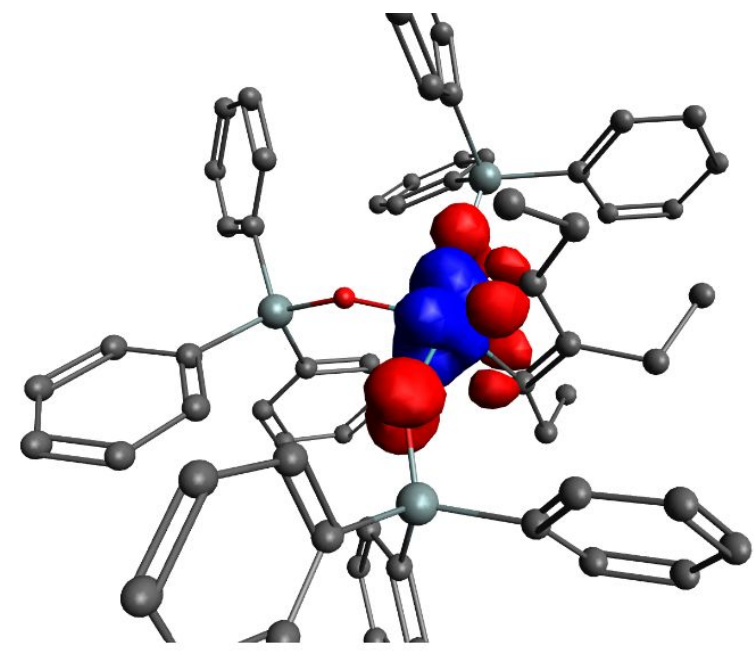

transition 4

Figure S24: Difference densites of the calculated transitions 1 and 4 at $17482 \mathrm{~cm}^{-1}$ and $31214 \mathrm{~cm}^{-1}$ respectively, of the 1MCBD. Blue corresponds to a gain in electron density while red represents a loss. Isosurface at 0.003 .

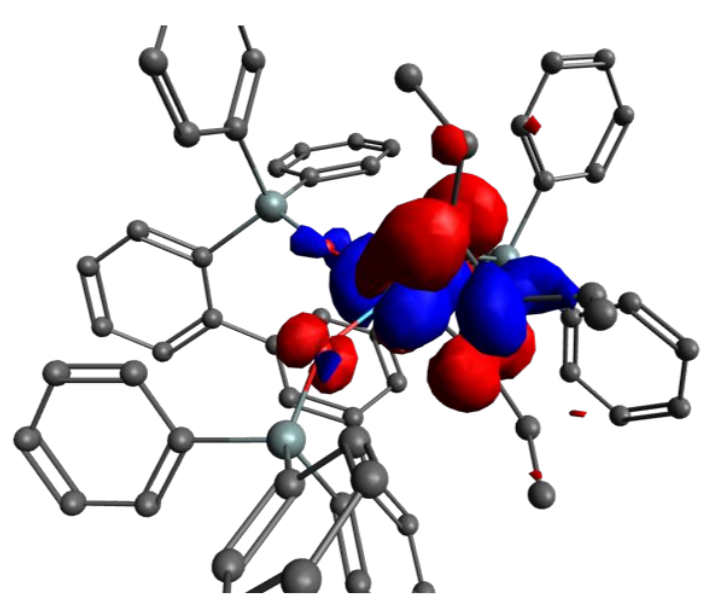

transition 1

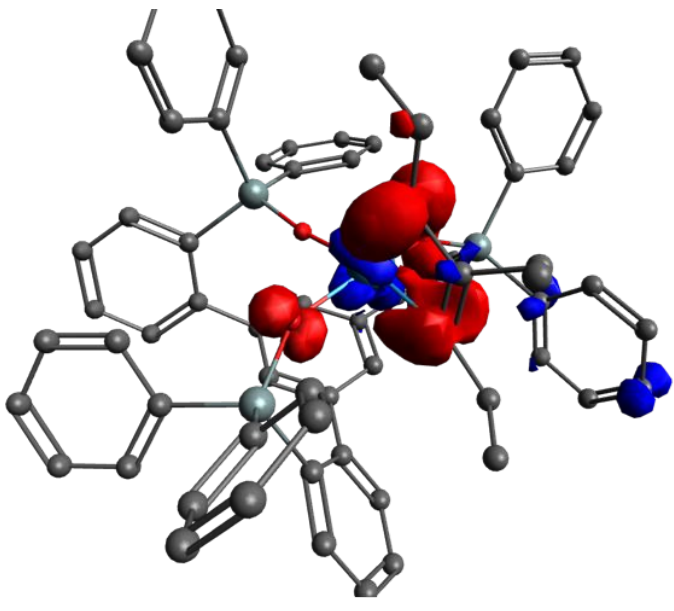

transition 3

Figure S25: Difference densites of the calculated transitions 1 and 3 at $19259 \mathrm{~cm}^{-1}$ and $30362 \mathrm{~cm}^{-1}$ respectively, of the 4MCBD. Blue corresponds to a gain in electron density while red represents a loss. Isosurface at 0.003 . 


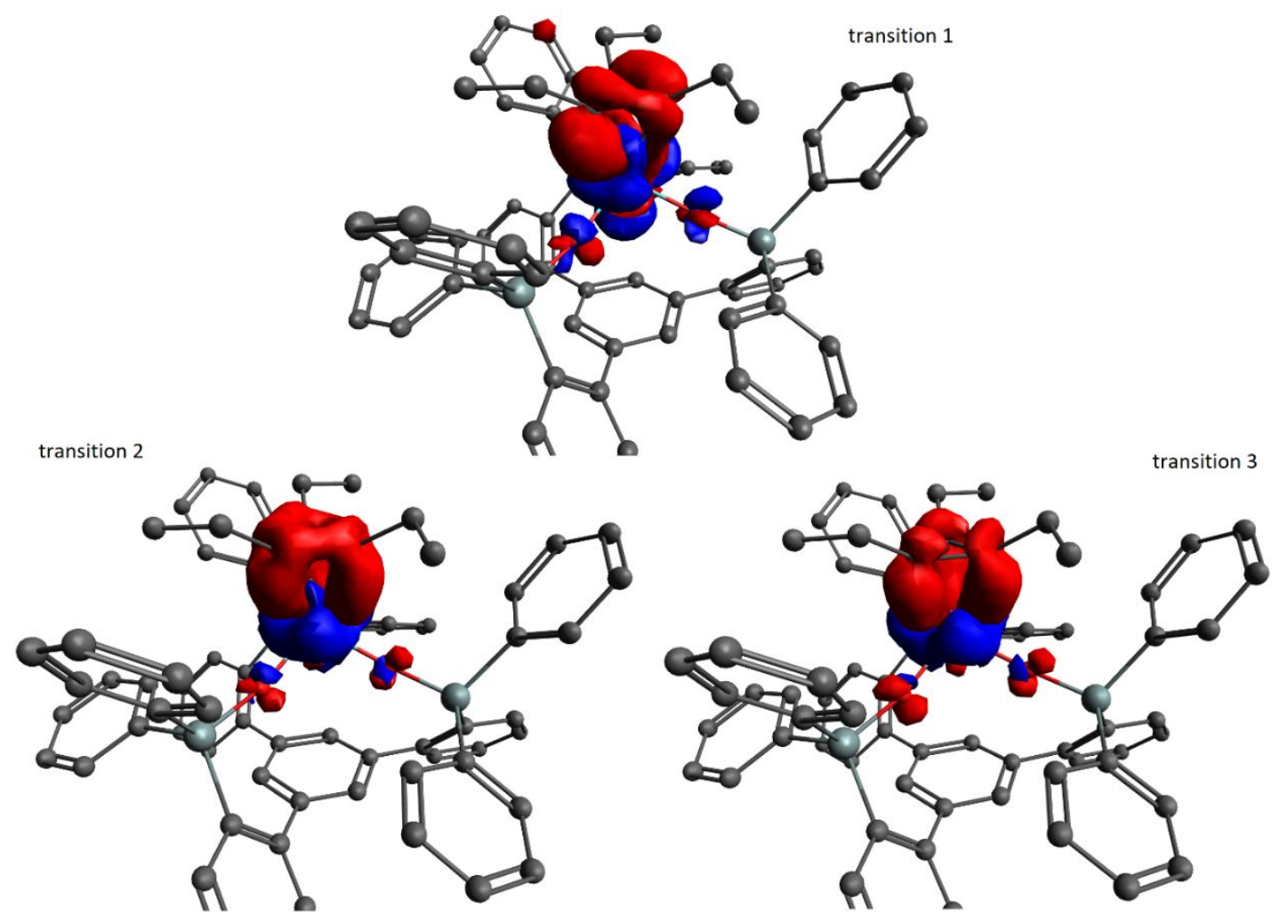

Figure S26: Difference densties of the calculated transitions 1-3 at $19650 \mathrm{~cm}^{-1}, 22660 \mathrm{~cm}^{-1}$ and $25918 \mathrm{~cm}^{-1}$, respectively, of the 2-MTd complex. Blue corresponds to a gain in electron density while red represents a loss. Isosurface at 0.003 . 


\section{NMR comparison}

For further comparison of the electronic structure from experiment and calculation, ${ }^{1} \mathrm{H}$ - and ${ }^{13} \mathrm{C}-\mathrm{NMR}$ spectra were measured (see EXPERIMENTAL NMR-SPECTRA below) and computed. For the calculations, again the B3LYP-D3BJ functional (and dispersion correction) were used. We increased the basis set to def2-TZVPP and also increased the grid size for the RIJCOSX approximation. To transform the calculated NMR shieldings into chemical shifts, an external or internal reference is needed. We chose to always use an internal reference, mostly an alkyl group with small chemical shifts. Since the ${ }^{13} \mathrm{C}-\mathrm{NMR}$ spectra are of more interest with respect to the electronic structure of the core complexes, we will restrict our discussion on these data.
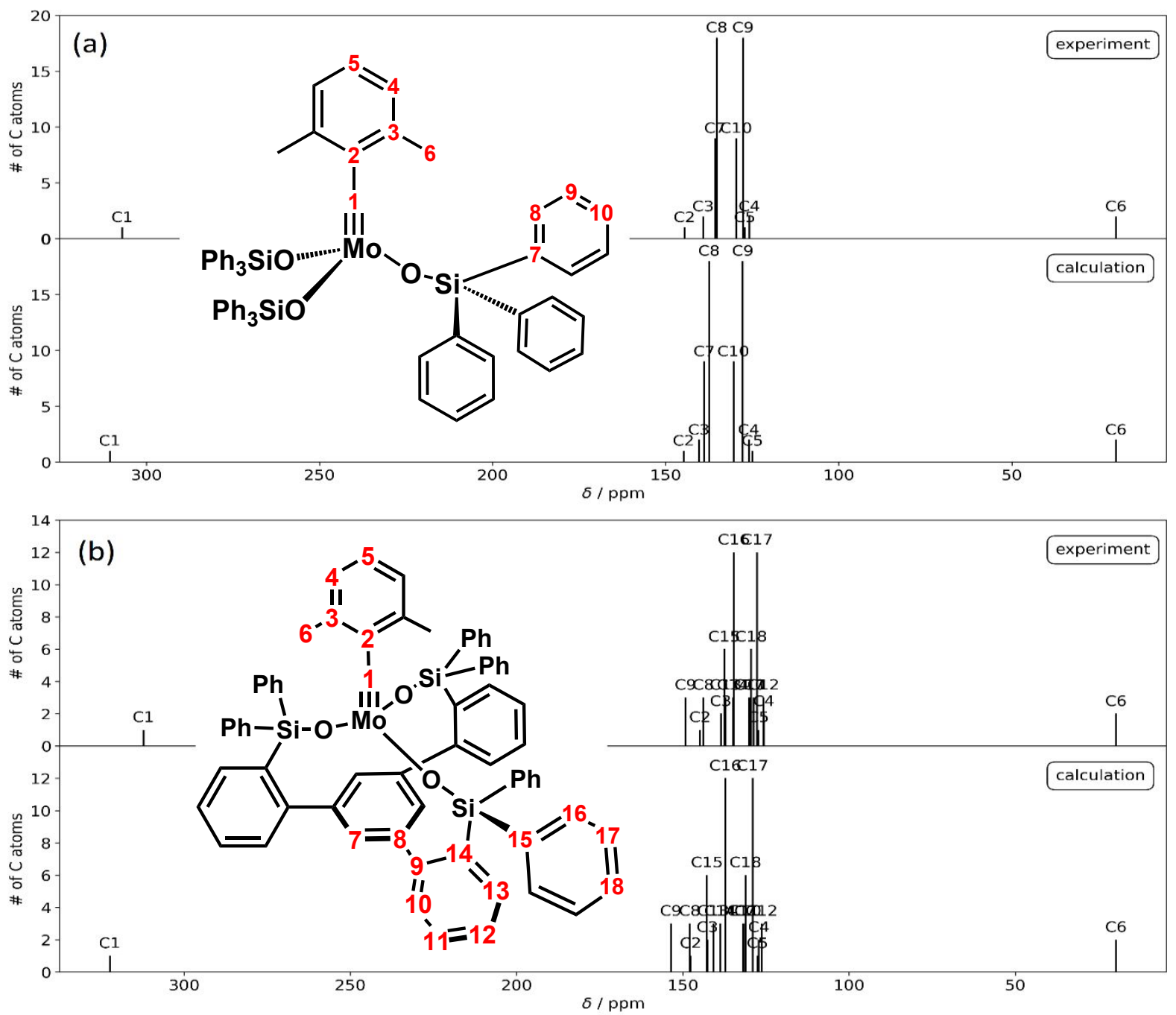

Figure S27: Experimental and calculated ${ }^{13} \mathrm{C}$ shifts (no fine structure) of (a) the 1-CAr and (b) the 2-CAr complex. For both calculations $C 6$ was used as internal reference. 

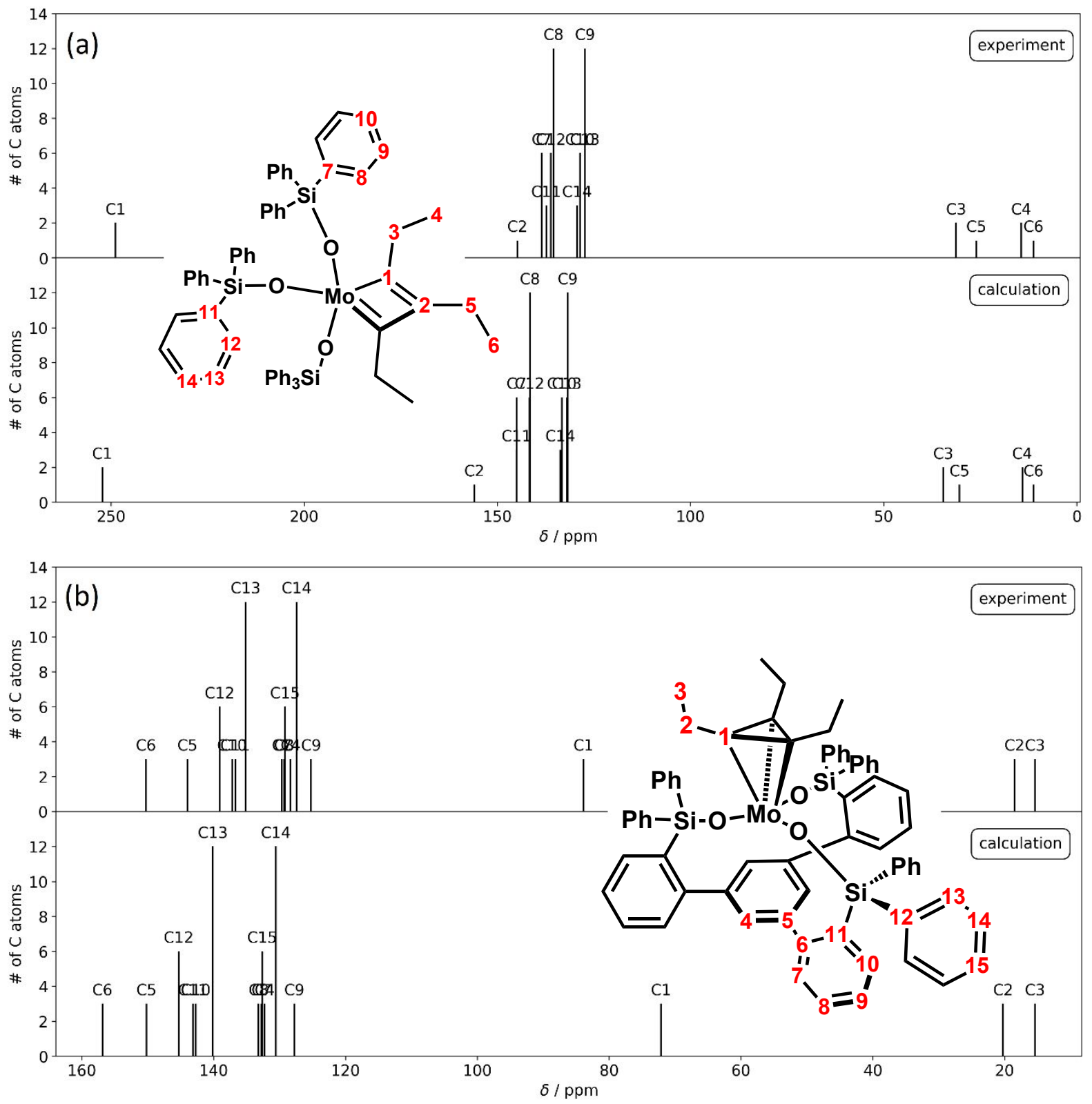

Figure S28: Experimental and calculated ${ }^{13} \mathrm{C}$ shifts (no fine structure) of (a) the 1-MCBD complex and (b) the 2-MTd complex. For the calculations $C 6$ and $C 3$, respectively, were used as internal reference. 


\section{Kinetic Modeling}

\section{Nudged-Elastic-Band calculations}

The NEB method yields a number of structures (images), that connect two minima via a smooth transition. We normally choose 16 images. These form the minimum energy path (MEP). We always performed climbing image NEB (NEB-Cl) calculation in which the highest energy image (HEI) is pushed uphill along the path tangent. This way, a very good approximation to the actual transition state (TS), which lies on the MEP, is obtained, especially since we used rather tight convergence criteria for the Cls. Hessians calculated at the Cls always revealed the TS mode with the largest imaginary frequency and only few low-lying imaginary frequencies were obtained alongside. The Cls together with their Hessians were used for a subsequent TS search. Unfortunately, especially for the association reactions, these TS optimizations often failed due to the complex structure of the PES caused by many internal rotations and soft vibrations of the complexes. We thus often had to use the $\mathrm{Cl}$ and its Hessian as an approximation to the TSs. We are confident that this only introduces small errors since the energy differences between Cls and TSs (in those cases, where they were found) were below $5 \mathrm{~kJ} / \mathrm{mol}$.

\section{Rate constant estimation using Eyring}

Using the Eyring theory, the rate constant $k$ of a unimolecular reaction can be estimated from the difference of the Gibbs free energy of the reactant and the corresponding transition state, $\Delta G^{\ddagger}$, by:

$$
k(T)=\kappa \frac{k_{B} T}{h} \exp \left(-\frac{\Delta G^{\ddagger}}{R T}\right)
$$

where $\kappa$ is the transition coefficient (we assume 0.5), $k_{B}$ is the Boltzmann constant, $h$ is Planck's constant, $T$ is the absolute temperature and $R$ is the ideal gas constant (since $\Delta G^{\ddagger}$ is applied as molar quantity).

If the equilibrium constant $K$ between two stable minima is needed, the forward and backward reaction rates, $k_{f}$ and $k_{b}$, respectively, can be used:

$$
K=\frac{k_{f}}{k_{b}}=\exp \left(-\frac{\Delta G}{R T}\right)
$$

where $\Delta G$ is the difference of Gibbs free energy of the two minima. Here we assumed $\kappa_{f}=\kappa_{b}$, thus cancelling the whole pre-exponential factor in the ratio of the rate constants. 


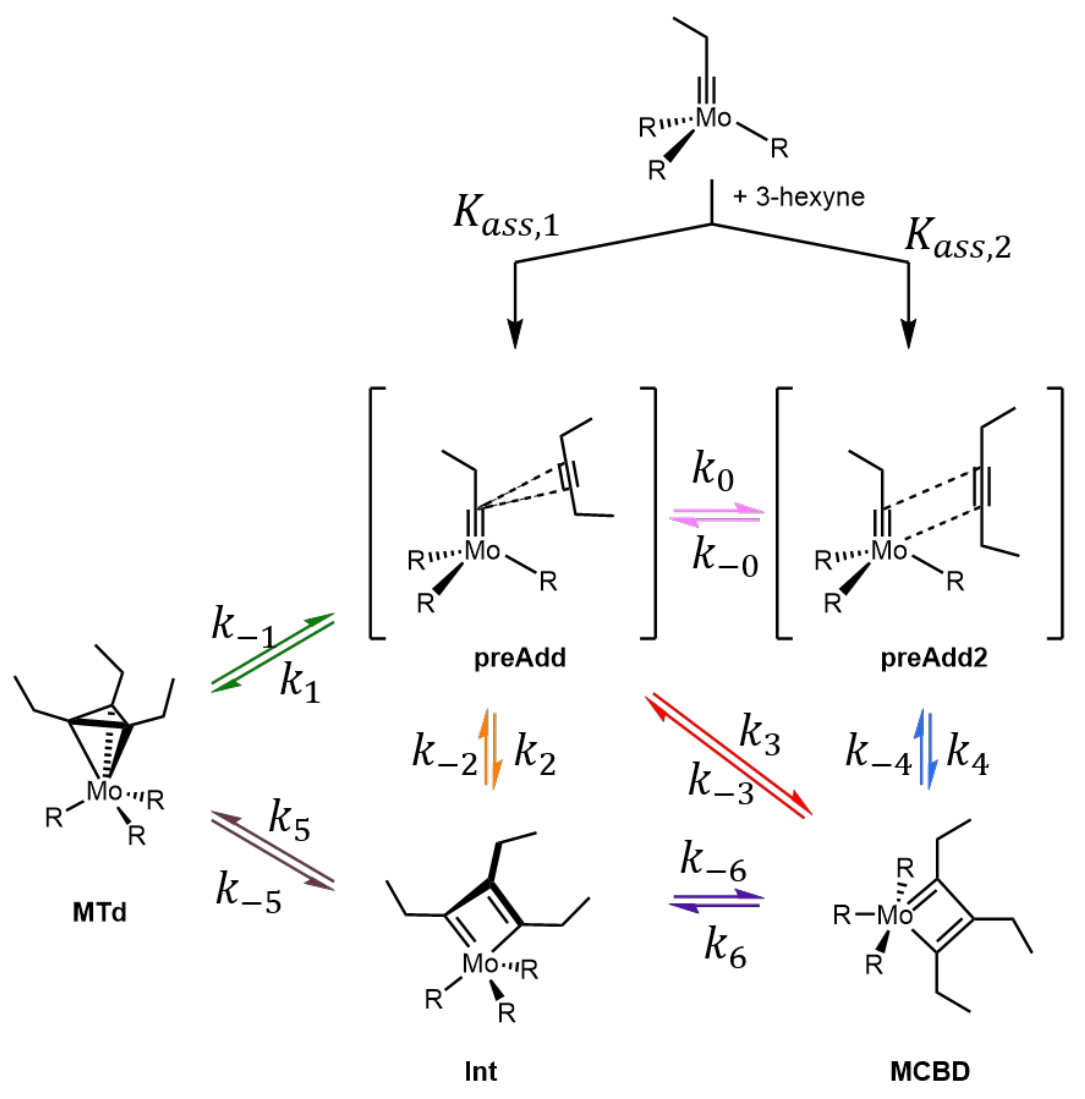

Figure S29: Full Reaction System with all rate constants.

\section{Temporal evolution}

To model the temporal evolution of our reaction system, we made a few simplifications. I.e., we never explicitly considered the population of the pre-adduct complexes but only modeled the dissociated state ("diss") and the three stable intermediates.

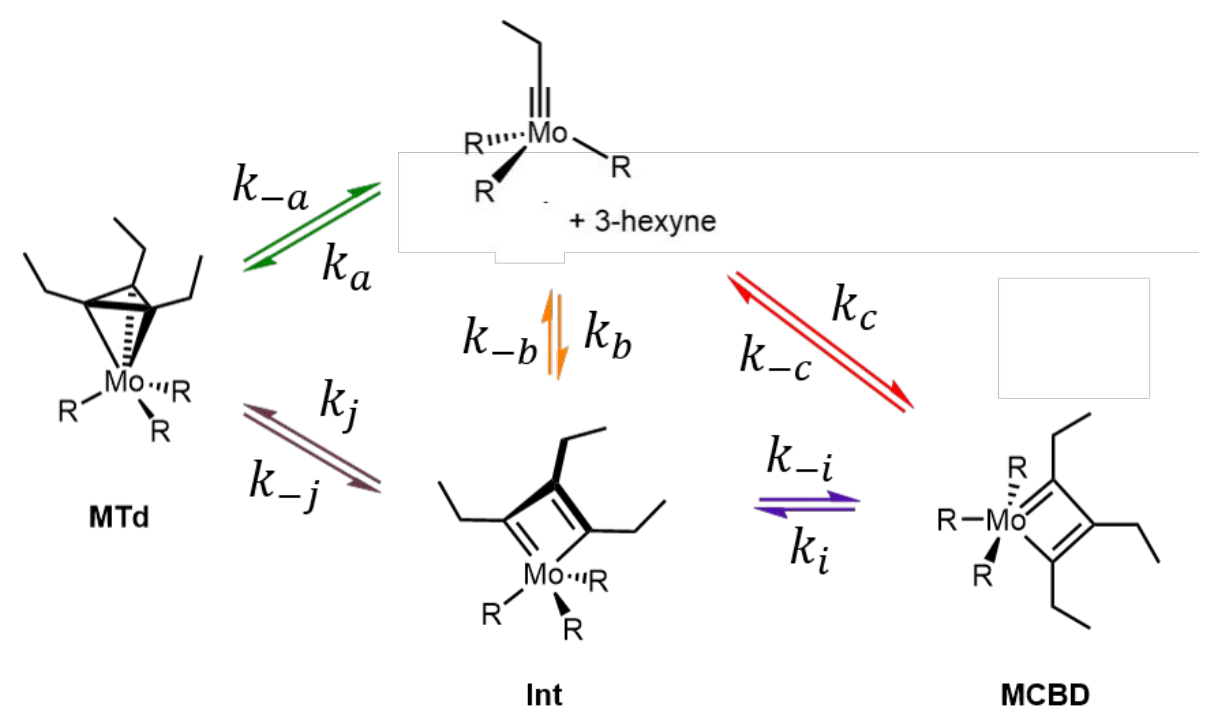

Figure S30: Simplified Reaction System with rate constants. 
Thus, the system at a point in time $t$ can be described by a vector of concentrations

$$
\boldsymbol{x}(t)=\left(\begin{array}{c}
{[\text { diss }]} \\
{[M T d]} \\
{[\text { Int }]} \\
{[M C B D]}
\end{array}\right)
$$

Formulating all rate equations for this system is fairly easy and can also be written in matrix form:

$$
\dot{\boldsymbol{x}}(t)=\boldsymbol{k} \cdot \boldsymbol{x}(t)=\left(\begin{array}{cccc}
-\left(k_{a}+k_{b}+k_{c}\right) & k_{-a} & k_{-b} & k_{-c} \\
k_{a} & -\left(k_{-a}+k_{-j}\right) & k_{j} & 0 \\
k_{b} & k_{-j} & -\left(k_{j}+k_{-b}+k_{-i}\right) & k_{i} \\
k_{c} & 0 & k_{-i} & -\left(k_{-c}+k_{i}\right)
\end{array}\right) \cdot \boldsymbol{x}(t)
$$

where $\dot{\boldsymbol{x}}(t)$ is the temporal derivative of the state vector and we call $\boldsymbol{k}$ the rate matrix.

To obtain the rate constants for the simplified system from those of the full system, we made the assumption that the equilibration between the dissociated state and the pre-adduct complexes is always fast. Thus, the formation of e.g., MTd from diss can be described by [alkyne] $\times K_{a s s, 1} \times k_{1}$. We used slightly different models for $\mathbf{2}$ and $\mathbf{3}$ with respect to preAdd2. For $\mathbf{2}$, we assumed that $k_{0} \gg k_{4}$. For $\mathbf{3}$, we treated both pre-adduct complexes the same. We thus used the following two reaction systems

\begin{tabular}{|l|l|c|c|c|}
\hline Reactant & Product & $\begin{array}{c}\text { Name of rate } \\
\text { constant }\end{array}$ & Composition in 2 & Composition in 3 \\
\hline Diss & MTd & $k_{a}$ & \multicolumn{2}{|c|}{$k_{1} \cdot K_{a s s, 1} \cdot[$ alkyne $]$} \\
\hline MTd & Diss & $k_{-a}$ & \multicolumn{2}{|c|}{$k_{-1}$} \\
\hline Diss & Int & $k_{b}$ & \multicolumn{2}{|c|}{$k_{2} \cdot K_{a s s, 1} \cdot[$ alkyne $]$} \\
\hline Int & Diss & $k_{-b}$ & \multicolumn{2}{|c|}{$k_{-2}$} \\
\hline Diss & MCBD & $k_{c}$ & $\left(k_{3}+k_{0}\right) \cdot K_{\text {ass }, 1} \cdot[$ alkyne $]$ & $\left(k_{3} \cdot K_{\text {ass }, 1}+k_{4} \cdot K_{\text {ass }, 2}\right) \cdot[$ alky \\
\hline MCBD & Diss & $k_{-c}$ & $k_{-3}+k_{0} k_{4} / k_{-4}$ & $k_{-3}+k_{-4}$ \\
\hline MCBD & Int & $k_{i}$ & \multicolumn{2}{|c|}{$k_{6}$} \\
\hline Int & MCBD & $k_{-i}$ & \multicolumn{2}{|c|}{$k_{-6}$} \\
\hline Int & MTd & $k_{j}$ & \multicolumn{2}{|c|}{$k_{-5}$} \\
\hline MTd & Int & $k_{-j}$ & \multicolumn{2}{|c|}{} \\
\hline
\end{tabular}

For numerical integration over time, we used state-transition theory and calculated the statetransition matrix $\phi(\Delta t)$ using matrix exponentials. 


$$
\boldsymbol{\phi}(\Delta t)=\exp (\Delta t \cdot \boldsymbol{k})
$$

$\Delta t$ has to be chosen small enough that the Taylor expansion of the matrix exponential still converges. We took $\Delta t$ as $10 \%$ of the fastest rate in $\boldsymbol{k}$. With that, we can integrate using either of the two equations:

$$
\begin{gathered}
x(t+\Delta t)=\boldsymbol{\phi}(\Delta t) \cdot \boldsymbol{x}(t) \\
\boldsymbol{x}(t+n \cdot \Delta t)=[\boldsymbol{\phi}(\Delta t)]^{n} \cdot \boldsymbol{x}(t)
\end{gathered}
$$

The latter equation allows us to take timesteps $n \cdot \Delta t$, which would normally be too large for the matrix exponential. I.e., numerically $[\phi(\Delta t)]^{n} \neq \boldsymbol{\phi}(n \cdot \Delta t)$, which normally should be the case.

For reference, we report the used state-transition matrices:

Table S11: State-transition matrices of the two reaction systems (2-CEt + 3-hexyne and 3-CEt + 3-hexyne). The entry $\phi_{i j}$ can be read as the portion of $j$ that flows into $i$ within the given time step through all channels.

\begin{tabular}{c|cccc|cccc}
\hline to\from & 2-CEt & 2-MTd & 2-Int & 2-MCBD & 3-CEt & 3-MTd & 3-Int & 3-MCBD \\
\hline X-CEt & $1.00 \mathrm{E}+00$ & $4.11 \mathrm{E}-19$ & $9.31 \mathrm{E}-10$ & $2.95 \mathrm{E}-06$ & $9.99 \mathrm{E}-01$ & $2.47 \mathrm{E}-18$ & $5.12 \mathrm{E}-06$ & $3.26 \mathrm{E}-05$ \\
X-MTd & $6.70 \mathrm{E}-13$ & $1.00 \mathrm{E}+00$ & $1.00 \mathrm{E}+00$ & $1.44 \mathrm{E}-06$ & $3.43 \mathrm{E}-19$ & $1.00 \mathrm{E}+00$ & $4.87 \mathrm{E}-06$ & $9.60 \mathrm{E}-16$ \\
X-Int & $1.24 \mathrm{E}-15$ & $8.16 \mathrm{E}-13$ & $1.24 \mathrm{E}-12$ & $1.33 \mathrm{E}-09$ & $1.28 \mathrm{E}-13$ & $8.77 \mathrm{E}-13$ & $7.04 \mathrm{E}-01$ & $3.14 \mathrm{E}-10$ \\
X-MCBD & $9.31 \mathrm{E}-07$ & $2.79 \mathrm{E}-13$ & $3.16 \mathrm{E}-04$ & $1.00 \mathrm{E}+00$ & $7.68 \mathrm{E}-04$ & $1.63 \mathrm{E}-13$ & $2.96 \mathrm{E}-01$ & $1.00 \mathrm{E}+00$ \\
\hline
\end{tabular}

Time steps are: $n \cdot \Delta t(2)=10^{-7} \mathrm{~s}$ and $n \cdot \Delta t(2)=10^{-13} \mathrm{~S}$ 


\section{EXPERIMENTAL NMR-SPECTRA}

${ }^{1} \mathrm{H}$ NMR of Complex S1, $400 \mathrm{MHz}, \mathrm{C}_{6} \mathrm{D}_{6}, 25^{\circ} \mathrm{C}$

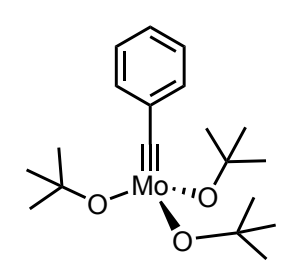




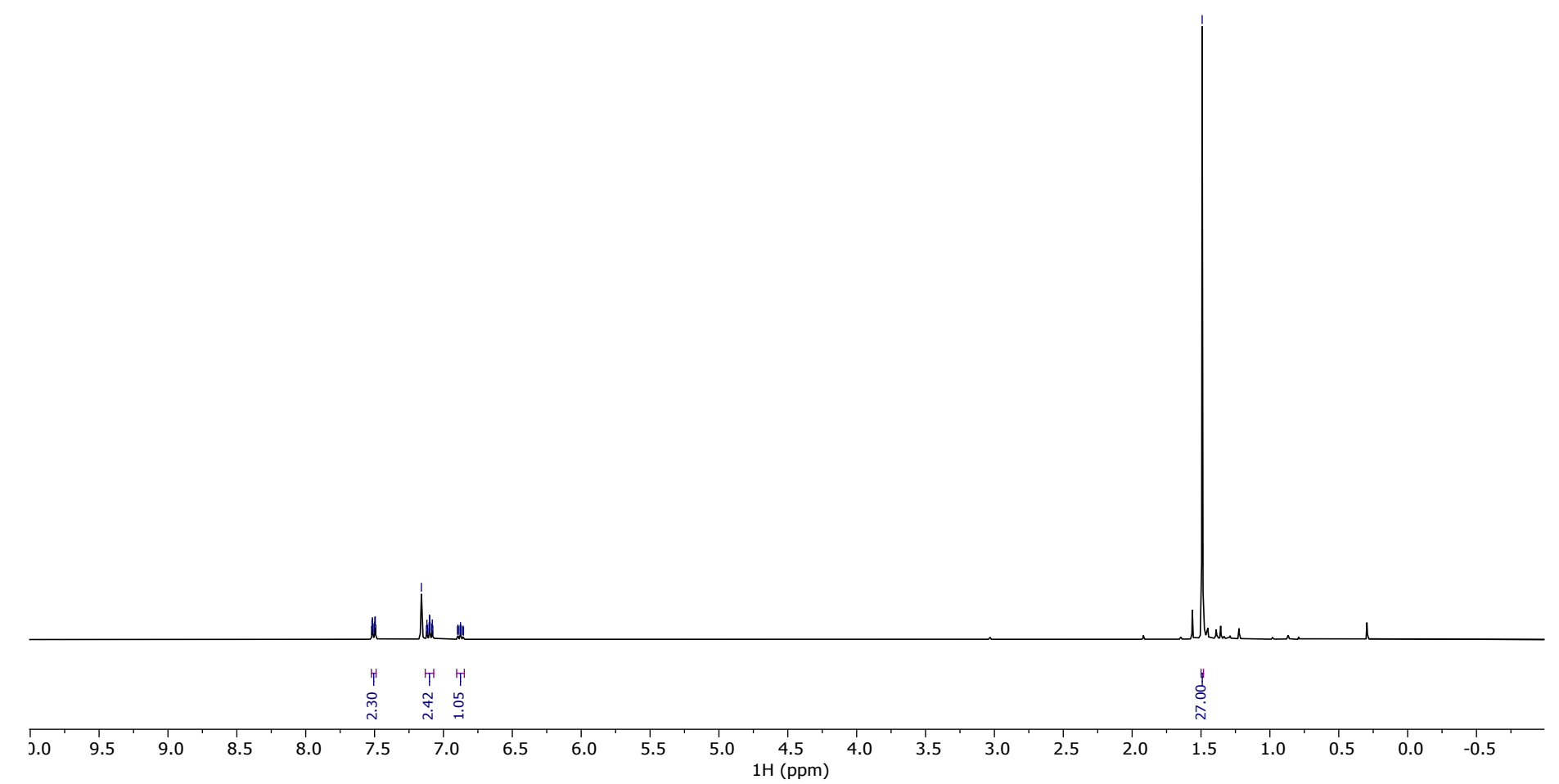

${ }^{13} \mathrm{C}$ NMR of Complex S1, $101 \mathrm{MHz}, \mathrm{C}_{6} \mathrm{D}_{6}, 25^{\circ} \mathrm{C}$

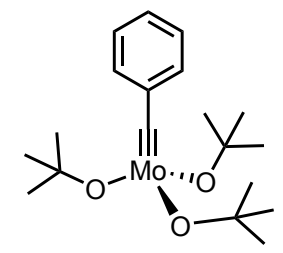




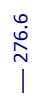
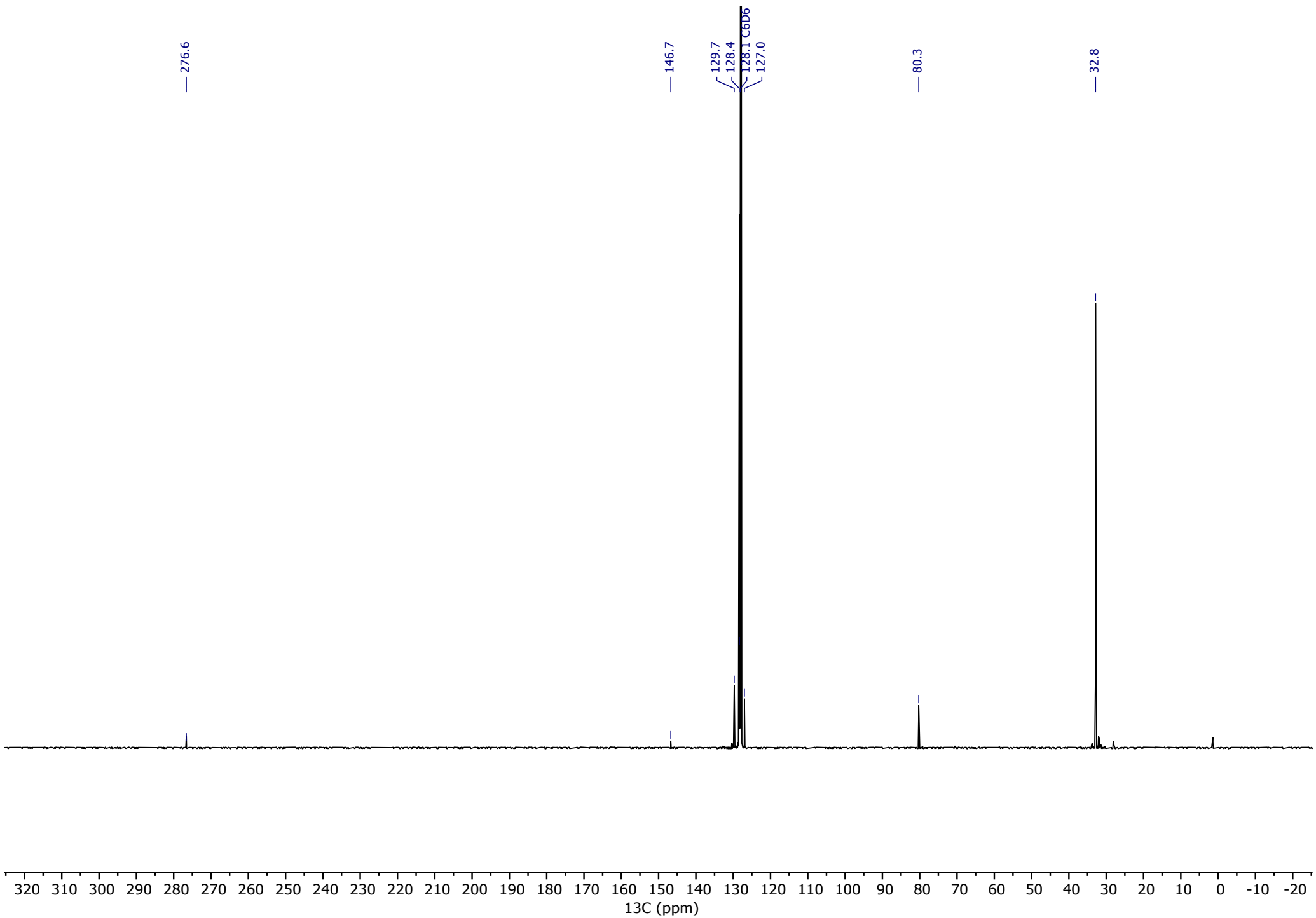

${ }^{95} \mathrm{Mo}$ NMR of Complex S1, $26 \mathrm{MHz}, \mathrm{C}_{6} \mathrm{D}_{5} \mathrm{CD}_{3}, 60^{\circ} \mathrm{C}$

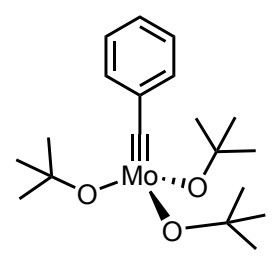



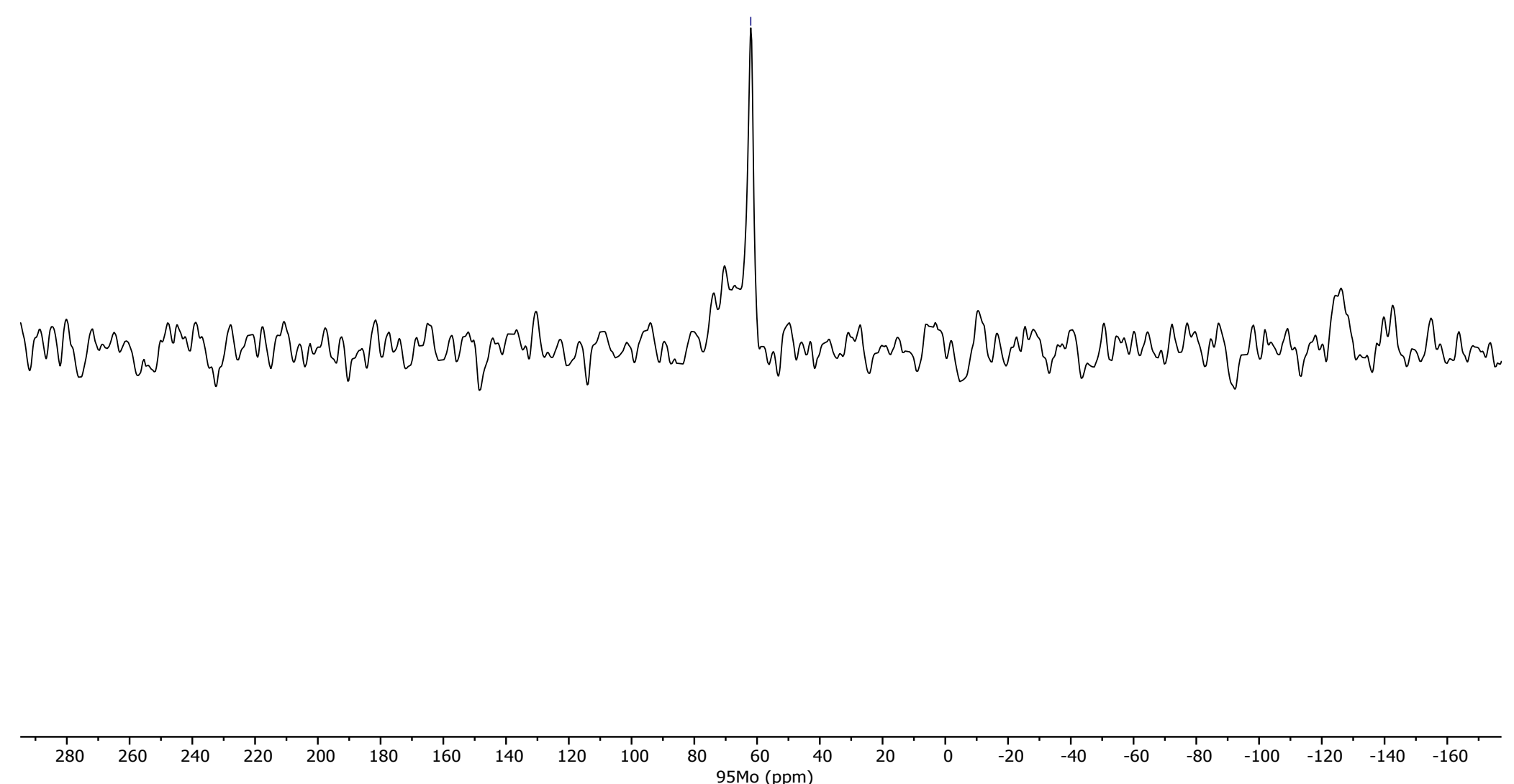

${ }^{1} \mathrm{H}$ NMR of Conversion of Complex $[\mathrm{S} 3]_{2}$ to $\mathrm{S} 3, \mathrm{C}_{6} \mathrm{D}_{5} \mathrm{CD}_{3}, 1 \mathrm{~h}$ at $60{ }^{\circ} \mathrm{C}$ 


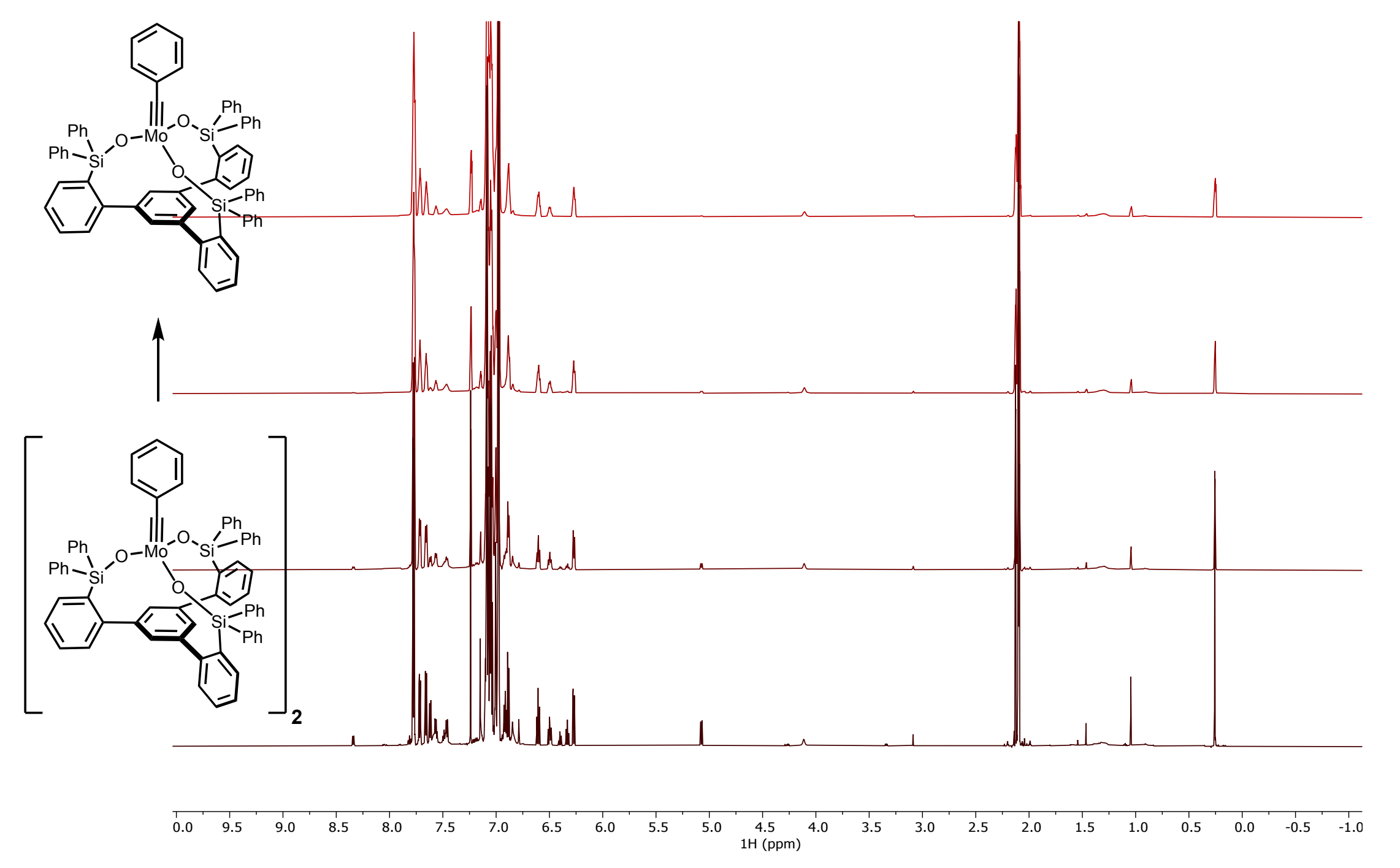


${ }^{1} \mathrm{H}$ NMR of Complex S3, $600 \mathrm{MHz}, \mathrm{C}_{6} \mathrm{D}_{5} \mathrm{CD}_{3}, 25^{\circ} \mathrm{C}$

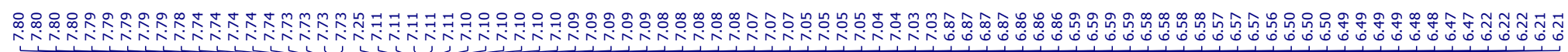

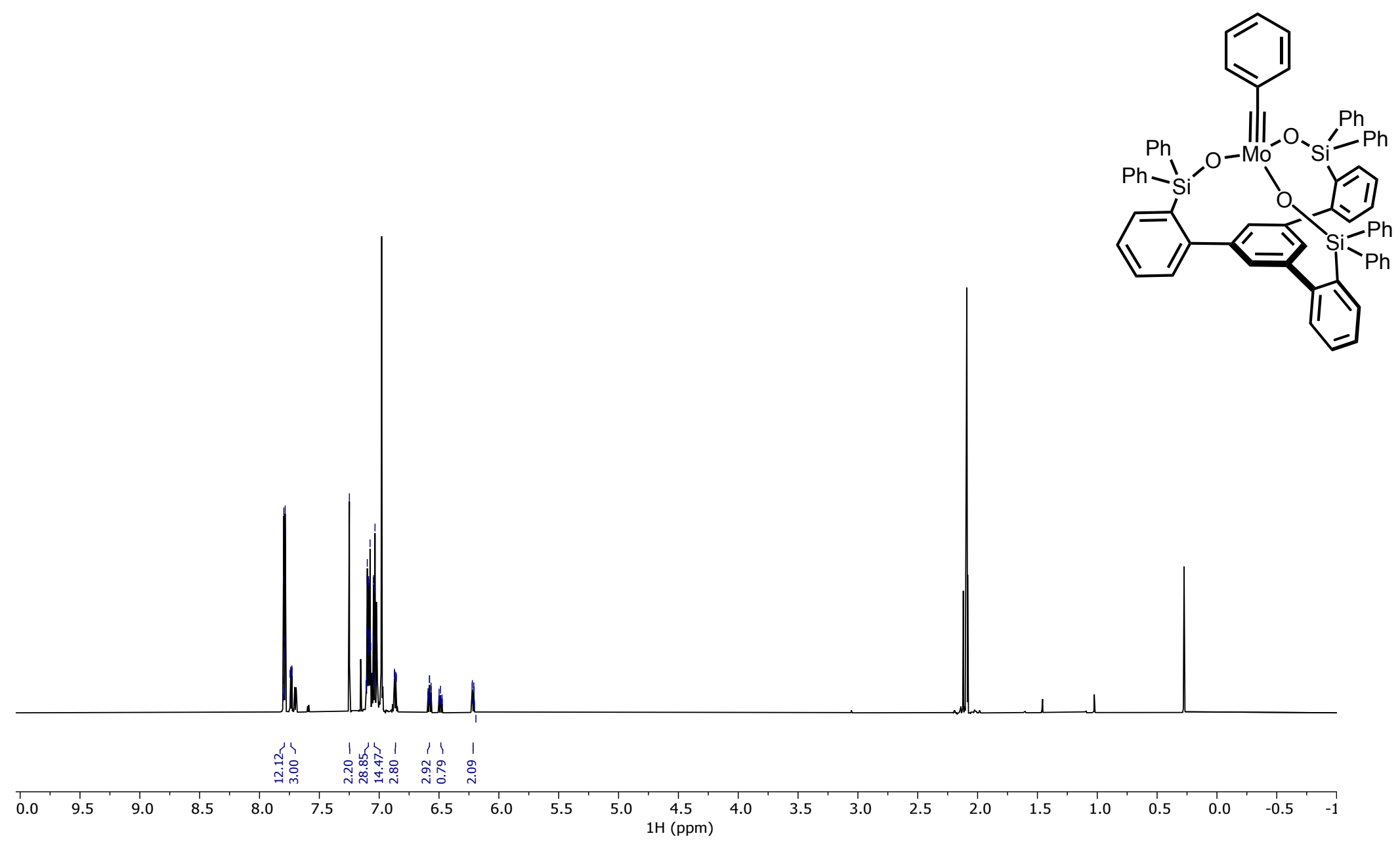


${ }^{13} \mathrm{C}$ NMR of Complex S3, $151 \mathrm{MHz}, \mathrm{C}_{6} \mathrm{D}_{5} \mathrm{CD}_{3}, 25^{\circ} \mathrm{C}$ 


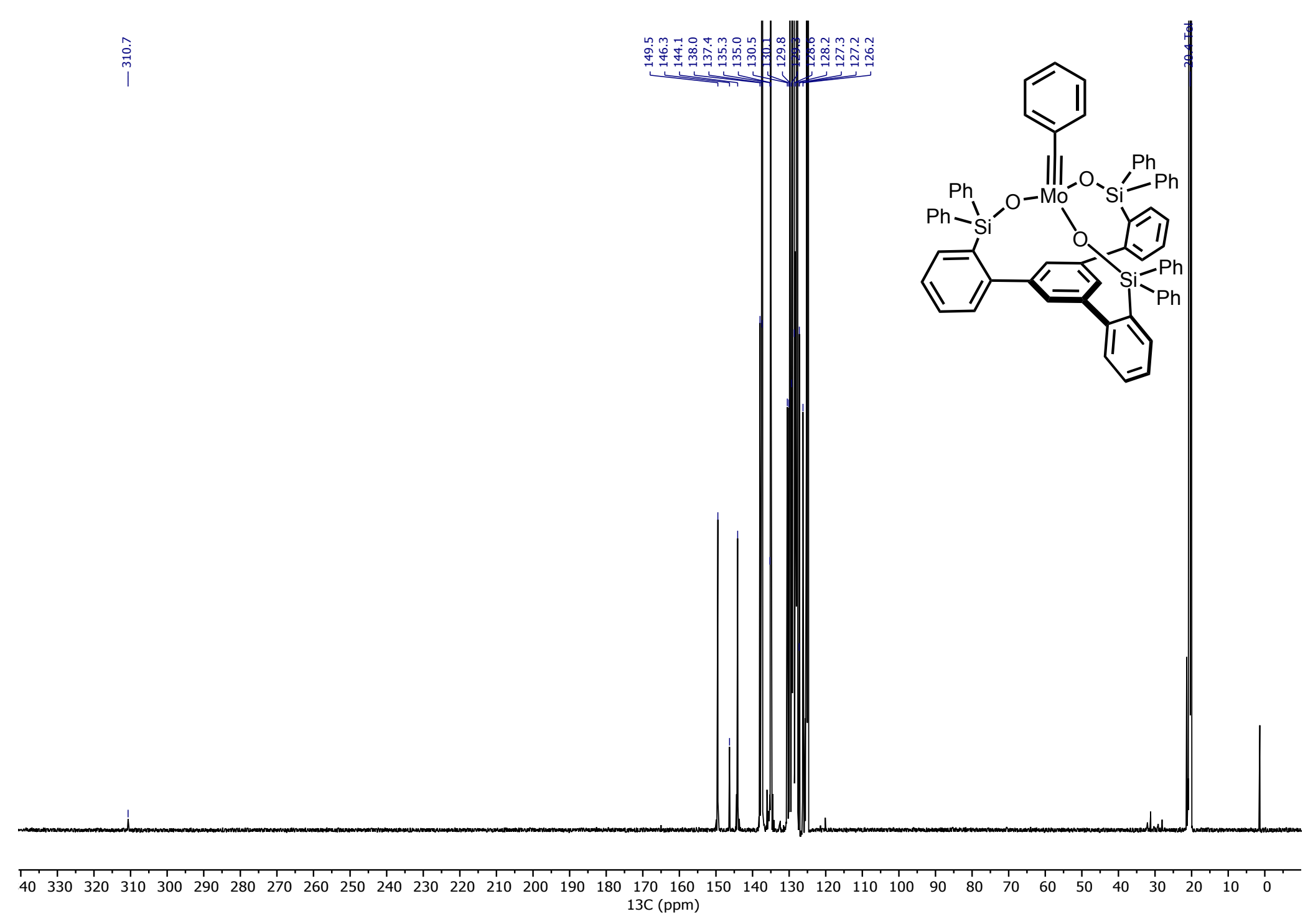


${ }^{29} \mathrm{Si}$ NMR of Complex S3, $119 \mathrm{MHz}, \mathrm{C}_{6} \mathrm{D}_{5} \mathrm{CD}_{3}, 25^{\circ} \mathrm{C}$ 

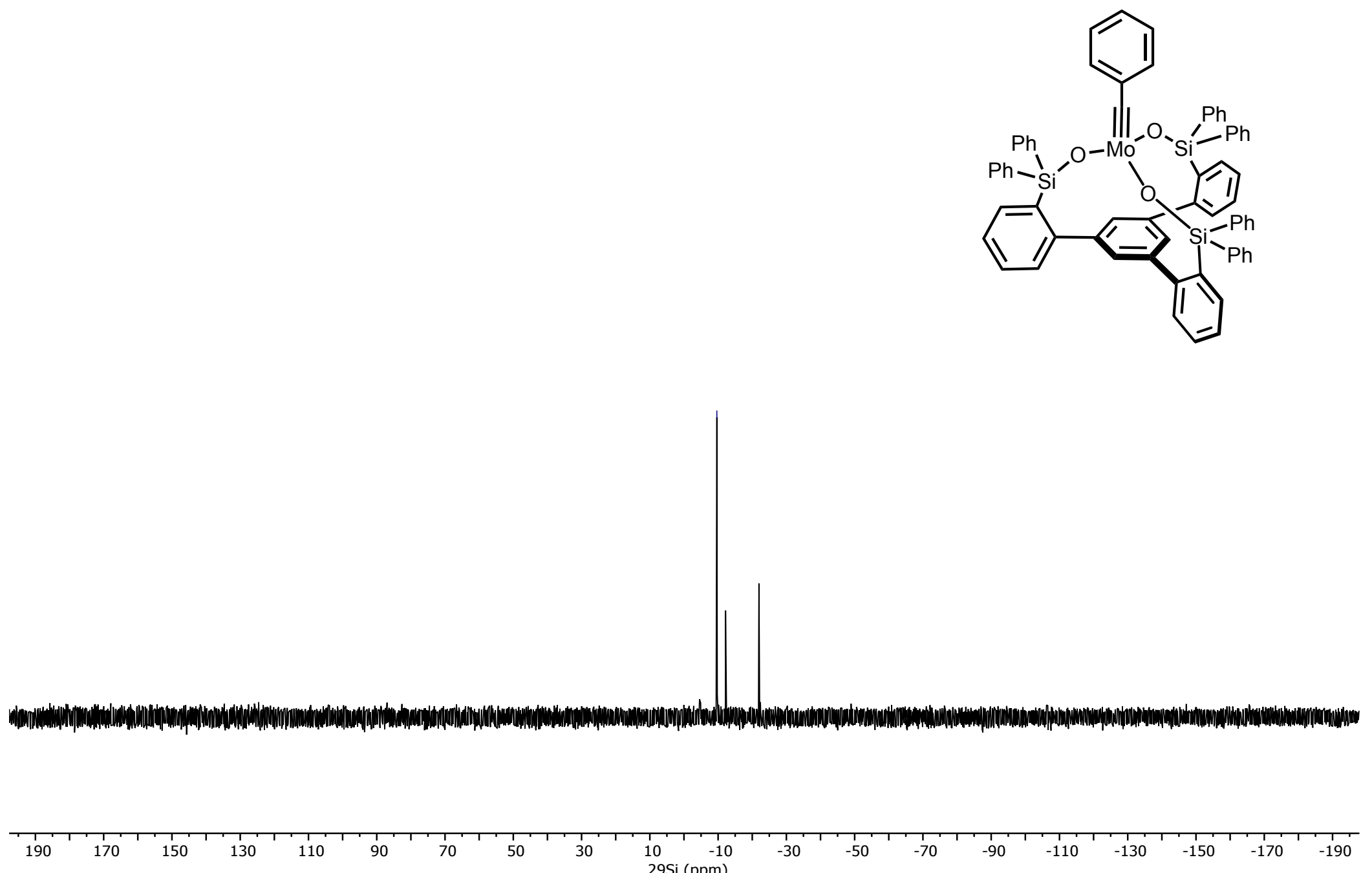
${ }^{95} \mathrm{Mo}$ NMR of Complex S3, $26 \mathrm{MHz}, \mathrm{C}_{6} \mathrm{D}_{5} \mathrm{CD}_{3}, 60^{\circ} \mathrm{C}$ 

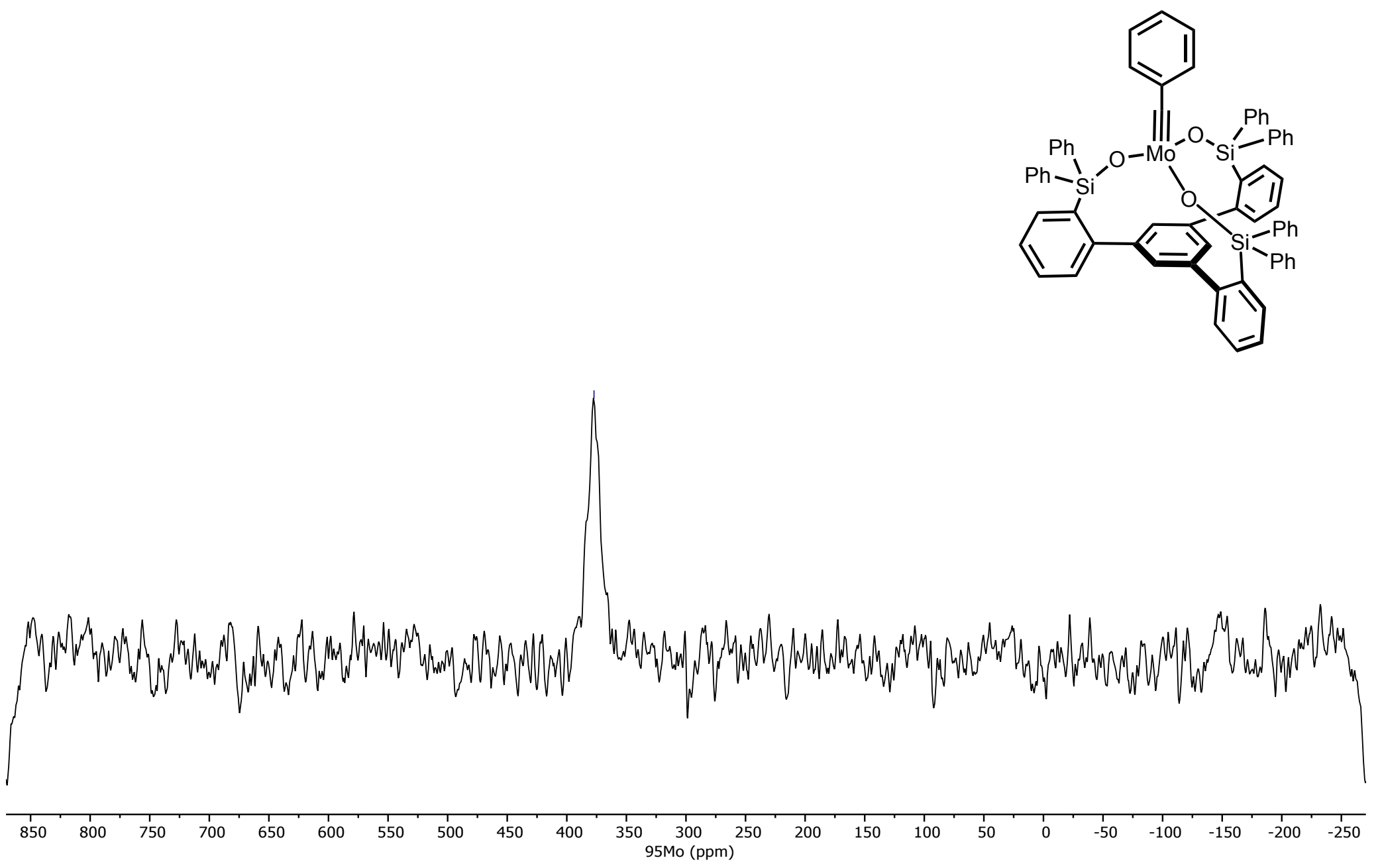

NMR characterization of 2-MTd 
The sample is a complex mixture, but the following four different species could be fully characterized. Please see the next pages for the characterization data of metallatetrahedrane 2-MTd.
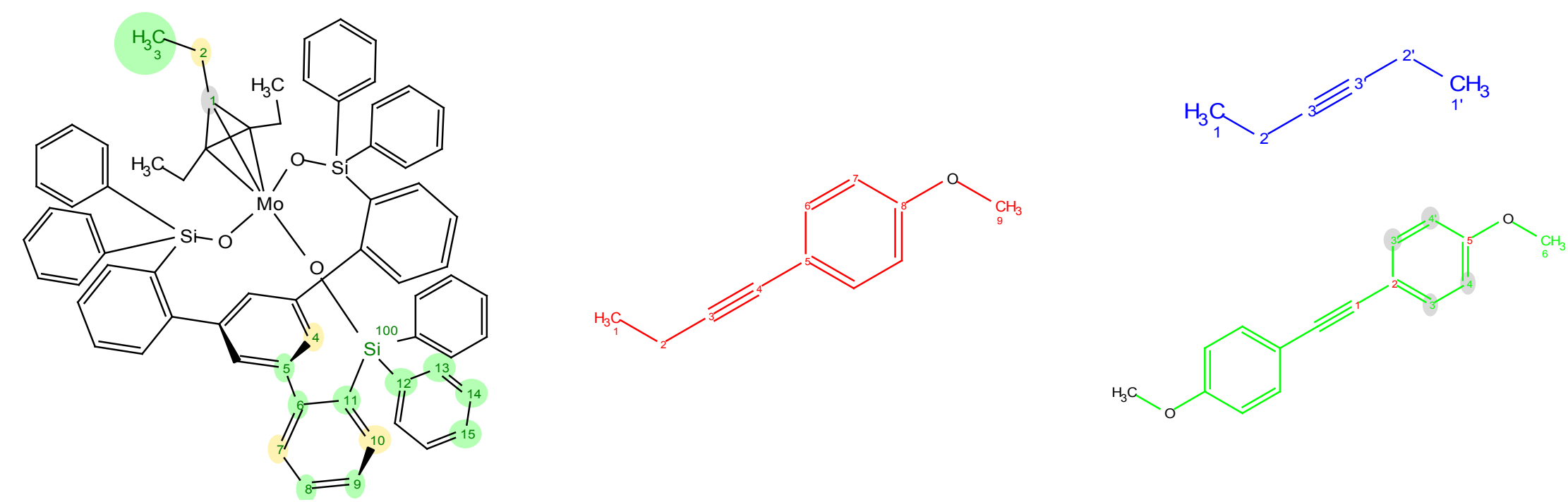

${ }^{1} \mathrm{H}$ NMR Studies of Complex 2-MTd, $600 \mathrm{MHz}, \mathrm{C}_{6} \mathrm{D}_{5} \mathrm{CD}_{3}, 25^{\circ} \mathrm{C}$ 


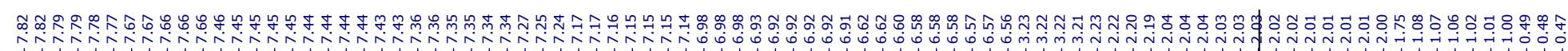

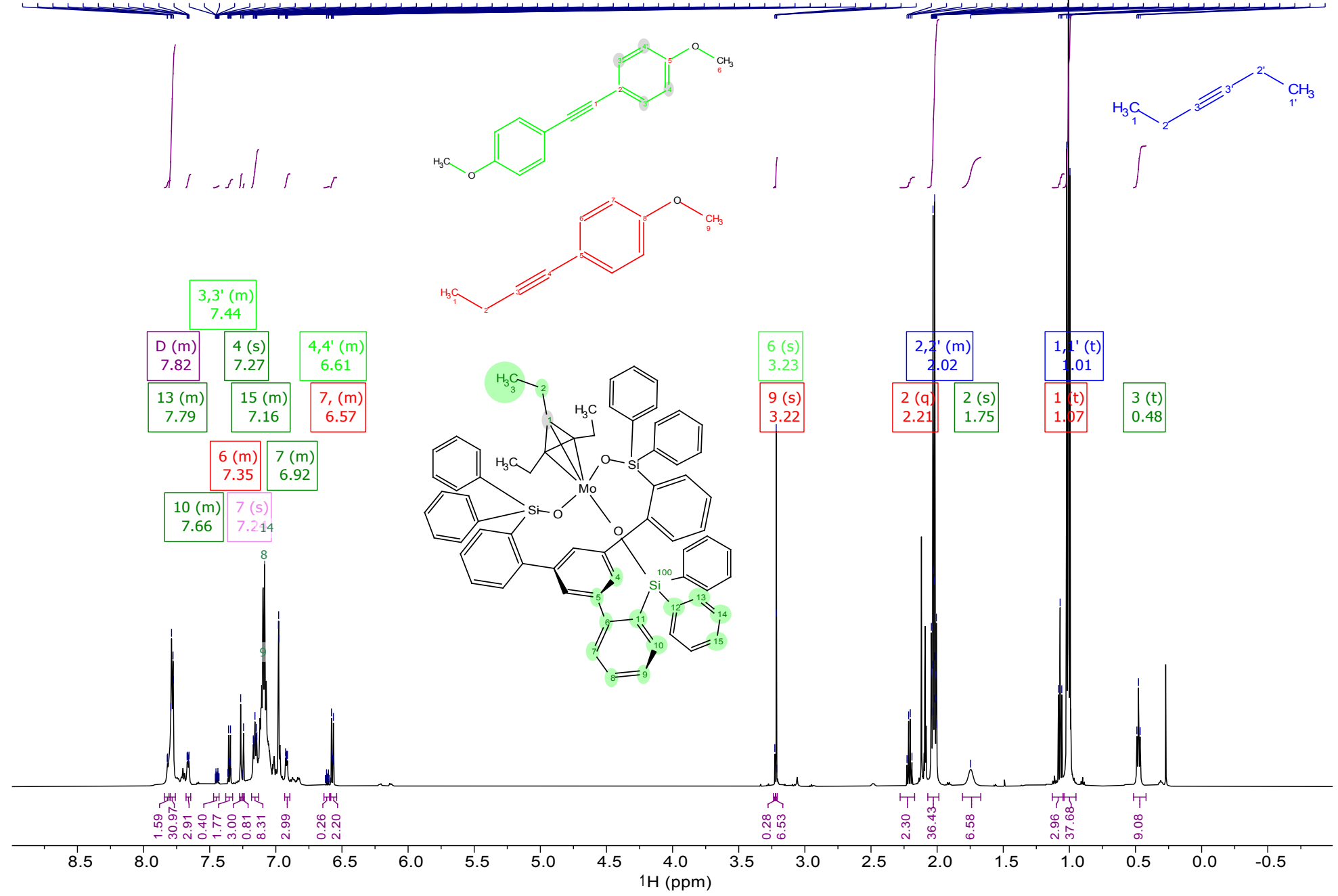

${ }^{13} \mathrm{C}$ NMR Studies of Complex 2-MTd, $151 \mathrm{MHz}, \mathrm{C}_{6} \mathrm{D}_{5} \mathrm{CD}_{3}, 25^{\circ} \mathrm{C}$ 


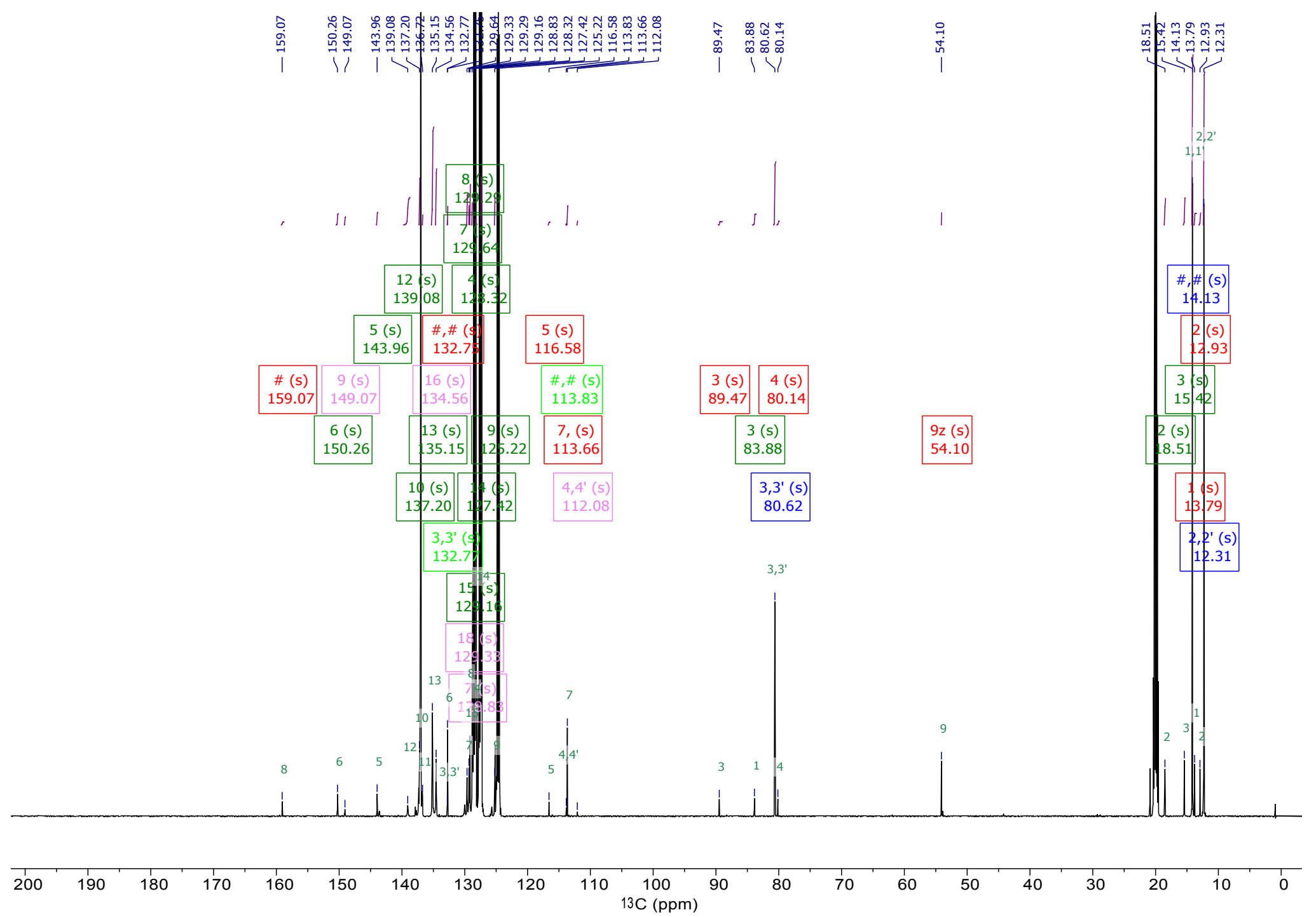

${ }^{29} \mathrm{Si}$ NMR Studies of Complex 2-MTd, $119 \mathrm{MHz}, \mathrm{C}_{6} \mathrm{D}_{5} \mathrm{CD}_{3}, 25{ }^{\circ} \mathrm{C}$ 
$29 \mathrm{Si},-1 \mathrm{D}$
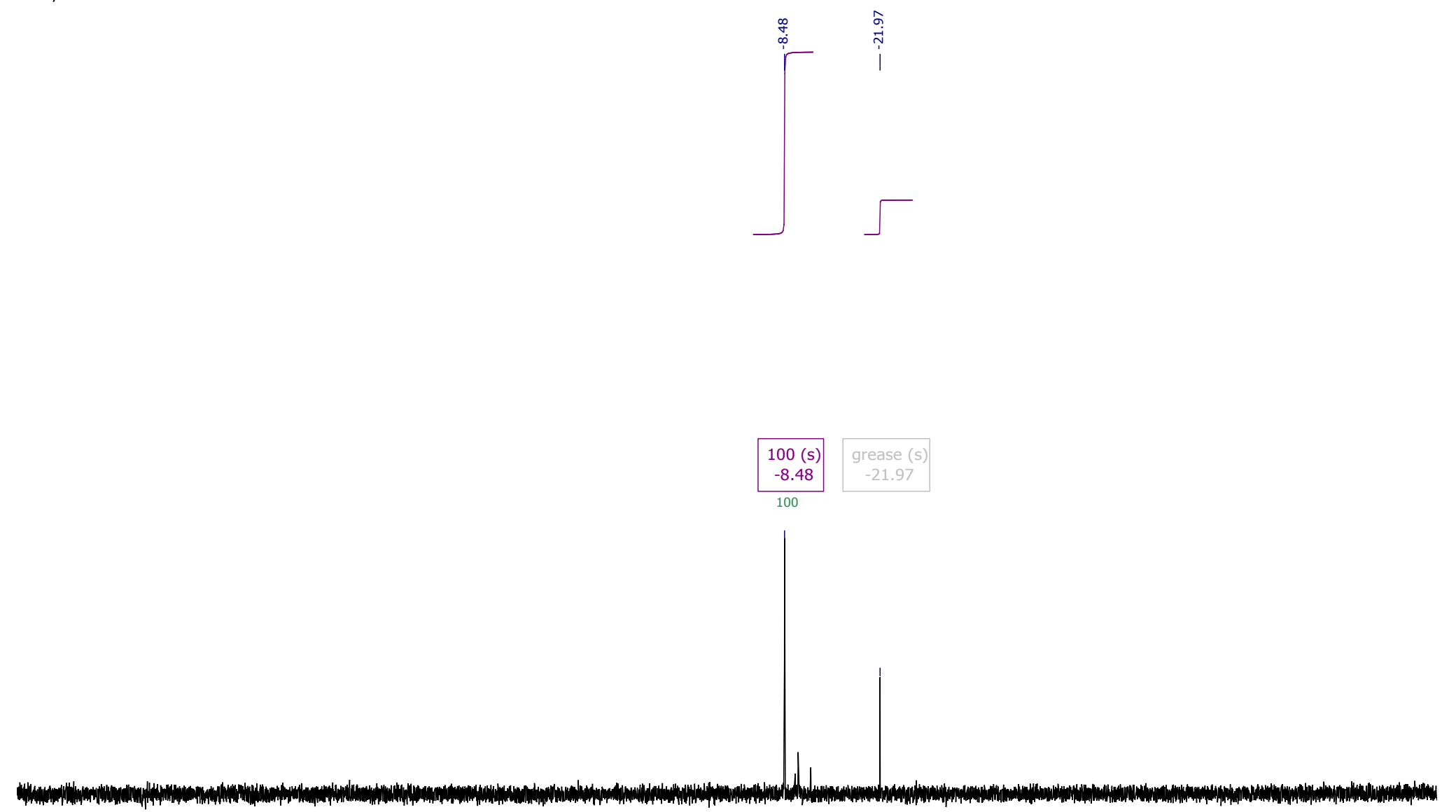

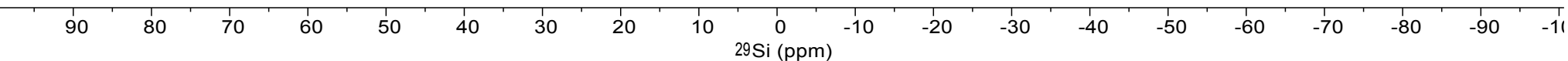

VT ${ }^{1} \mathrm{H}$ NMR Study of Complex 2-MTd, $500 \mathrm{MHz}, \mathrm{C}_{6} \mathrm{D}_{5} \mathrm{CD}_{3}, 25^{\circ} \mathrm{C}$ to $-70{ }^{\circ} \mathrm{C}$ 


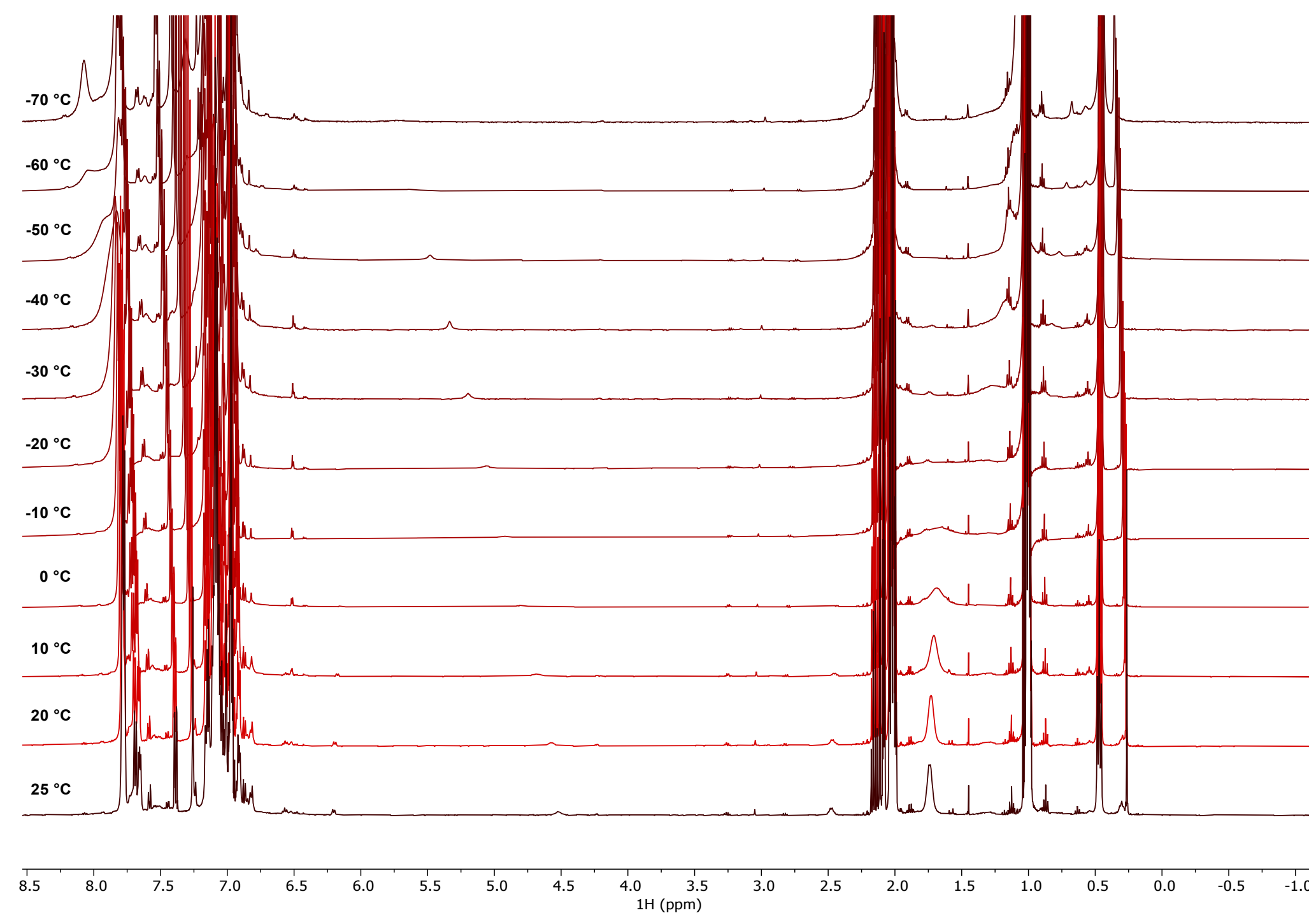

${ }^{1} \mathrm{H}-{ }^{1} \mathrm{H}$ NOESY NMR Study of Complex 2-MTd, $500 \mathrm{MHz}, \mathrm{C}_{6} \mathrm{D}_{5} \mathrm{CD}_{3}, 70^{\circ} \mathrm{C}$ 


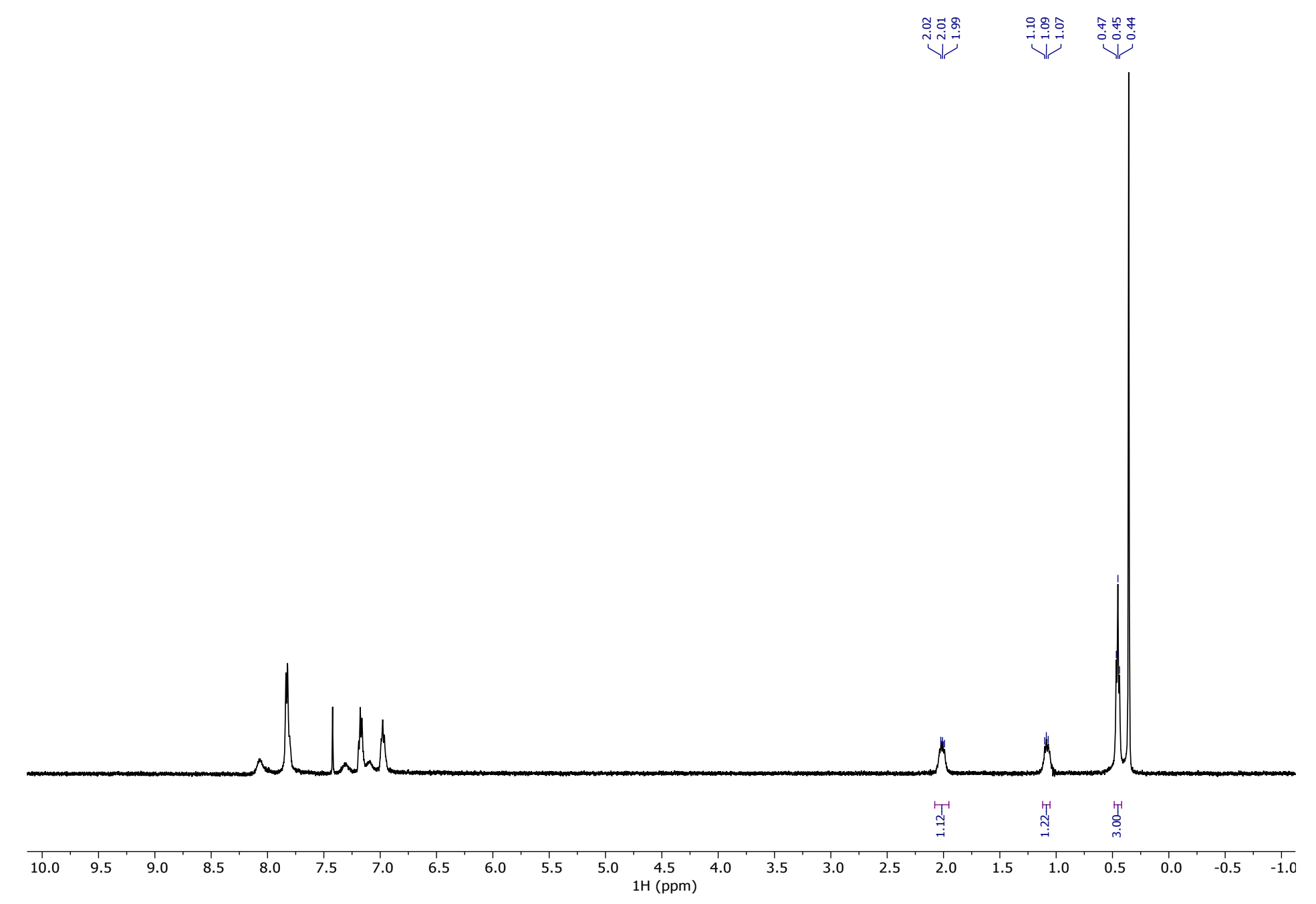




\section{References}

\footnotetext{
${ }^{1}$ Heppekausen, J.; Stade, R.; Kondoh, A.; Seidel, G.; Goddard, R.; Fürstner, A. Optimized Synthesis, Structural Investigations, Ligand Tuning and Synthetic Evaluation of Silyloxy-Based Alkyne Metathesis Catalysts. Chem. - A Eur. J. 2012, 18 (33), 10281-10299. https://doi.org/10.1002/chem.201200621.

${ }^{2}$ Hillenbrand, J.; van Gastel, M.; Bill, E.; Neese, F.; Fürstner, A. Isolation of a Homoleptic Non-Oxo Mo(V) Alkoxide Complex: Synthesis, Structure, and Electronic Properties of Penta- Tert -Butoxymolybdenum. J. Am. Chem. Soc. 2020, 142 (38), 16392-16402. https://doi.org/10.1021/jacs.0c07073.

${ }^{3}$ Harris, R. K.; Becker, E. D.; Cabral de Menezes, S. M.; Granger, P.; Hoffman, R. E.; Zilm, K. W. Further Conventions for NMR Shielding and Chemical Shifts (IUPAC Recommendations 2008). Pure Appl. Chem. 2008, 80 (1), 59-84. https://doi.org/10.1351/pac200880010059.

${ }^{4}$ McCullough, L. G.; Schrock, R. R.; Dewan, J. C.; Murdzek, J. C. Multiple Metal-Carbon Bonds. 38. Preparation of Trialkoxymolybdenum(VI) Alkylidyne Complexes, Their Reactions with Acetylenes, and the $x$-Ray Structure of $\mathrm{Mo}\left[\mathrm{C}_{3}\left(\mathrm{CMe}_{3}\right)_{2}\right]\left[\mathrm{OCH}\left(\mathrm{CF}_{3}\right)_{2}\right]\left(\mathrm{C}_{5} \mathrm{H}_{5} \mathrm{~N}\right)_{2}$. J. Am. Chem. Soc. 1985, 107 (21), 5987-5998. https://doi.org/10.1021/ja00307a025.

${ }^{5}$ Thompson, R. R.; Rotella, M. E.; Du, P.; Zhou, X.; Fronczek, F. R.; Kumar, R.; Gutierrez, O.; Lee, S. Siloxide Podand Ligand as a Scaffold for Molybdenum-Catalyzed Alkyne Metathesis and Isolation of a Dynamic Metallatetrahedrane Intermediate. Organometallics 2019, 38 (21), 4054-4059. https://doi.org/10.1021/acs.organomet.9b00430.
} 